\title{
A local tumor microenvironment acquired super- enhancer induces an oncogenic driver for efficient growth under oxidative conditions in colorectal carcinoma
}

\section{Royce Zhou}

Icahn School of Medicine at Mount Sinai

Jia Xu

Icahn School of Medicine at Mount Sinai

Tiphaine Martin

Icahn School of Medicine at Mount Sinai https://orcid.org/0000-0001-9990-1455

Sait Ozturk

Icahn School of Medicine at Mount Sinai

Alexis Zachem

Icahn School of Medicine at Mount Sinai

John He

Icahn School of Medicine at Mount Sinai

Ankita Bansal

Icahn School of Medicine at Mount Sinai

Andrew Trotta

Icahn School of Medicine at Mount Sinai

\section{Bruno Giotti}

Icahn School of Medicine at Mount Sinai

\section{Berkley Gryder}

Genetics Branch, NCl, NIH https://orcid.org/0000-0003-0130-2302

Shen Yao

Icahn School of Medicine at Mount Sinai

Xuewei WU

The University of Hong Kong

\section{Saul Carcamo}

Icahn School of Medicine at Mount Sinai

Kaitlyn Bosch

Icahn School of Medicine at Mount Sinai

Benjamin Hopkins

Icahn School of Medicine at Mount Sinai https://orcid.org/0000-0002-7970-6430 


\section{Alexander Tsankov \\ Icahn School of Medicine at Mount Sinai \\ Randolph Steinhagen \\ Icahn School of Medicine at Mount Sinai \\ Drew Jones}

New York University Langone Medical Center

\section{John Asara}

Beth Israel Deaconess Medical Center

\section{Jerry Chipuk}

Icahn School of Medicine at Mount Sinai

\section{Rachel Brody}

Icahn School of Medicine at Mount Sinai

\section{Steven Itzkowitz}

Icahn School of Medicine at Mount Sinai

\section{Christine Chio}

Columbia University

\section{Dan Hasson}

Icahn School of Medicine at Mount Sinai

\section{Emily Bernstein}

Icahn School of Medicine https://orcid.org/0000-0001-6533-8326

Ramon Parsons ( $\square$ ramon.parsons@mssm.edu )

Icahn School of Medicine at Mount Sinai https://orcid.org/0000-0002-6656-3514

\section{Article}

Keywords: colorectal cancer, carcinoma, tumors, PDZK1IP1

Posted Date: August 24th, 2021

DOl: https://doi.org/10.21203/rs.3.rs-799320/v1

License: (c) (i) This work is licensed under a Creative Commons Attribution 4.0 International License. Read Full License

Version of Record: A version of this preprint was published at Nature Communications on October 17th, 2022. See the published version at https://doi.org/10.1038/s41467-022-33377-8. 


\section{A local tumor microenvironment acquired super-enhancer induces an oncogenic driver for efficient growth under oxidative conditions in colorectal carcinoma}

Royce W. Zhou ${ }^{1,2,3}$, Jia Xu ${ }^{1 \dagger}$, Tiphaine C. Martin ${ }^{1 \dagger}$, Sait Ozturk ${ }^{1 \dagger}$, Alexis L. Zachem ${ }^{1}$, John He ${ }^{1,2}$, Ankita Bansal ${ }^{1}$, Andrew P. Trotta ${ }^{1}$, Bruno Giotti $^{4}$, Berkley Gryder ${ }^{5}$, Yao Shen ${ }^{1}$, Xuewei Wu $^{1}$, Saul

Carcamo $^{1,2}$, Kaitlyn Bosch ${ }^{1,2}$, Benjamin Hopkins ${ }^{1,2,4}$, Alexander Tsankov ${ }^{2,4}$, Randolph Steinhagen ${ }^{6}$,

Drew R. Jones ${ }^{7}$, John Asara ${ }^{8}$, Jerry E. Chipuk ${ }^{1,2}$, Rachel Brody ${ }^{9}$, Steven Itzkowitz ${ }^{10}$, Iok In Christine Chio ${ }^{11}$, Dan Hasson ${ }^{1,2}$, Emily Bernstein ${ }^{1,2}$, Ramon E. Parsons ${ }^{1,2 *}$

${ }^{1}$ Department of Oncological Sciences, The Tisch Cancer Institute, Icahn School of Medicine at Mount Sinai; New York, NY, 10029, USA.

${ }^{2}$ Graduate School of Biomedical Sciences, Icahn School of Medicine at Mount Sinai; New York, NY, 10029, USA.

${ }^{3}$ Medical Scientist Training Program, Icahn School of Medicine at Mount Sinai; New York, NY, 10029, USA.

${ }^{4}$ Department of Genetics and Genomic Sciences, Icahn School of Medicine at Mount Sinai; New York, NY, 10029, USA.

${ }^{5}$ Department of Genetics and Genome Sciences, Case Western Reserve University; Cleveland, OH, 44106, USA.

${ }^{6}$ Division of Colon and Rectal Surgery, Department of Surgery, Icahn School of Medicine at Mount Sinai; New York, NY, 10029, USA.

${ }^{7}$ Metabolomics Core Resource Laboratory, NYU Langone Health; New York, NY, 10016, USA.

${ }^{8}$ Mass Spectrometry Core, Beth Israel Deaconess Medical Center; Boston, MA, 02215, USA.

${ }^{9}$ Mount Sinai Biorepository, Department of Pathology, Icahn School of Medicine at Mount Sinai, New York, NY, 10029, USA.

$25 \quad{ }^{10}$ Division of Gastroenterology, Department of Medicine, Icahn School of Medicine at Mount Sinai; New York, NY, 10029, USA.

${ }^{11}$ Institute for Cancer Genetics, Department of Genetics and Development; Columbia University Medical Center, New York, NY, 10032, USA.

*Corresponding author. Email: ramon.parsons@mssm.edu.

These authors contributed equally to this work. 


\section{Abstract}

Tumors exhibit widespread enhancer landscape reprogramming compared to normal tissue. The etiology is believed to be largely cell-intrinsic in non-hormonal cancers, attributed to such genomic alterations as focal amplification of non-coding regions, aberrant activation of transcription factors, and non-coding mutations creating de novo transcription factor binding sites. Here, using 40 freshly resected primary CRC tumors and patient-matched adjacent normal colon epithelia, we find divergent epigenetic landscapes between primary CRC tumors and CRC cell lines. We identify a unique super-enhancer signature largely absent in cell culture. Intriguingly, this phenomenon extends to highly recurrent aberrant super-enhancers gained in CRC over patientmatched normal epithelium suggesting novel insight into the etiology of enhancer reprogramming in $\mathrm{CRC}$ and its downstream relevance to tumor biology. We find one such super-enhancer activated in epithelial cancer cells due to surrounding inflammation in the tumor microenvironment. We restore this super-enhancer and its expressed gene, $P D Z K 1 I P 1$, following treatment with cytokines or xenotransplantation into nude mice, thus demonstrating its etiology via local tumor microenvironment acquisition. Building on its known role in glucose uptake via SGLT receptors, we demonstrate mechanistically that PDZK1IP1 enhances the reductive capacity CRC cancer cells via the pentose phosphate pathway using polar metabolomic profiling. We show this activation enables efficient growth under oxidative conditions both in vitro and in vivo, challenging the previous notion that PDZKIIPI acts as a tumor suppressor in CRC. Collectively, these observations highlight the biologic significance of epigenomic profiling on patient-matched primary specimens and identify this microenvironment-acquired super-enhancer as an oncogenic driver in the setting of the inflamed tumor. 


\section{Introduction}

Cells commit exceptional density of histone 3 lysine 27 acetylation (H3K27ac) and transcriptional machinery to large genomic regulatory regions termed super-enhancers (SEs)(Whyte et al., 2013). First described in embryonic stem cells, SEs control expression of genes critical for cell identity required for pluripotency in this context(Hnisz et al., 2013; Whyte et al., 2013). Dysregulation of the SE landscape occurs in cancer(Akhtar-Zaidi et al., 2012; AlonsoCurbelo et al., 2021; Bradner et al., 2017; Hnisz et al., 2015; Loven et al., 2013; Mack et al., 2018; Mansour et al., 2014; Morton et al., 2019; Roe et al., 2017; Sengupta and George, 2017; Zhang et al., 2016). Certain SE loci exhibit increased H3K27ac to potentiate oncogene expression, including $M Y C$ in several malignancies, $K L F 5$ in CRC, brachyury $(T)$ in chordoma, $F 3$ in osteosarcoma, and TAL1 in T-cell acute lymphoblastic leukemia(Loven et al., 2013; Mansour et al., 2014; Morrow et al., 2018; Sharifnia et al., 2019; Zhang et al., 2018). Identification of dysregulated SEs between primary tumors and patient-matched normal remains incomplete for many cancers, and downstream validation for functional relevance for tumor growth is scarce.

The etiology of SE reprogramming in cancer is incompletely understood but is widely attributed to cancer cell-intrinsic genomic alterations. In CRC, highly prevalent somatic mutations in the $A P C$ tumor suppressor result in aberrant $\beta$-catenin translocation to the nucleus to activate the TCF family of transcription factors (TFs) that converge on the epigenome(Akhtar-Zaidi et al., 2012; Cohen et al., 2017; Hnisz et al., 2015). Non-coding SE can become focally amplified in multiple malignancies(Zhang et al., 2018; Zhang et al., 2016). Somatic non-coding mutations that create a de novo MYB TF binding site resulting in formation of an oncogenic SE at TALl has been described in T-ALL(Mansour et al., 2014). Similarly, inherited polymorphisms within SEs contribute to their activation and susceptibility to neuroblastoma(Oldridge et al., 2015). 
The enhancer and SE landscapes are dynamic with regard to environment. One study observed the SE landscape of hair follicle stem cells to be niche-dependent mediated by pioneer and lineage factors(Adam et al., 2015). Pro-inflammatory cytokines upstream of NF- $\kappa B$ and STAT family TFs have been reported to alter the SE landscape in endothelial as well as immune cells(Brown et al., 2014; Vahedi et al., 2012). Androgen and estrogen receptors respond to physiologic endocrine signaling to converge on the epigenome in hormonal cancers(Pomerantz et al., 2015; Ross-Innes et al., 2012; Wang et al., 2009). Whether the local tumor microenvironment influences the SE landscape of cancer cells is poorly understood. One previous study observed divergent enhancer landscapes between primary medulloblastoma tumors versus medulloblastoma cell lines, suggesting the possibility of local microenvironment influence(Lin et al., 2016).

First isolated based on its overexpression in epithelial cancers relative to normal tissue, PDZK1IP1 (also known as DD96 and MAP17) encodes a $17 \mathrm{kDa}$ transmembrane protein that interacts with the protein PDZK1, which contains four PDZ domains(Kocher et al., 1995; Kocher et al., 1996). PDZK1IP1 stimulates the sodium dependent uptake of mannose and glucose through the regulation of sodium-glucose linked transporter (SGLT) family and bypasses TNF- $\alpha$ dependent growth arrest(Blasco et al., 2003; Calado et al., 2018; Coady et al., 2017; Guijarro et al., 2007a; Kocher et al., 1998; Perez et al., 2013). PDZK1IP1 is reported to have contradictory effects on cell growth in culture and tumor growth in nude mice. This may be explained by the different cancer cell line models used and its modest induction of reactive oxygen species measured in one of the model systems, which is reported to inhibit PTEN to activate AKT signaling(Guijarro et al., 2007b; Guijarro et al., 2007d; Kocher et al., 1996). Expression of PDZK1IP1 in cancer is broadly correlated with markers of inflammation; moreover, its expression occurs in many other inflammatory diseases(Garcia-Heredia et al., 2017). 
Here, we identify that one of the most highly recurrent SEs in CRC upregulates the expression of $P D Z K 1 I P 1$ and that this is activated by inflammatory cytokines and the tumor microenvironment. PDZK1IP1 overexpression or deletion in multiple model systems altered growth of $\mathrm{CRC}$ in the tumor microenvironment more dramatically than in tissue culture. PDZK1IP1 overexpression was associated with an increase in glucose uptake, which generated enhanced levels of reductive capacity as measure by glutathione and NADPH. Our findings argue that the tumor microenvironment activates PDZK1IP1 in colorectal epithelial cells where it acts as an oncogenic driver of tumor growth in collaboration with genetic drivers of the disease.

\section{Results}

The super-enhancer landscape of primary CRC and patient-matched adjacent normal mucosa

$\mathrm{CRC}$ is the second leading cause of cancer-related deaths in the United States and one of the first cancers in which a divergent enhancer landscape between tumor and normal was described (Akhtar-Zaidi et al., 2012; Siegel et al., 2020). We profiled SE landscapes in 15 CRC patients using H3K27ac chromatin immunoprecipitation and sequencing (ChIP-seq), with the aim of leveraging recurrently dysregulated SEs to identify novel dependency genes in CRC. To control for batch effect and patient heterogeneity, we processed each tumor in parallel with matched adjacent normal colon mucosa, totaling 30 unique tissue samples (Figure 1A). We identified 2026 total SEs in tumor and normal, which accounted for approximately 50\% of the H3K27ac signal, with $95 \%$ saturation of unique SE discovery at 10 and 11 patients for adjacent normal and primary CRC, respectively (Figure S1A-C). H3K27ac deposition at these 2026 SEs exhibits tissue-oforigin specificity, clustering separately from other malignancies under hierarchical unsupervised analyses when re-processed together with our datasets using the same pipeline (Figure S1D, see Methods for accessions). 


\section{Divergent super-enhancer landscapes between primary CRC and matched normal}

To compare CRC and normal mucosa SE landscapes, we performed principal component analysis (PCA) of H3K27ac signal at all 2026 SEs. We observed distinct clustering of CRC and normal mucosa suggestive of divergent SE landscapes (Figure 1B). As further validation, we included previous datasets from colon crypts harboring normal intestinal stem cells and Familial Adenomatous Polyposis adenomas(Cohen et al., 2017). Crypts clustered near normal mucosa and adenomas occupied the boundary between normal mucosa and CRC, corroborating a previously described enhancer transition state in these early lesions(Cohen et al., 2017) (Figure 1B).

To identify dysregulated SEs between CRC and normal colon epithelium, we rank-ordered SEs by mean $\log _{2}$ fold-change in $\mathrm{H} 3 \mathrm{~K} 27 \mathrm{ac}$ signal. SE changes corresponded with proximal gene expression enabling prediction of target genes (Figure 1C-D). The most up-regulated SE in CRC (H3K27ac signal $\log _{2}$ fold change $2.73 ; P=0.0027$ ) was associated with $A S C L 2$, a TF for intestinal stem cell fate (Figure 1E, S2A)(Schuijers et al., 2015). To prioritize SEs for downstream analyses, we overlapped 1) the top 100 SEs up-regulated in CRC with 2) SEs recurrent in 9 or more out of the total of 15 patients (Figure 1F-G). We identified 12 candidate SEs enriched in primary CRC over adjacent normal with high recurrence in patients, including SEs assigned to genes previously implicated in CRC including Wnt target genes MYC and ASCL2 (Figure 1F, S2B)(He et al., 1998; Sansom et al., 2007; Schuijers et al., 2015).

\section{Unique super-enhancers in primary CRC over CRC cell lines}

Due to the technical challenges and cellular material demands for high-resolution ChIPseq, many investigators continue to rely on commercially available cell lines as starting input for epigenomic studies. We investigated the extent commercially available CRC cell lines 
assess whether such SEs could reveal oncogenic factors in epithelial cells that are not discoverable in tumor cell lines.

To assess whether any of our identified 2026 SEs were unique to primary specimens, we compared them with 13 commercially available CRC cell lines routinely used in laboratory studies, from previously published $\mathrm{H} 3 \mathrm{~K} 27 \mathrm{ac}$ datasets as well as those generated for this study (Supplementary Table 1)(Cohen et al., 2017; McCleland et al., 2016; Nakamura et al., 2017). PCA analysis revealed distinct clustering of $\mathrm{H} 3 \mathrm{~K} 27 \mathrm{ac}$ signal between primary CRC and CRC cell lines at all 2026 SEs, including three CRC cell lines assayed in our laboratory as an internal control for potential batch effects (Figure 2A). This observation suggests some SEs in CRC may be dependent upon the physiological environment within the living human body and not recapitulated in common laboratory cell line models of $\mathrm{CRC}$ and corroborates a previous finding in medulloblastoma(Lin et al., 2016).

We identified 221 SEs $(\sim 11 \%)$ as significantly under-represented in CRC cell lines hereafter referred to as primary specimen enriched SEs (Figure 2B). 18 of these SEs were highly under-represented with a mean $\mathrm{H} 3 \mathrm{~K} 27 \mathrm{ac}$ signal $\log _{2}$ fold change less than -2 . In contrast, only 12 SEs were significantly over-represented in CRC cell lines (Supplementary Table 2). It is possible this is an under-estimate as the master list of SEs queried were derived from primary CRC and matched normal colon mucosa and therefore biased towards physiologically relevant loci.

\section{Upstream TF regulation of primary specimen enriched SEs}

We next wished to better understand the TFs upstream of this SE discrepancy between primary $\mathrm{CRC}$ and $\mathrm{CRC}$ cells. We queried publicly available assay for transposase-accessible chromatin using sequencing (ATAC-seq) datasets from 81 patients with primary CRC from TCGA 
We found open chromatin at primary specimen enriched SEs was enriched for motifs of TFs with niche-dependent activity particularly in response to inflammation including $H N F 4 A, \mathrm{NF}-\kappa \mathrm{B}$, STAT3, and KLF4 (Figure S3A)(Babeu and Boudreau, 2014; Ghaleb and Yang, 2017). SEs boundaries are often flanked by CTCF sites for structural regulation, which validated in this analysis as the third most enriched motif(Gong et al., 2018; Shin, 2019).

We next wished to assess whether primary specimen enriched SEs had functional consequences on gene expression. We queried RNA-seq datasets from all 51 CRC cell lines from the Cancer Cell Line Encyclopedia (CCLE) in comparison with data from our primary CRCs (PRJNA523380)(Ghandi et al., 2019). Integrating our target gene predictions with this CCLE analysis, we derived a gene signature downstream of primary specimen enriched SEs up-regulated in primary CRCs over CCLE cell lines (Figure 2C). Pathway analysis indicated an enrichment in genes involved in ion transport and homeostasis which are among the physiologic roles of the colon, as well as cytokine signaling (Figure S3B) (Field, 2003). Furthermore, ARCHS4 algorithm analysis of these genes to predict upstream transcriptional regulation identify large intestine lineage factors $C D X 1$ and $C D X 2$ as top hits (Figure S3C)(Guo et al., 2004; Lachmann et al., 2018; Silberg et al., 2000). Interestingly, ARSHS4 analysis also corroborated TRAP motif analysis identification of $H N F 4 A$ as a significantly discovered motif in primary specimen enriched SEs (Figure S3C).

Many of these genes have been implicated in cancer progression (Supplementary Table 3). The phosphatase $P T P 4 A 3$ is associated with greater risk for metastasis in uveal melanoma patients(Laurent et al., 2011). The transmembrane protein TMEM176B attenuates the inflammasome and hinders anti-tumor activity in response to immune checkpoint blockade therapy(Segovia et al., 2019). MAPK3 (also known as ERK1) is a major unit of the MAP kinase signaling pathway frequently activated in $\mathrm{CRC}$ through $B R A F$ or $K R A S$ mutations(Cancer Genome 
Atlas, 2012). KLF4 has been described as an oncogenic driver in some contexts in transformed cells(Rowland et al., 2005).

\section{A local tumor microenvironment acquired super-enhancer at PDZK1IP1}

Of the primary specimen enriched SEs, 9 SEs were among the top 100 SEs we found to be enriched in primary CRC over patient-matched normal colon (Figure 2D, Supplementary Table

4). Intriguingly, two of them were previously identified in Figure 1 as among the top recurrently dysregulated SEs in CRC tumors over patient-matched normal epithelium. One SE, associated with the gene PDZK1IP1, ranked second out of 2026 SEs for recurrence in CRC, meeting ROSE criteria for SE calling in 12 out of 15 primary CRC tumors, 1 out of 15 patient-matched normal colon epithelia, and 0 out of 13 CRC cell lines (H3K27ac signal $\log _{2}$ fold change $-2.07, P=1.7 \mathrm{e}^{-}$

${ }^{6}$ ) (Figure 3A-B, S4). The other SE, adjacent to and most significantly associated with the expression of interferon induced transmembrane protein IFITM1, met ROSE criteria for SE calling in 9 out of 15 primary CRC tumors, 0 out of 15 patient-matched normal colon epithelia, and 0 out of 13 CRC cell lines (H3K27ac signal $\log _{2}$ fold change $\left.-2.89, P=1.8 \mathrm{e} 10^{-5}\right)$ (Figure S5A).

The SE at PDZK1IP1 spans the entire gene body of PDZK1IP1 as well as the long noncoding RNA LINC00853. RNA-seq analysis of all primary CRCs in our cohort found LINC00853 expression to be significantly below 1 TPM, our absolute minimum cutoff for expression, whereas the mean RNA-seq expression of PDZK1IPl was 88.8 TPM. This observation suggests the H3K27ac and open chromatin peak at LINC00853 may serve as a distal regulatory region for PDZK1IP1. As validation, we assessed PDZK1IP1 mRNA expression between CRC cell lines from the CCLE and primary CRCs. We discovered a 21.5-fold higher median PDZK1IP1 mRNA levels in primary CRCs over CCLE cell lines, suggesting widespread inactivation of PDZK1IP1 expression in culture (Figure 3C). CCLE cell line expression was lower than normal mucosa, suggesting up-regulation of PDZK1IP1 in CRC is microenvironment acquired (Figure 3C). As 
proof-of-principle, high-expressing CRC surgical specimens significantly reduced PDZK1IP1 mRNA levels when transferred to culture as 3D organoids in two separate cohorts(Della Chiara et al., 2021) (Dr. Benjamin Hopkins, personal communication) (Figure 3D-E).

The tumor microenvironment contains cancer cells as well as immune, stromal, and other non-cancer cells. We wished to assess the expression distribution of PDZK1IP1 and IFITM1 across these cell populations. Analysis of published single cell RNA-seq analyses identified epithelial cancer cells as having the highest expression of PDZK1IP1 within primary CRCs (Figure 3FG)(Lee et al., 2020). In contrast, IFITM1 exhibited significant expression in stromal and immune cells in addition to epithelial cells (Figure S5B-D). This suggests the PDZK1IP1 expression discrepancy between primary specimens and tissue culture is unlikely due to the exclusion of other cell populations but rather is an epithelial cell re-programming phenomenon. For this reason, we chose to focus on PDZK1IP1 for downstream functional analyses.

The IFITM1 expression pattern led us to consider the level contamination of bulk tumor H3K27ac ChIP-seq datasets with immune and stromal cell types, an unavoidable confounder when starting with primary tumor specimens. To this end, we performed de-convolution of cell type populations all primary CRCs for which sample-matched bulk tumor RNA was available using the xCell algorithm (Aran et al., 2017). Our analyses showed a dominant epithelial cell signature for most tumors (Figure S5E). Interestingly, the two cases predicted to have a low epithelial signature score were among the three cases that did not meet ROSE criteria for PDZK1IP1 SE calling (Figure S4E, see patients 17787 and 19282). Sample-matched RNA-seq data was not available to assess the third case with the absent PDZK1IP1 SE.

Single cell RNA-seq also revealed PDZK1IP1 expression in all four consensus molecular subtypes (CMS) of CRC (Figure S5F) (Dienstmann et al., 2017; Guinney et al., 2015; Lee et al., 2020). Expression was mostly enriched in CMS1-3, and especially prevalent in CMS3, previously 
described as a predominantly metabolic signature (Figure S5F) (Guinney et al., 2015). Most CRC cases are sporadic, initiated by mutations in the $A P C$ tumor suppressor gene, which largely comprise CMS2 and CMS3(Rajamaki et al., 2021). PDZK1IP1 single cell expression is less prevalent among CMS4, described as stromal-like and best recapitulates the transcriptomes of colitis-associated colorectal carcinomas, a small subset of the disease(Rajamaki et al., 2021). This finding supports the observed absence of the PDZKIIPI SE in two tumors annotated as having a high stromal composition by xCell (Figure S5E). These data further support the association of PDZK1IP1 expression with intra-tumoral epithelial cells as a re-programming event.

\section{Unique super-enhancers in primary CRC over 3D CRC organoids}

H3K27ac ChIP-seq datasets from human CRC 3D organoids were re-analyzed through our pipeline for comparison to our primary CRCs (Della Chiara et al., 2021). We similarly observed distinct clustering away from primary CRCs (Figure S6A). We identified $180(\sim 8.9 \%)$ SEs differentially expressed between 3D organoids and primary tumors $(P<0.01$ Student's $t$-test, H3K27ac signal absolute $\log _{2}$ fold change $>1$ ) (Figure S6B). In contrast to 2D commercial cell lines, most of these loci (127 SEs) were enriched in organoids over primary CRC (Figure S6B), notably at TGF- $\beta$ signaling genes $B M P 4$ and $R G M B$ (Figure S6D). Our data suggests $3 \mathrm{D}$ organoids improve recapitulation of the SE landscape of primary CRC at the 221 loci under-represented in commercial 2D CRC cell lines but nevertheless diverge from primary CRC (Figure S6C).

Importantly, 3D CRC organoid culture validated the decreased H3K27ac signal at the PDZK1IP1 ( $\log _{2}$ fold change $\left.-0.48, P=0.05\right)$ and IFITM1 ( $\log _{2}$ fold change $\left.-1.87, P=0.0002\right)$ SEs observed in 2D culture (Figure S6E-F). The findings corroborate the observed decrease in PDZK1IP1 mRNA expression between patient-matched primary CRCs and derived 3D CRC organoids (Figure 3D-E).

Xenotransplantation as tumors results in acquisition of the PDZK1IP1 super-enhancer 
We first assessed genomic alterations as a possible etiology of the PDZK1IP1 SE. The SE resides on chromosome $1 \mathrm{p}$ which rarely exhibits amplification in 195 CRC cases from TCGA(Cancer Genome Atlas, 2012). Inspection of H3K27ac reads within the PDZK1IP1 SE did not reveal any recurrent mutations in CRC over patient-matched normal. Moreover, PDZKIIP1 SE status failed to correlate with individual somatic protein-coding mutations at other loci, microsatellite instability (MSI), or tumor stage (Supplementary Table 5-7). One normal colon epithelium case in our cohort met ROSE criteria for PDZK1IP1 SE calling, further suggesting tumor initiating mutations may be dispensable for induction.

As a proof-of-principle that the PDZK1IP1 SE is under cell-extrinsic control by the tumor environment, we grew the CRC cell line HT29, which expresses low levels of PDZK1IP1, in culture or as subcutaneous xenografts in nude mice (Figure 4A). Remarkably, we observed increased $\mathrm{H} 3 \mathrm{~K} 27$ ac deposition ( $\log _{2}$ fold change 1.24) at the PDZK1IP1 locus that met SE criteria in three independent xenograft tumors, but not parental cells grown in vitro (Figure 4B). Although the H3K27ac antibody employed reacts to both human and mouse epitopes, sequenced ChIP-seq reads were mapped only to the human genome to specifically capture signal from human CRC cells within the xenograft. Broadly, HT29 xenotransplantation failed to restore SE expression at other loci under-represented in cell lines, including at IFITMI ( $\log _{2}-0.34$-fold).

We next assessed the effects of SE induction on PDZK1IP1 expression, using antibodies and quantitative real-time PCR (qRT-PCR) primers specific to human PDZK1IP1 to exclude any signal contribution from mouse cell xenograft tumor infiltrates. HT29 xenograft tumors exhibited a 34.4-fold increase of PDZK1IP1 mRNA, which validated by immunoblot (Figure 4C-D). To assess whether SE induction regulates other proximal genes, we performed RNA-seq on HT29 xenograft tumors and parental cells. PDZK1IP1 was the only differentially expressed protein 
coding gene within $500 \mathrm{~kb}$ of the SE (Figure 4E). Importantly, HT29 xenograft tumors recapitulate PDZK1IP1 mRNA and protein levels observed in most primary CRCs (Figure S7).

\section{The PDZK1IP1 super-enhancer is regulated by inflammation}

To better understand PDZK1IP1 epigenetic regulation by the microenvironment, we queried bulk tumor ATAC-seq and RNA-seq datasets from TCGA(Corces et al., 2018). We

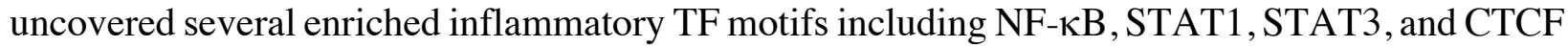
at open chromatin in the PDZK1IP1 promoter and SE (Figure S8A-D). We validated TF binding in various tissues and cell lines based on analysis of published ChIP-seq data (Figure S8E, see Methods for accessions). In support, gene set enrichment analysis (GSEA) demonstrated a strong correlation between PDZK1IP1 mRNA expression and inflammatory signatures including TNF $\alpha$, IFN $\gamma$, IL-6, and IFN $\beta$ signaling from TCGA (Figure 5A, S8F-I). As proof-of-principle, stimulation of HT29 cells in vitro with the upstream pro-inflammatory cytokines TNF $\alpha$, IFN $\gamma$, and IL-6, but not IFN $\beta$, induced PDZK1IP1 expression (Figure 5B). Cytokines resulted in additive potentiation of PDZK1IP1 expression suggesting these TFs act independently and cooperatively, and phenocopies levels observed in xenografts (Figure S8J). In support, stimulation of HT29 in culture with TNF $\alpha$, IFN $\gamma$, and IL-6 likewise phenocopied and induced the PDZK1IP1 SE (Figure 5C).

Multiple orthogonal approaches link inflammation in the setting of HT29 xenografts with PDZK1IP1 induction. Consistent with our observations in human samples, we observed increased inflammatory TF signaling in HT29 xenografts relative to cells grown in culture. GSEA

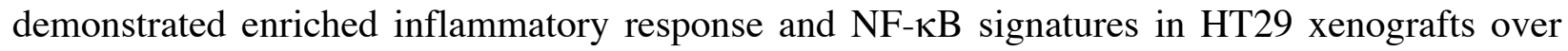
parental cells (Figure S8K). Next, the ChIP-X Enrichment Analysis (ChEA) algorithm identified NF- $\kappa$ B subunit RELA as the top TF central to up-regulated genes $\left(\log _{2}\right.$ fold change $\left.>2\right)$ in HT29 xenografts over parental cells (Figure S8L)(Keenan et al., 2019). In support of this data, gained 
enhancers in HT29 xenografts over parental cells ( $\log _{2}$ fold change H3K27ac signal $>1$ ) similarly enriched for NF-kB and STAT3 motifs via the TRAP algorithm (Figure S8M-N). Cytokine array profiling of xenografts detected elevated human as well as murine pro-inflammatory cytokines and chemokines, including TNF $\alpha$ and IL-6 (Figure S9). Immunohistochemical analysis of HT29 xenograft tumors readily detected CD68+ and Ly6G+ cell staining, suggesting robust infiltration by macrophages and neutrophils or other granulocytes, respectively (Figure S9)(Daley et al., 2008; Holness and Simmons, 1993).

Cell-specific super-enhancer reprogramming in response to microenvironment

CRC cells grown in culture exhibit decreased STAT3 signaling compared to primary tumors, and growing HT29 cells as a xenograft tumor reactivates this signaling(Corvinus et al., 2005). Intriguingly, we validated this phenotype as unique to HT29 cells compared to COLO205 and DLD1, two other human CRC cell lines with low expression of PDZK1IP1. COLO205 and DLD1 failed to phenocopy induction of PDZK1IP1 protein levels, correlating with poor STAT3 reactivation in these lines (Figure S10). In line with this finding, we did not observe increased H3K27ac signal in COLO205 liver metastasis xenografts in nude mice from orthotopic splenic vein injections (GSE126188) nor in subcutaneous DLD1 xenografts in nude mice (this study), over respective parental lines maintained in culture (Figure S10)(Hung et al., 2019). Multiple other CRC cell lines we screened (including CACO2, SW48, SW480, SW620, RKO, and HCT116) exhibited no detectable expression of PDZKIIPI by RNA-seq or immunoblot. These cells failed to express PDZK1IP1 in response to inflammatory cytokines or xenotransplantation (Figure S10C). The finding that some cell lines lose the ability to respond to inflammation at the PDZK1IPI locus is perhaps explained by selection of known immune modulators to avoid growth inhibitory effects of inflammation(Inagaki-Ohara et al., 2013).

\section{Tumor microenvironment recapitulates enhancer reprogramming in cancer}


A comparison of $\log _{2}$ fold change in $\mathrm{H} 3 \mathrm{~K} 27 \mathrm{ac}$ signal at all enhancers between xenografts and in vitro cytokine stimulated cells demonstrate that pro-inflammatory cytokines correlate with xenograft tumor induced enhancer reprogramming $(R=0.22, P<0.0001)$ (Figure S11). In addition, xenograft induced enhancer changes modestly but significantly recapitulated those observed in CRC $(R=0.11, P<0.0001)$ (Figure S11). This trend validated in independent COLO205 peritoneal deposit and liver metastasis xenografts $(R=0.19, P<0.0001)$ (Figure S11)(Hung et al., 2019). These findings more broadly implicate cytokines and the tumor environment as novel contributors to reprogramming throughout the CRC enhancer landscape.

\section{$P D Z K 1 I P 1$ is an oncogenic driver specific to the tumor microenvironment setting}

PDZK1IP1 (also known as MAP17, DD96) encodes a 114-residue protein overexpressed in multiple carcinomas (Figure S4)(Guijarro et al., 2007c; Kocher et al., 1995; Kocher et al., 1996). Although PDZKIIP1 has been previously linked to tumorigenesis, there is conflicting data on its role in modulating tumor growth. At least two groups have reported that over-expression of PDZK1IP1 in cell line models of CRC and prostate adenocarcinoma inhibit cell growth in vitro and tumor growth in xenografted mice (Ikeno et al., 2019; Kocher et al., 1996). On the other hand, multiple studies published by other groups have reported PDZKIIPI is oncogenic in in vitro and in xenograft models of cell lines derived from melanoma and hepatocellular carcinoma (HCC) (Dong et al., 2021; Garcia-Heredia et al., 2017; Guijarro et al., 2007a; Guijarro et al., 2007b; Guijarro et al., 2007c; Guijarro et al., 2007d). High mRNA expression of PDZK1IP1 negatively prognosticates patient survival in multiple cancers including low-grade gliomas, glioblastomas, pancreatic adenocarcinoma, but not CRC using data from TCGA (Figure S12).

Given the presence of a highly recurrent CRC-enriched and microenvironment acquired super-enhancer at $P D Z K 1 I P 1$, we assessed whether it reflects a novel transcriptional dependency 
(shRNA) silencing decreases growth of human breast and HCC cell lines in in vitro assays(Dong et al., 2021; Guijarro et al., 2007b). We deleted PDZK1IP1 using two independent and nonoverlapping CRISPR-cas9 guide RNAs (hereafter referred to as sgPDZK1IP1) and assessed the ability of human CRC lines to proliferate in vitro (Figure S13A-D). We observed a very modest decrease in growth rate in HT29 cells whereas DLD1 cells remained unaffected using a 2D Incucyte proliferation assay over 6 days (Figure S13A-D). This observation conflicts with previous observations in other cancers, suggesting PDZKIIP1 may exhibit cancer-specific effects on proliferation in culture. As a possible explanation, we notably observed severe off-target toxicity on CRC proliferation in culture in nearly all commercially available shRNAs (Sigma) against PDZK1IP1, that were non-reproducible in isogenic CRISPR-cas9 loss of function models.

Given the observed induction of PDZK1IP1 in vivo in HT29 cells, we grew the same lines as subcutaneous xenografts in nude mice. Remarkably, PDZK1IP1 was critical for CRC tumor growth in vivo (Figure 6A-B, S13E-F). The same trend is repeated in DLD1, which expressed PDZKIIP1 at a much lower level, although the sgPDZK1IP1 growth defect was not as large as observed in HT29. These data suggest that PDZK1IP1 contributes to tumor growth when grafted into mice.

As validation, we observed the same trend using gain of function models of PDZKIIPI. Given low levels of PDZK1IP1 in vitro, we re-introduced V5-tagged PDZK1IP1 cDNA (PDZK1IP1-V5) by titrating to protein levels comparable to that observed in primary CRCs and 385 HT29 xenograft tumors (Figure S13G). PDZK1IP1-V5 and EV cells grew at similar rates in culture in HT29, COLO205, and DLD1 cells (Figure S13H-J). When the same lines were grown as xenograft tumors, additional ectopic overexpression of PDZK1IP1-V5 significantly increased tumor growth in HT29 over empty vector controls (Figure 6C). PDZK1IP1-V5 also significantly increased tumor growth of DLD1 (xenografts tumors for this model fail to endogenously induce 
PDZK1IP1) (Figure 6D). Taken together, our data demonstrate PDZK1IP1 is more important for tumor cell growth in mice, where it can be induced, than in tissue culture where it is largely silent (Figure 6E).

\section{PDZK1IP1 regulates cancer metabolism}

The mechanism by which $P D Z K 1 I P 1$ regulates tumor growth remains incompletely understood. Under normal physiology, $P D Z K 1 I P 1$ is largely expressed in the proximal tubules of the kidney, where it is proposed to facilitate glucose reabsorption via the SGLT family of sodiumdependent glucose transporters (Coady et al., 2017). Indeed, in a cohort of familial renal glucosuria primarily composed of patients with inactivating mutations in SLC5A2 encoding the renal glucose transporter SGLT2, one patient was found to have a mutually exclusive homozygous truncating mutation in PDZK1IP1(Coady et al., 2017; Santer and Calado, 2010).

As previously observed, PDZK1IP1-V5 and EV cells grew at similar rates in culture and thus any metabolic phenotypes identified are independent of proliferation in this context (Figure S13). However, PDZK1IP1 over-expression has been reported to increase glucose uptake in breast cancer cells in a SGLT1 and SGLT2-dependent manner(Guijarro et al., 2007b). To determine whether PDZK1IP1 could affect glucose uptake in CRC cells, we measured its uptake in DLD1 overexpressing PDZK1IP1-V5 relative to empty vector and found that it could indeed enhance glucose uptake. Moreover, consistent with the literature, use of sotagliflozin, a SGLT1 and SGLT2 inhibitor approved for the management of diabetes mellitus in Europe but not currently by the FDA, could rescue the increase in glucose uptake caused by PDZK1IP1-V5 (Figure S14A)(Bhatt inactivation of surplus glucose uptake. As an additional control, we performed a cellular uptake assay using 2-deoxyglucose (2DG), which is a poor substrate for SGLT family glucose transporters but is readily taken up by the GLUT family of passive glucose transporters. We observed no 
difference in 2DG uptake between PDZK1IP1-V5 and EV DLD1 cells, further supporting the

415 increase in intracellular glucose is due to SGLT glucose transporters (Figure S14B).

The association of PDZK1IP1 expression and metabolism gene signatures was independently noted in primary CRC tumors. PDZK1IP1-high primary CRCs from TCGA were enriched for glycolysis and oxidative phosphorylation gene sets by GSEA to nearly the same extent detected for inflammation and cytokines (Figure S14C-D). In single cell analyses, we previously observed CMS3 as the CRC subtype with the highest incidence of PDZK1IP1 expression across 23 primary CRCs, which is defined by a highly metabolic gene signature (Figure S5F) (Guinney et al., 2015).

Thus, we considered whether PDZK1IPI affects downstream metabolism in CRC. A recent study demonstrated increased glycolytic rate in Seahorse live-cell assays with PDZK1IP1 expression in HCC cells(Dong et al., 2021). Surprisingly, in Seahorse live-cell assays, PDZK1IP1V5 cells reproducibly exhibited decreased extracellular acidification rate (ECAR), a read-out of glycolysis, and oxygen consumption rate (OCR), a read-out of mitochondrial respiration, compared to EV cells (Figure S15A-D). We corroborated this result by performing a rapid glycolysis carbon tracing experiment using uniformly labeled $\mathrm{C}^{13}$ glucose. We observed a significant decrease in M+6 fructose 1,6 bisphosphate isotopologues in PDZK1IP1-V5 cells compared to EV, suggesting PDZK1IP1 may modulate phosphofructokinase, a key rate-limiting regulatory enzyme in control of glycolysis (Figure S15E-F)(Al Hasawi et al., 2014; Yi et al., 2012). However, these decreases in ECAR and OCR did not significantly negatively impact cell proliferation. Furthermore, we did not notice consistent decreases in the ATP/ADP ratio with PDZK1IP1-V5 expression (Figure S15G-H). Similarly, reverse phase protein array screening between PDZK1IP1-V5 and EV cells did not indicate a difference in phosphorylation of AMPK $\alpha$ suggesting energy signaling is not compromised. 
We next performed global polar metabolite profiling by liquid chromatography-mass spectrometry to assess the effects of increased glucose uptake and decreased glycolytic rate on in CRC cells. We identified five consensus metabolites up-regulated in PDZK1IP1-V5 (>1.25-fold, $P<0.05)$ in HT29, DLD1, and COLO205 lines. Intriguingly, four of these-6-phosphogluconate, ribose 5-phosphate, IMP, and AMP - are intermediates or derivatives of the pentose phosphate pathway (PPP) (Figure 7A-B, S16A). To assess increased PPP activity, we performed a carbon tracing experiment utilizing 1,2-C $\mathrm{C}^{13}$-glucose. PDZK1IP1-V5 increased relative abundance of $\mathrm{C}^{13}$ labeled 6-phosphogluconolactone, the first and committed intermediate of the PPP in HT29, COLO205, and DLD1 lines (Figure 7C-F).

The ratio of $\mathrm{M}+1: \mathrm{M}+2$ lactate is a readout of PPP flux relative to glycolysis(Jang et al., 2018). We did not observe an increase in $M+1: M+2$ lactate between PDZK1IP1-V5 and EV cells despite increased M+2 6-phosphogluconolactone labeling (Figure S16B-D). This suggests the increase in PPP activity is more likely due to increased glucose uptake rather than shunting of glycolytic intermediates.

The best understood role of the PPP in cancer is protection against reactive oxygen species (ROS)(Patra and Hay, 2014). In this regard, we observed an increase in both NADPH/NADP+ ratios and glutathione levels in PDZK1IP1-V5 cells at steady state (Figure 7G-J, S16E). To assess whether this metabolic change in reductive capacity exhibits a cellular phenotype, we challenged cells with oxidative stress. We observed lower intracellular ROS levels in PDZK1IP1-V5 cells in response to the thiol oxidizing agent diamide in HT29 and DLD1 lines (Figure 7K-L). Furthermore, PDZK1IP1-V5 exhibited increased cell viability when cultured under $1 \% \mathrm{O}_{2}$ or treated with diamide in HT29 lines (Figure S16F-H). Taken together, we demonstrate PDZK1IP1 protects against oxidative stress in CRC cells. 
We next assessed whether PDZK1IP1 regulation of PPP and reductive capacity was relevant towards the observed growth phenotype in vivo. Importantly, supplementing nude mice bearing sgPDZK1IP1 xenograft tumors with the antioxidant $\mathrm{N}$-acetylcysteine in drinking water partially rescued tumor growth (Fig. 7M).

\section{Discussion}

Super-enhancers are select areas of the genome at which cells commit exceptionally high levels of histone acetylation and active transcriptional machinery. Cancer cells are associated with enhancer reprogramming that extends to the super-enhancer landscape to activate oncogenes and other transcriptional dependencies. Profiling the super-enhancer landscape has emerged as a powerful tool for uncovering novel target genes in cancer, particularly in those with few recurrently mutated genes(Mack et al., 2018).

The mechanisms by which super-enhancer reprogramming occur in cancer are not fully understood. They include somatic mutations resulting in oncogenic signaling converging on the epigenome such as $A P C$ mutations activating TCF family TFs, focal amplification of TF binding sites within SE regions, endocrine signaling to estrogen and androgen receptors that similarly converge on the epigenome in hormonal cancers, somatic non-coding mutations that create de novo TF binding sites, as well as inherited polymorphisms that create de novo TF binding sites. The enhancer landscape of cancer cell lines has been observed to diverge from their cancer counterparts, suggesting the possibility of cell-extrinsic microenvironment influences on the epigenetic landscape that could contribute to tumor cell development and growth.

Here, we demonstrate the local tumor microenvironment induces super-enhancer reprogramming in $\mathrm{CRC}$. We find the SE landscape of primary $\mathrm{CRC}$ to diverge from in vitro CRC models, corroborating a previous observation in medulloblastoma(Lin et al., 2016). Attempts to restore the tumor microenvironment in cell lines to model changes in the human epigenome are 
inherently flawed due to the requirement of immunocompromised mouse models. We expect the recapitulation of super-enhancer changes in this model to be limited given the notable absence of $\mathrm{T}$ cells in the microenvironment of our nude mouse model, especially at loci under regulation by inflammatory signaling such as $P D Z K 1 I P 1$ which may explain failure of some cell lines to induce PDZK1IP1 upon xenotransplantation. Nevertheless, its super-enhancer in HT29 cells is restored upon treatment with pro-inflammatory cytokines or xenotransplantation into nude mice, correlating with phosphorylation of STAT3 specifically in this line.

We identify its target, $P D Z K 1 I P 1$, as a novel positive regulator of CRC growth. Oncogenic non-coding regions have been described but most occur in a small fraction of cases. We identified the PDZK1IP1 SE as among the most recurrently up-regulated SEs across 15 patient CRC samples, 495 which is consistent with the common up-regulation of PDZK1IP1 in epithelial carcinomas(Kocher et al., 1995; Kocher et al., 1996). Pro-tumorigenic roles for inflammation in the tumor environment are well-described, including paracrine signaling between immune and cancer cells(AlonsoCurbelo et al., 2021; Coussens and Werb, 2002; Greten and Grivennikov, 2019; Wyckoff et al.,

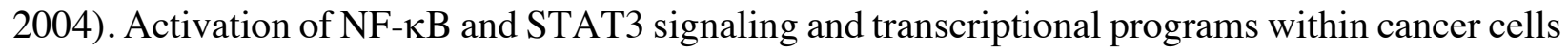
promote disease progression in multiple malignancies, including $\mathrm{CRC}($ Grivennikov and Karin, 2010; Huynh et al., 2019; Taniguchi and Karin, 2018; Xia et al., 2014; Yu et al., 2014). Although regulation of $P D Z K 1 I P 1$ expression by hypoxia was recently noted, we found its up-regulation to be negligible compared to levels induced by cytokines and xenotransplantation(Dong et al., 2021). Our findings suggest that inflammation in the microenvironment activates PDZK1IP1 to stimulate tumor growth in a large proportion of CRC, likely in situations of moderate inflammation where PDZK1IP1 is part of an adaptive response to signals that inhibit epithelial cell growth and viability.

In cancer cells, we find PDZK11IP1 facilitates surplus glucose uptake via SGLT glucose transporters. SGLT2 inhibitors are FDA approved and undergoing Phase I/II clinical trials in solid 
tumors following promising pre-clinical results as monotherapy or in combination with PI3K or

510 inhibitors or other therapies (canagliflozin: NCT04073680; dapagliflozin: NCT02695121, NCT04899349, NCT04542291)(Hopkins et al., 2018; Scafoglio et al., 2015; Scafoglio et al., 2018). Previous studies suggest PDZK1IPI increases ROS to contribute to cell proliferation. However, this does not agree with growing literature on KRAS and BRAF mutant tumors demonstrating the opposite. Rather, it is the mitigation of ROS that benefits tumor growth in this context (Lim et al., 2019; Sayin et al., 2014; Shaw et al., 2011; Yun et al., 2015). Moreover, KRAS and BRAF are among the most frequently mutated oncogenes in $\mathrm{CRC}(\mathrm{Cancer}$ Genome Atlas, 2012). We notably observed increased PPP activity, reductive capacity, and resistance to oxidative stress in HT29 (BRAF mutant), DLD1 (KRAS mutant), and COLO205 (BRAF mutant) cells. Our data show this novel function of PDZK1IP1 endows tumor cells with a growth advantage in the tumor microenvironment but not in tissue culture. Thus, we elucidate a novel link between the context of $P D Z K 1 I P 1$ super-enhancer activation and $P D Z K 1 I P 1$ relevance to $C R C$ growth.

It is unclear why our results conflict directly with previous other studies on PDZK1IP1, which report increased ROS levels as well as glycolytic and mitochondrial respiration rate (Dong et al., 2021; Guijarro et al., 2007b). While all studies over-expressed PDZK1IP1, they used different cancer cell lines with different lineage and mutation backgrounds to measure its effect. In addition, we chose a level of ectopic expression that mimics endogenous protein levels observed upon induction in xenografts as well as primary CRC tumors. Thus, a second possible explanation is that the other studies may be reporting the effect at different gene doses. Finally, ROS levels were measured by others using different probes.

Collectively, our observations broaden our notion of super-enhancers and highlights the importance of epigenomic profiling of primary tumor specimens and patient-matched controls. Our work further supports the need to assess and validate tumor-enriched super-enhancers to 
identify novel target genes. Antagonizing distal cell-extrinsic androgen or estrogen signaling to the cancer epigenome is a mainstay of initial therapy for hormonal cancers(Takeda et al., 2018). A greater understanding of local microenvironment factors and upstream intracellular signaling expands the scope for therapeutic strategies towards silencing cell-extrinsic enhancers and superenhancers in control of transcriptional dependencies in vivo. Targeted therapy that reduces inflammation to lower the level of expression of PDZKIIPI could be of benefit for patients with colorectal cancer.

\section{Acknowledgments}

We thank members of the Ramon Parsons Laboratory, Bert Vogelstein, Matthew Vander Heiden, and Lewis Cantley for discussions. We thank Emily Bernstein, Dan Hasson, James Manfredi, Jian Jin, and Matthew Vander Heiden as members of Royce W. Zhou's Dissertation committee. We thank Saboor Hekmaty, Kevin Mohammed, and Ravi Sachidanandam from the Mount Sinai

545 Oncological Sciences Sequencing Core Facility. We thank the Division of Colon and Rectal Surgery at Mount Sinai and the TCI Biorepository Core in Development for their assistance with sample collection. This study was supported by the following: National Institutes of Health grant F30CA243207 to R.W.Z., R35CA220491 to R.E.P., R01CA230854 to R.E.P., P30CA196521 to R.E.P, R01CA154683 to E.B., and R01CA218024 to E.B.

\section{$550 \quad$ Financial disclosures}

Ramon Parsons is a co-founder of, owns equity in, receives royalty from, and serves on the scientific advisory board of Therapten Inc. Ramon Parsons also receives royalty payments from Cullgen Inc. Steven Itzkowitz has consulted for CEGX, EXACT Sciences Corporation, and the 555 Colon Cancer Alliance. Steven Itzkowitz receives royalty payments from Bio-Raad Laboratories Inc. None of the other authors declare any financial disclosures or conflicts of interest. 


\section{Author contributions:}

Conceptualization: R.W.Z., R.E.P.

Methodology: R.W.Z., A.L.Z., S.O., J.X., T.C.M., A.B., J.H., A.P.T., B.G., Y.S., X.W., S.C., K.B., J.A.,

Investigation: B.H., A.T.

Funding acquisition: R.E.P., R.W.Z.

Project administration: R.B., R.S.,

Supervision: D.R.J., J.E.C., S.I., I.I.C.C., D.H., E.B., R.E.P.

Writing - original draft: R.W.Z, R.E.P.

Data and material availability: H3K27ac ChIP-seq and RNA-seq datasets generated in this study are deposited at the NCBI Gene Expression Omnibus under the accession GSE166254. Any materials are available from the corresponding author upon reasonable request. 
A

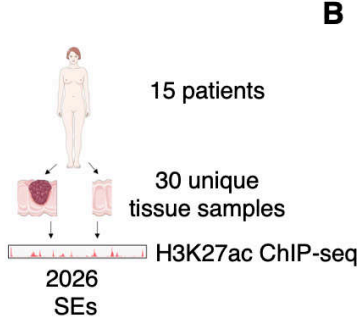

B

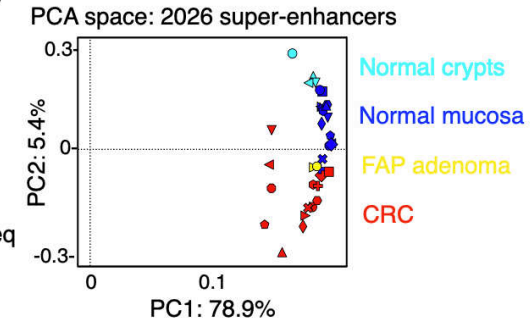

$\mathbf{F}$

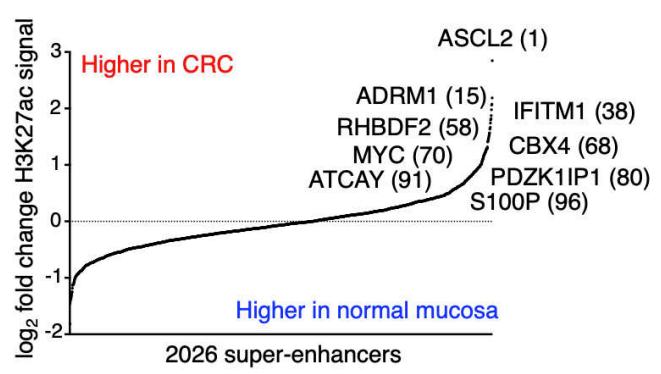

G

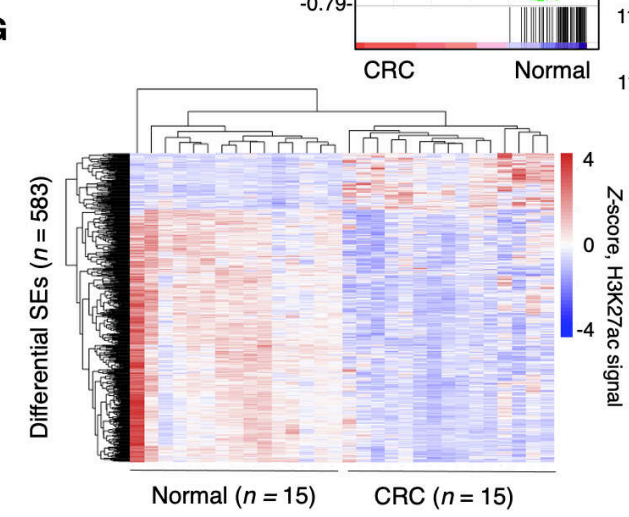

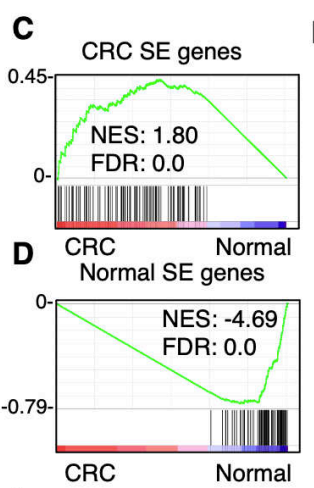

H3K27ac

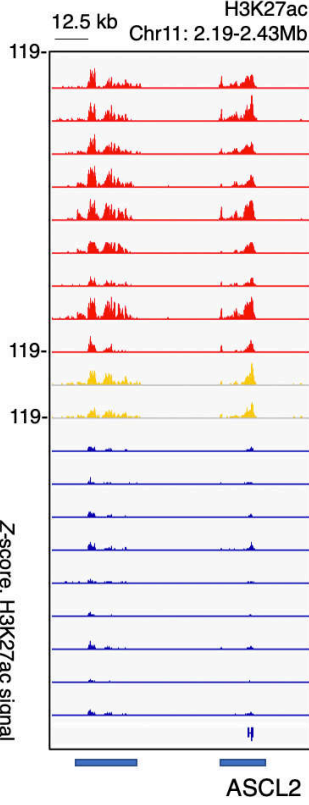

Figure 1. Recurrently dysregulated super-enhancers in CRC patients.

(A) Study overview.

(B) PCA of H3K27ac signal at 2026 SEs in CRC ( $n=15$ independent tissue samples), normal mucosa $(n=15)$, crypts $(n=4)$, and FAP adenomas $(n=2)$.

(C-D) GSEA between SE proximal genes and differentially expressed genes between CRC and normal.

(E) H3K27ac ChIP-seq track near ASCL2. Two proximal SEs are underlined.

(F) 2026 SEs by $\log _{2}$ fold change in H3K27ac signal with 12 candidate SE target genes based on overlap of ranking and recurrence annotated.

(G) Heatmap of H3K27ac signal at 583 differentially expressed SEs $(P<0.01$, Student's $t$-test). 


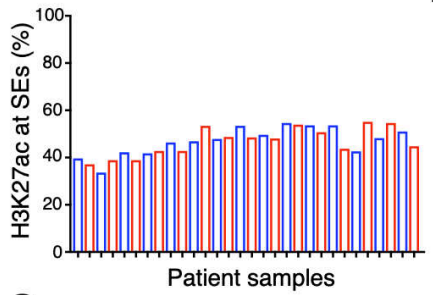

595

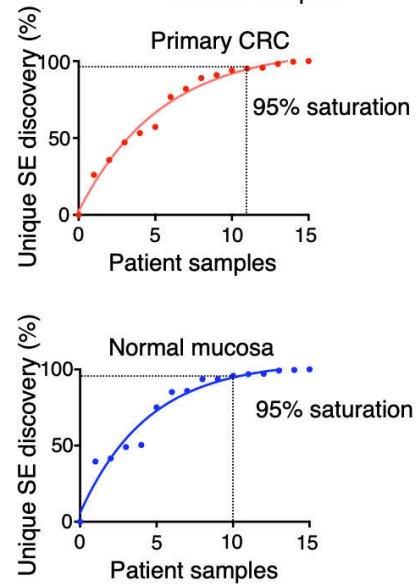

D

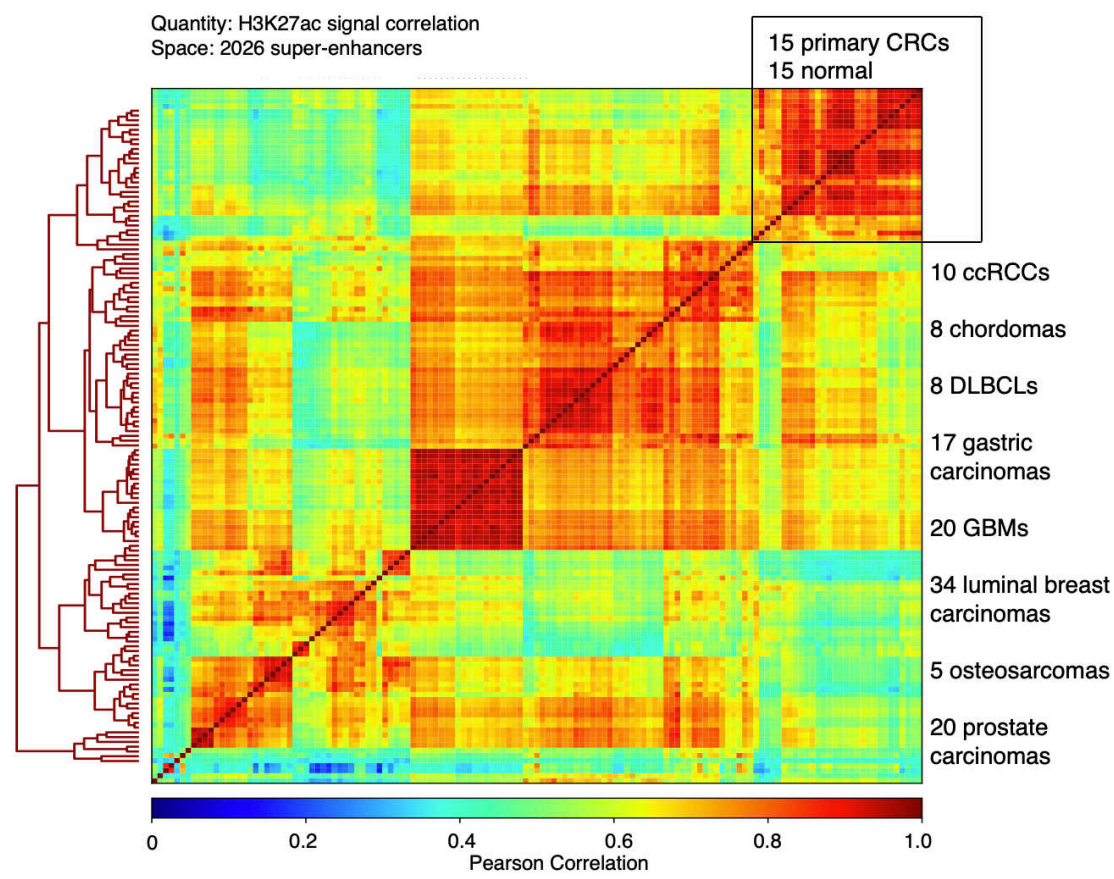

Figure S1. The super-enhancer landscape in primary $\mathrm{CRC}$ and patient-matched adjacent normal colon epithelium.

(A) Percentage of H3K27ac signal deposited solely at SEs. Each red or blue bar is an independent primary CRC ( $n=15$ independent samples) or normal colon epithelium sample $(n=15$ independent samples), respectively.

(B-C) Power analyses indicating cumulative percentage saturation of unique super-enhancer discovery with the addition of each patient in cohort. CRC in red, normal mucosa in blue.

(D) Unsupervised hierarchical clustering, H3K27ac signal Pearson correlations at 2026 SEs from 30 colorectal samples in our cohort ( $n=15$ independent CRC, $n=15$ independent normal mucosae) against clear cell renal cell carcinomas (ccRCC, $n=10$ independent tumors), chordomas ( $n=8$ independent tumors), diffuse large B-cell lymphomas (DLBCL, $n=4$ independent tumors), gastric carcinomas ( $n=17$ independent tumors), glioblastomas ( $n=20$ independent tumors), luminal 
breast cancer ( $n=34$ independent tumors), osteosarcoma ( $n=5$ independent tumors), and prostate carcinomas ( $n=20$ independent tumors). Please see Methods for accessions.

610 
A

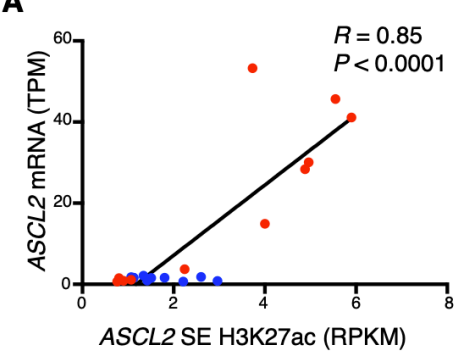

625

630

635

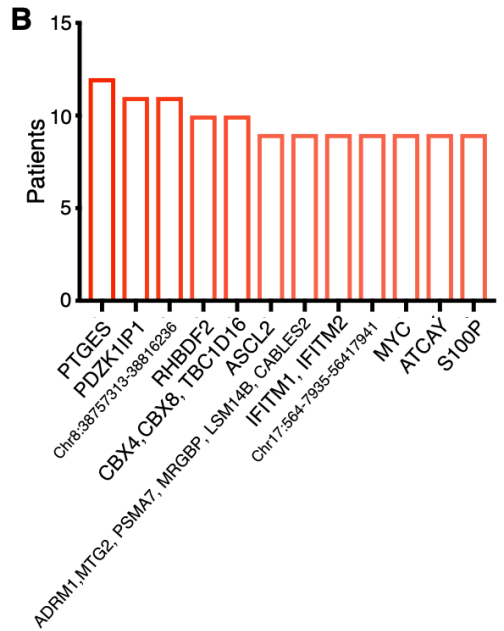

Figure S2. The super-enhancer landscape in CRC identifies target genes.

(A) Linear correlation of H3K27ac signal deposition at the ASCL2 SE and ASCL2 gene expression using sample matched CRC ( $n=11$ patients) and normal epithelium ( $n=10$ patients) Although 15 primary CRCs and 15 normal colons were used for ChIP-seq analyses, sample-matched RNAseq data was only available for $11 \mathrm{CRCs}$ and 10 normal colons, respectively. All available data was used in this analysis. Please see Methods for details.

(B) Histogram of 12 candidate SEs rank-ordered by gained recurrence (number of patients exhibiting SE gain, out of a total of 15). 
A

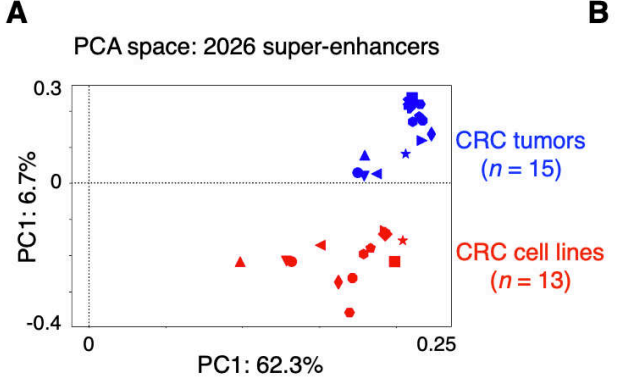

C

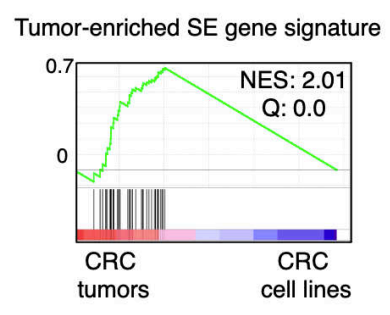

D
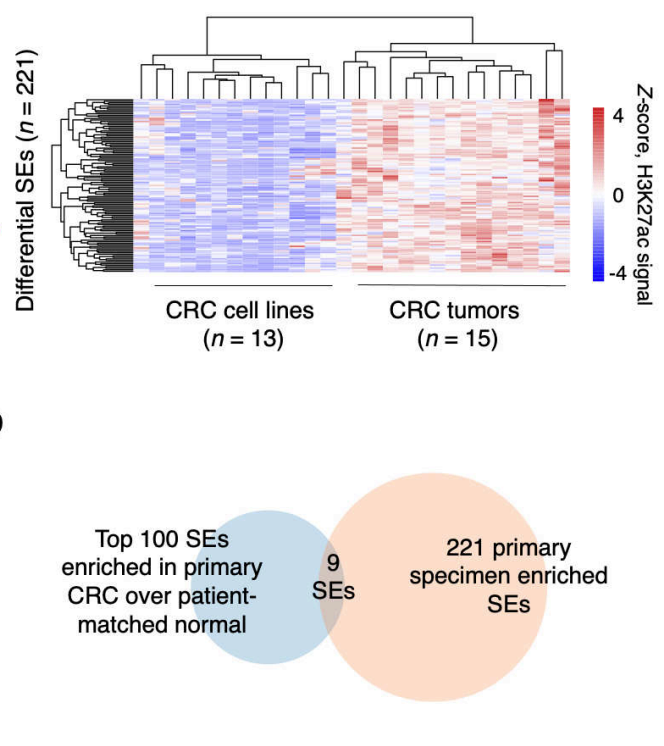

Figure 2. A subset of super-enhancers is specific to primary CRC specimens and not recapitulated in CRC cell lines.

(A) PCA of H3K27ac signal at 2026 SEs in CRC ( $n=15$ independent tissue samples) and CRC cell lines ( $n=13$ independent cell lines). Please see Methods for accessions.

(B) Heatmap of H3K27ac signal (Z-score) between CRC tumors and CRC cell lines with unsupervised hierarchical clustering. 221 SEs (out of 2026) down-regulated in CRC cell lines compared to primary tumors (mean $\mathrm{H} 3 \mathrm{~K} 27$ ac signal $\log _{2}$ fold change $<-1, P<0.01$ ).

(C) GSEA validation of a tumor-enriched SE gene signature imposed on differentially expressed genes between primary CRC and CRC cell lines. See Supplementary Table 3 for gene list.

(D) Venn diagram showing overlap between 221 SEs down-regulated in CRC cell lines from (B) with the top 100 gained SEs in primary CRC over patient-matched normal. 


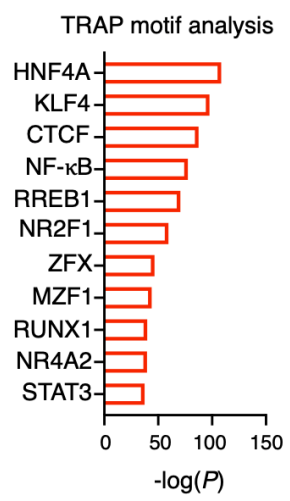

B

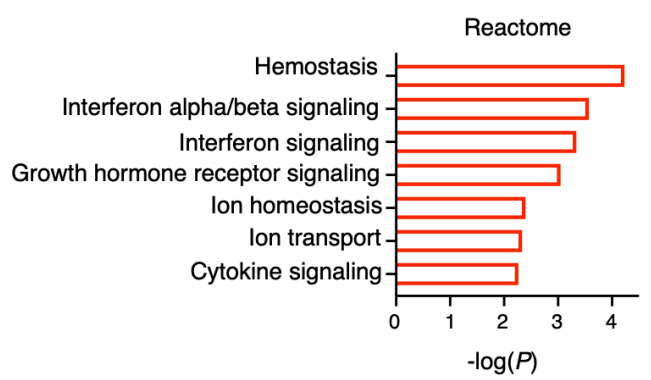

C

ARCHS4 upstream TF prediction

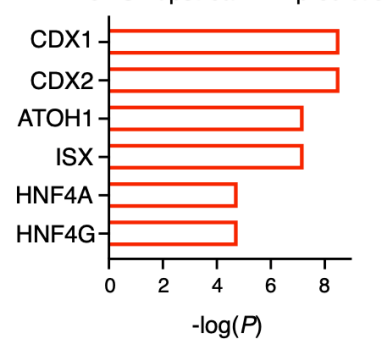

Figure S3. Characterization of super-enhancers is specific to primary CRC underrepresented in $\mathrm{CRC}$ cell lines.

(A) TRAP motif analysis of open chromatin regions within primary CRC-enriched SEs. Open chromatin regions defined by ATAC-seq data from 81 independent primary CRC tumors from TCGA. Please see Methods for accessions.

(B) ENRICHR pathway analysis of a primary CRC-enriched SE gene signature, using the Reactome gene set database.

(C) ENRICHR prediction of upstream transcription factors of the primary CRC-enriched SE gene signature using the ARCHS4 tool. 

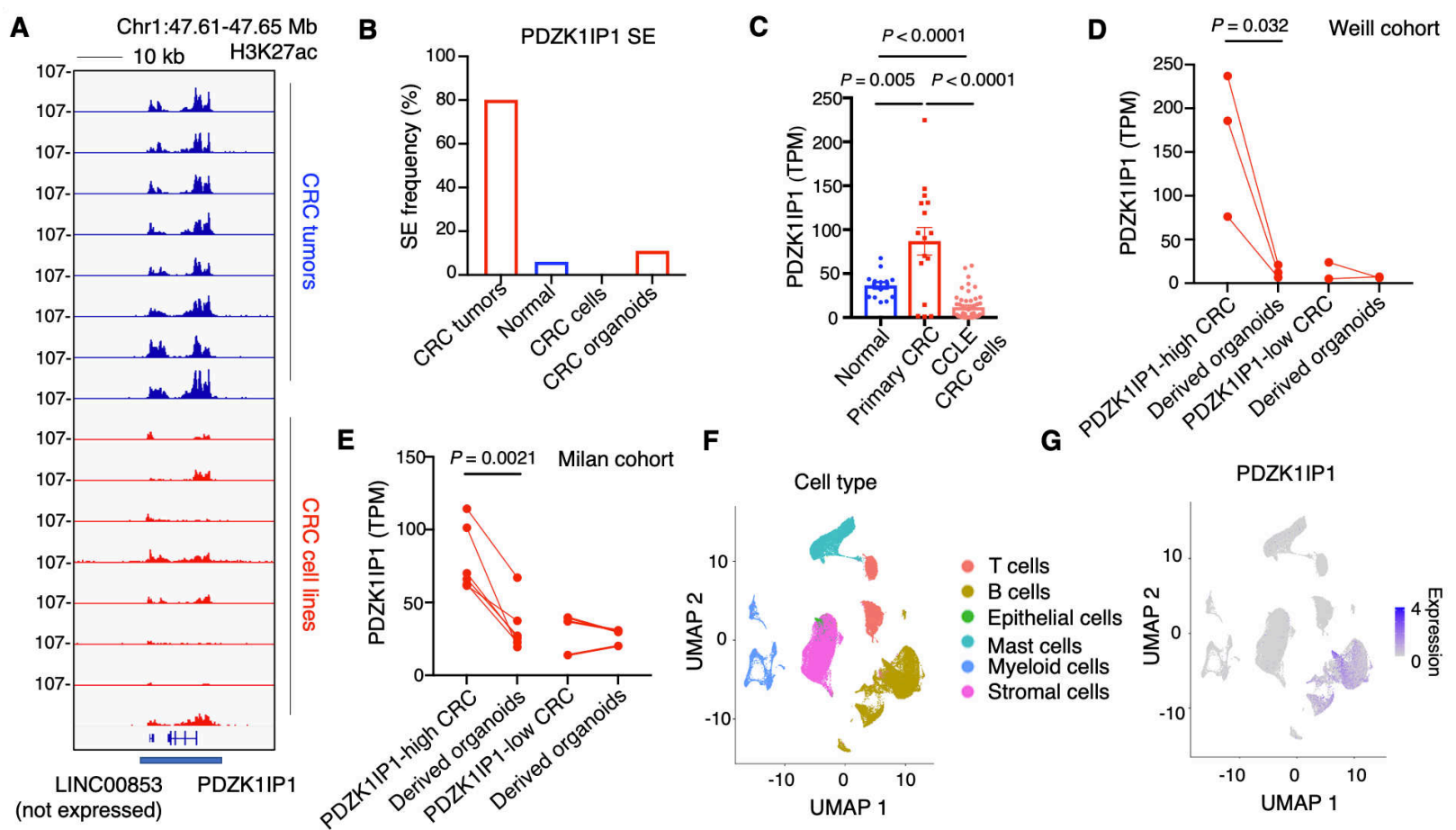

Figure 3. A context-dependent, primary CRC enriched super-enhancer at the locus of PDZK1IP1.

(A) H3K27ac ChIP-seq tracks at the PDZK1IP1 SE in primary CRCs $(n=8$ representative independent tumors) and CRC cell lines ( $n=8$ representative lines).

(B) Frequency of samples meeting ROSE criteria for SE calling at the PDZK1IP1 locus. $n=15$ independent CRC tumors, $n=15$ independent patient-matched normal colon mucosae, $n=13$ independent CRC cell lines, $n=9$ independent 3D CRC organoids.

(C) RNA-seq expression of PDZK1IP1 in primary CRC ( $n=16$ independent tumors), normal mucosa ( $n=15$ independent tissue samples), and CCLE CRC cell lines ( $n=51$ independent cell lines). Data presented as median \pm interquartile range. Significance was determined using Student's $t$-test.

(D-E) RNA-seq expression of PDZK1IP1 in primary CRCs and sample-matched patient-derived 3D CRC organoids. For the Weill cohort, $n=3$ for PDZK1IP1-high tumors and organoids, $n=2$ for PDZK1IP1-low tumors and organoids. For the Milan cohort, $n=6$ for PDZK1IP1-high tumors 
and organoids, $n=3$ for PDZK1IP1-low tumors and organoids. Significance determined by Student's $t$-test. Please see Methods for accessions.

(F-G) Uniform Manifold Approximation and Projection (UMAP) of single cells from 23 independent primary $\mathrm{CRC}$ tumors and 10 independent adjacent patient-matched normal colons 695 merged into a single plot, annotated with cell type and PDZK1IP1 expression. Please see Methods for accessions. 


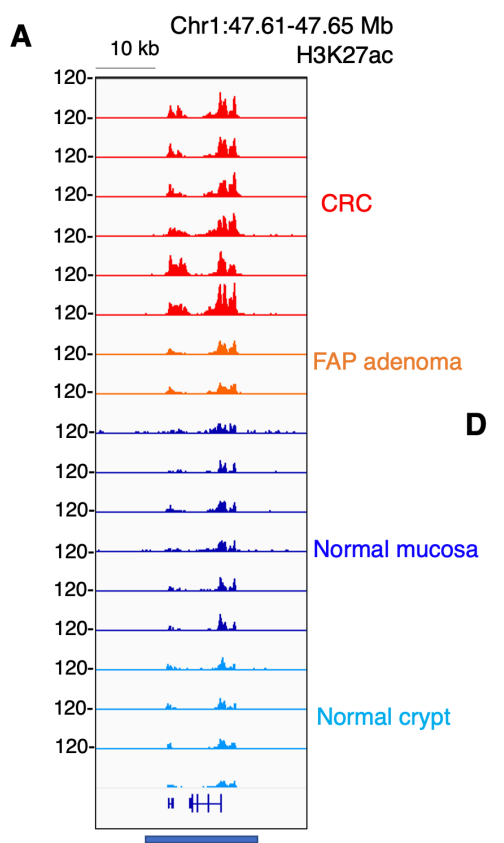

B

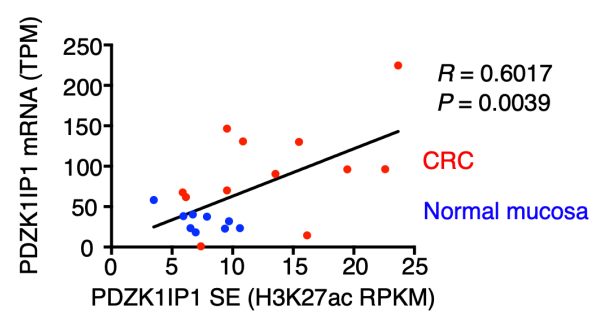

D

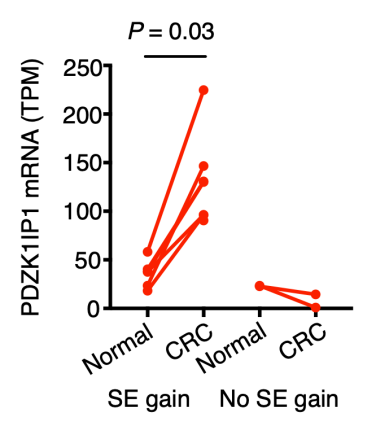

E

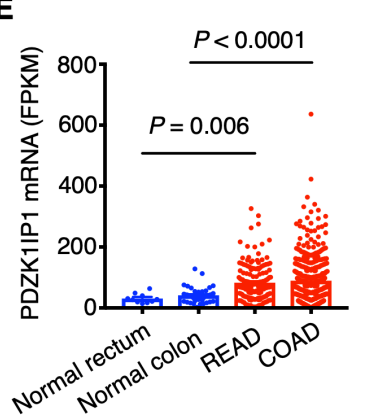

C

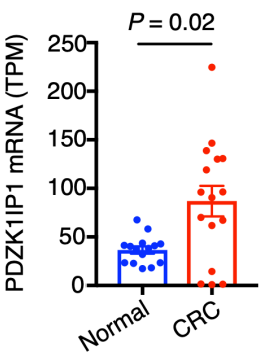

$\mathbf{F}$

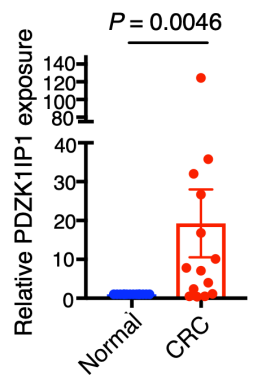

LINC00853 PDZK1IP1 (not expressed)

G

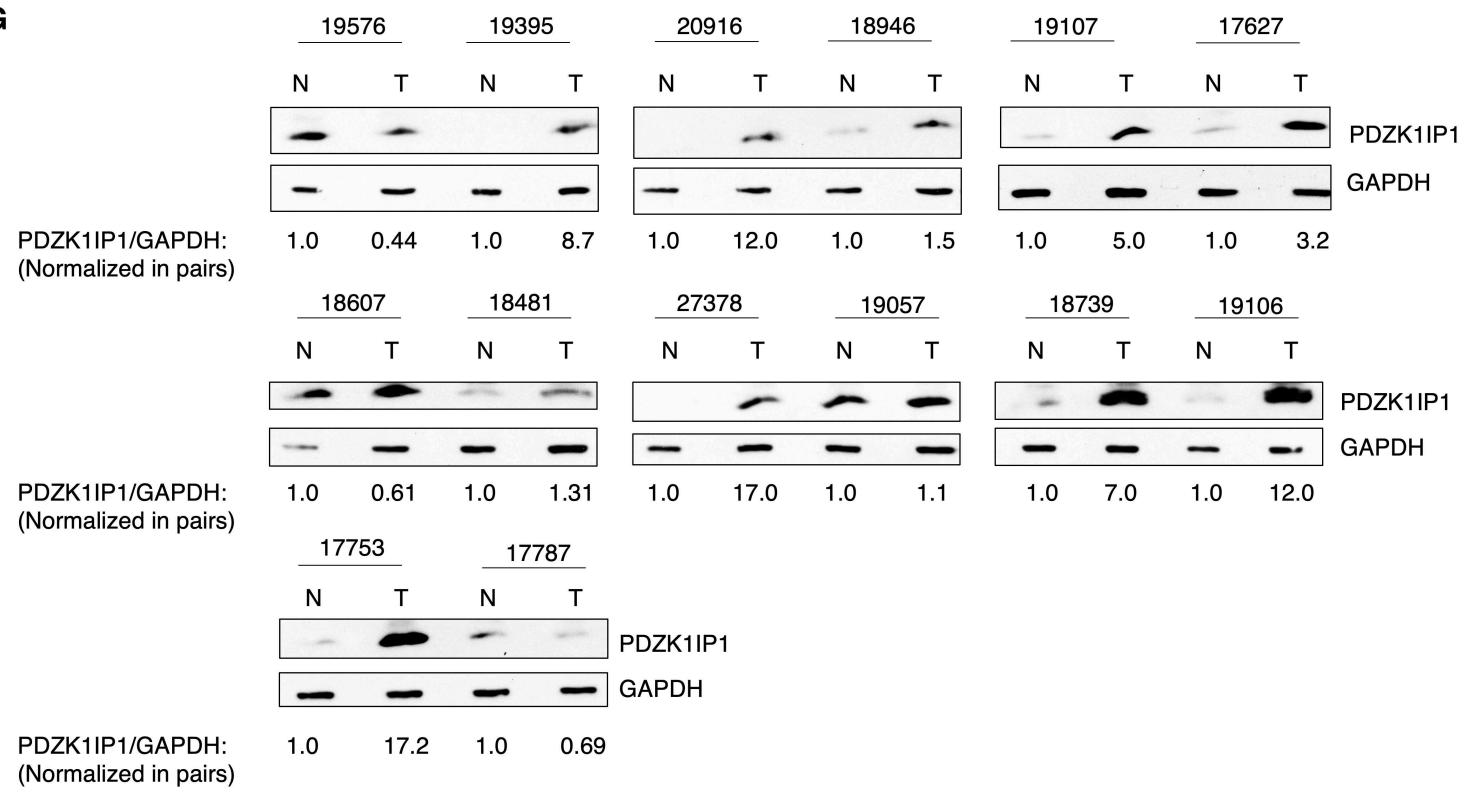

Figure S4. PDZK1IP1 and its super-enhancer are up-regulated in CRC.

(A) H3K27ac ChIP-seq track at the PDZK1IP1 SE (underlined) in 6 representative independent primary CRCs, 2 FAP adenomas, 6 representative independent normal colon epithelium samples, and 4 normal colon crypts. See Methods for accessions used for FAP and crypt samples.

(B) Correlation of PDZK1IP1 SE H3K27ac signal and PDZK1IP1 mRNA expression using sample-matched sequencing data. For CRC $n=11$ independent patient samples, for normal mucosa 
$n=10$. Although 15 primary CRCs and 15 normal colons were used for ChIP-seq analyses, sample-matched RNA-seq data was only available for 11 CRCs and 10 normal colons, respectively. All available data was used in this analysis.

(C-D) PDZK1IP1 mRNA expression by RNA-seq in our cohort of patients. For CRC $n=16$ independent tumors; for normal mucosa $n=15$ independent tissue samples. Data presented as mean \pm s.e.m. Significance was determined using Student's $t$-test.

(E) PDZK1IP1 mRNA expression by RNA-seq between normal colon ( $n=42$ independent cases), normal rectum ( $n=10$ independent cases) rectal adenocarcinoma (READ, $n=166$ independent cases), and colon adenocarcinoma (COAD, $n=475$ independent cases) from TCGA. Data presented as mean \pm s.e.m. Significance was determined using Student's $t$-test.

(F-G) PDZK1IP1 protein levels by immunoblot with ImageJ quantification (fold change, CRC over normal for each pair). $n=14$ de-identified patients, each with a matched tumor normal pair.

735 T - tumor, $\mathrm{N}-$ matched normal. Five-digit de-identified patient number. Data presented as mean \pm s.e.m. Significance was determined using Student's $t$-test. 

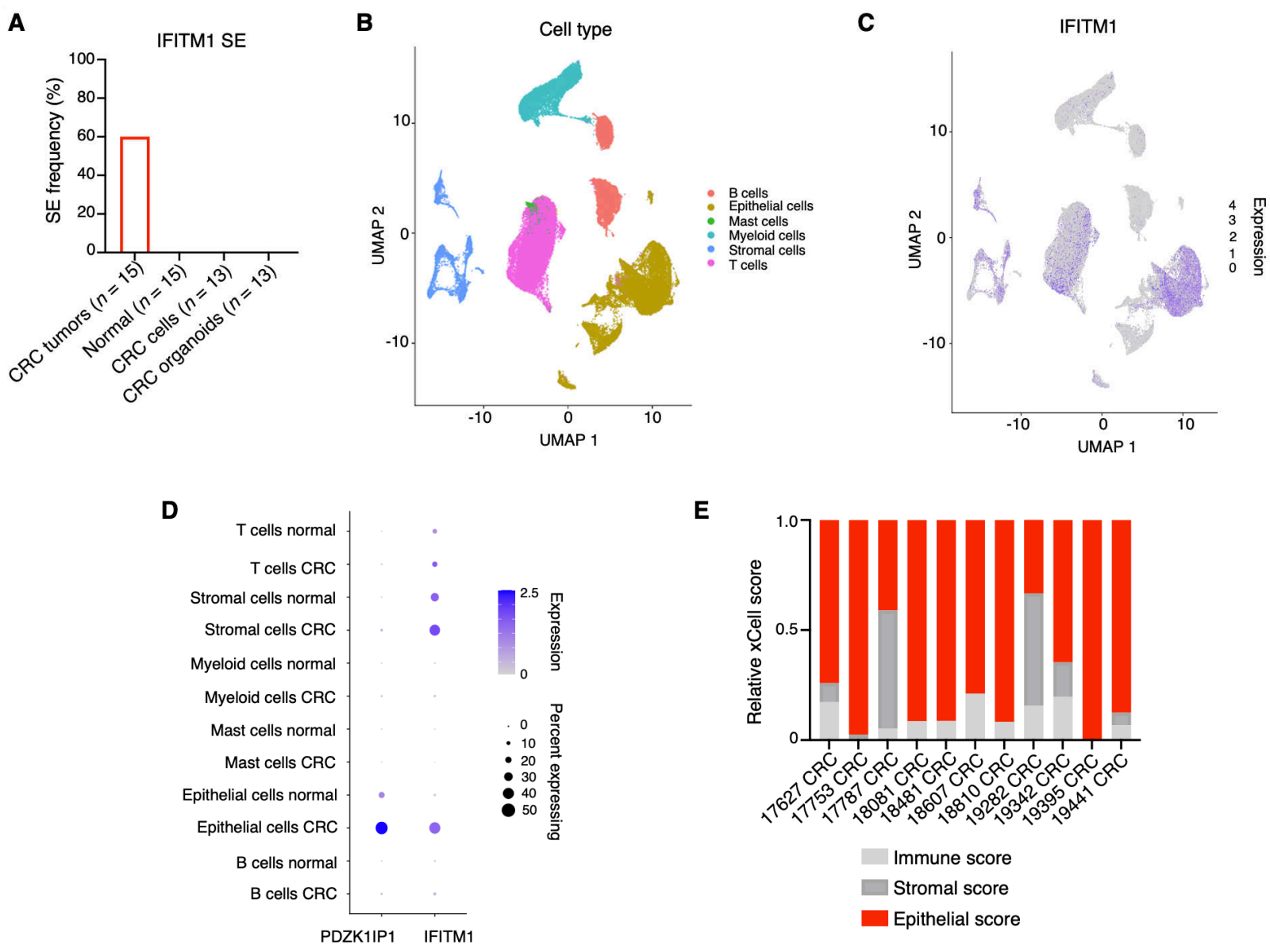

F

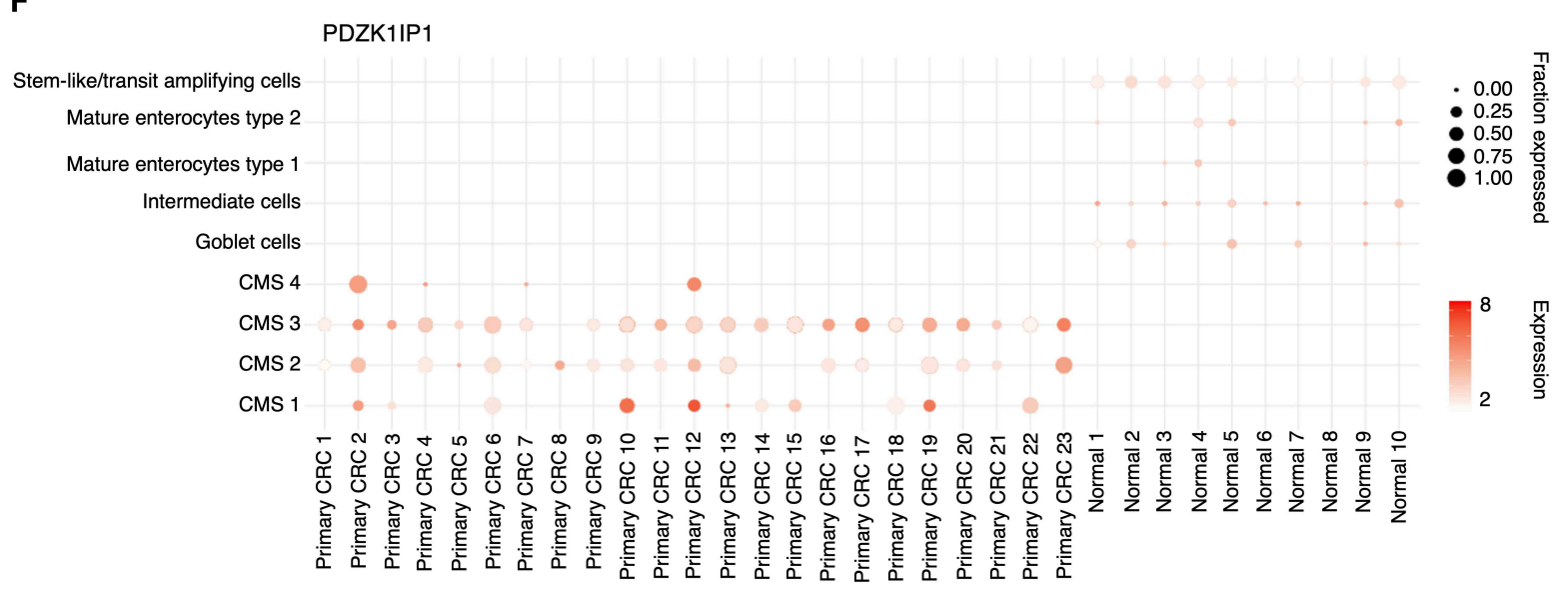

Figure S5. Characterization of CRC-enriched SEs at IFITM1 and PDZK1IP1.

(A) Frequency of samples meeting ROSE criteria for SE calling at the IFITMI locus. $n=15$ independent CRC tumors, $n=15$ independent patient-matched normal colon mucosae, $n=13$ independent CRC cell lines, $n=9$ independent 3D CRC organoids. 
(B-C) UMAP of single cells from 23 independent primary CRC tumors and 10 independent 750 adjacent patient-matched normal colons merged into a single plot, annotated with cell type and IFITM1 expression. Please see Methods for accessions.

(D) Dot plot of PDZKIIPI or IFITMI expression in single cells from primary CRC or adjacent normal colon epithelium.

(E) xCell de-convolution of bulk tumor RNA-seq into putative epithelial, immune, and stromal compositions. Out of the 15 primary CRCs for which H3K27ac ChIP-seq data is available, only 11 have sample-matched bulk tumor RNA-seq data. All available data was used in this analysis. (F) Dot plot of PDZK1IP1 expression in single cells of epithelial origin, from either primary CRC ( $n=23$ independent cases) or patient-matched adjacent normal epithelium $(n=10$ independent cases). CMS refers to the consensus molecular subtypes of CRC as previously assigned. Please see Methods for accessions. 
A

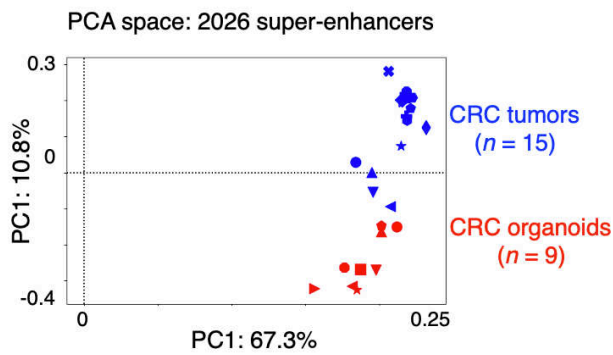

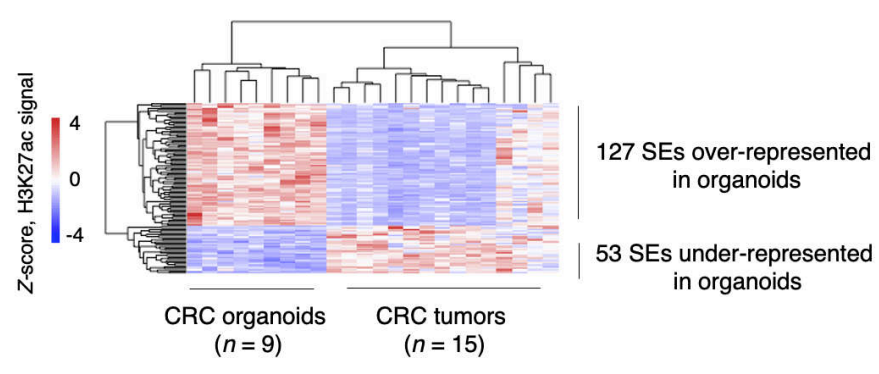

C
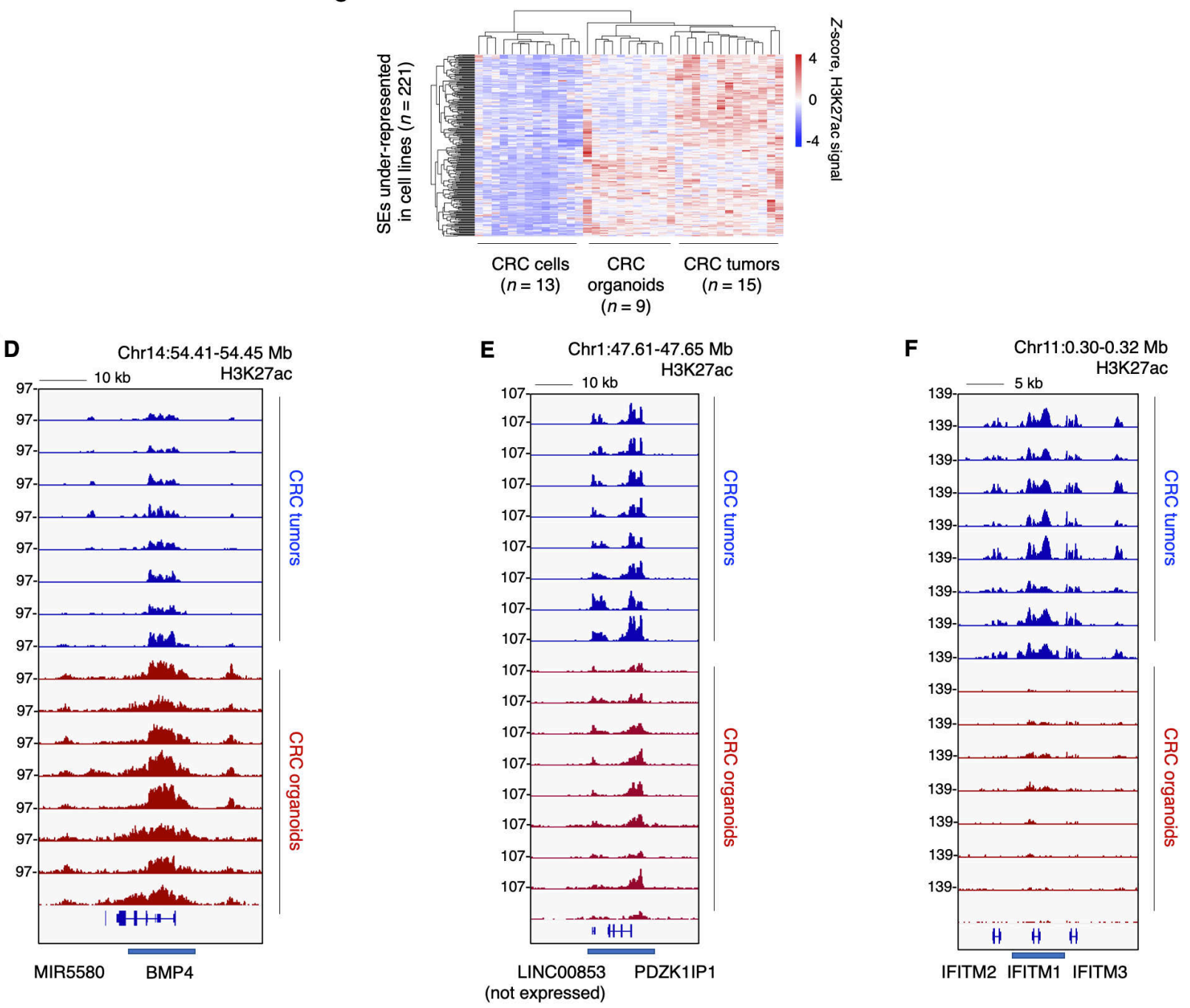
(not expressed)

Figure S6. Super-enhancers specific to primary CRC specimens and not recapitulated in 3D CRC organoids.

(A) PCA of H3K27ac signal at 2026 SEs in CRC ( $n=15$ independent tissue samples) and CRC 3D organoids (derived from $n=9$ independent patients). Please see Methods for accessions. 
(B) Heatmap of H3K27ac signal (Z-score) between CRC tumors and CRC 3D organoids with unsupervised hierarchical clustering at 180 differentially expressed SEs (absolute mean $\log _{2}$ fold change $>1, P<0.01)$.

(C) Incorporation of 3D CRC organoids into the heatmap of 221 SEs down-regulated in 2D CRC cell lines from Figure 2.

(D) H3K27ac ChIP-seq track of the SE at BMP4 (underlined) in $n=8$ representative primary CRCs and $n=8$ representative $3 \mathrm{D}$ CRC organoid cultures.

(E) H3K27ac ChIP-seq track of the SE at PDZK1IP1 (underlined) in $n=8$ representative primary CRCs and $n=8$ representative 3D CRC organoid cultures.

(F) H3K27ac ChIP-seq track of the SE at IFITM1 (underlined) in $n=8$ representative primary CRCs and $n=8$ representative 3D CRC organoid cultures. 

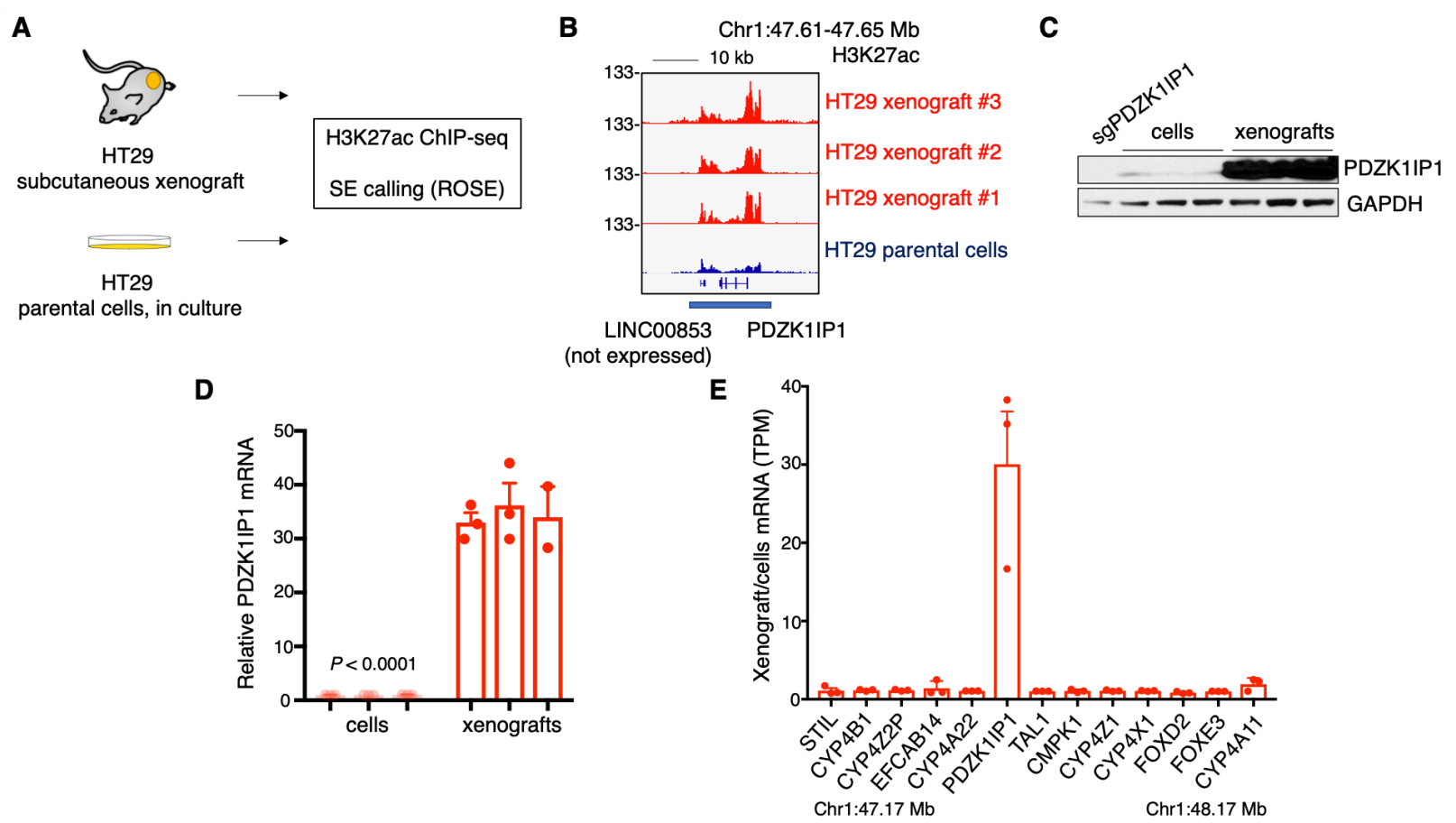

\section{5 \\ Figure 4. Xenotransplantation restores the PDZK1IP1 super-enhancer and expression.}

(A) Experiment overview.

(B) H3K27ac ChIP-seq track of the PDZK1IP1 SE (underlined) in HT29 xenografts $(n=3$ independent tumors) or HT29 parental cells maintained in culture.

(C) Immunoblot of PDZK1IP1 protein levels between HT29 xenografts $(n=3$ independent tumors) or HT29 parental cells maintained in culture ( $n=3$ biological replicates).

(D) Quantitative real-time PCR (qRT-PCR) of PDZK1IP1 mRNA expression between HT29 xenografts $(n=3$ independent tumors) or HT29 parental cells maintained in culture $(n=3$ biological replicates). Data presented as mean \pm s.e.m. Significance was determined using Student's $t$-test.

(E) Fold change gene expression by RNA-seq between HT29 xenografts ( $n=3$ independent tumors) or HT29 parental cells maintained in culture ( $n=3$ biological replicates). X-axis represents all protein-coding genes within $500 \mathrm{~kb}$ on either side of the PDZK1IP1 SE. Data presented as mean \pm s.e.m. 
A

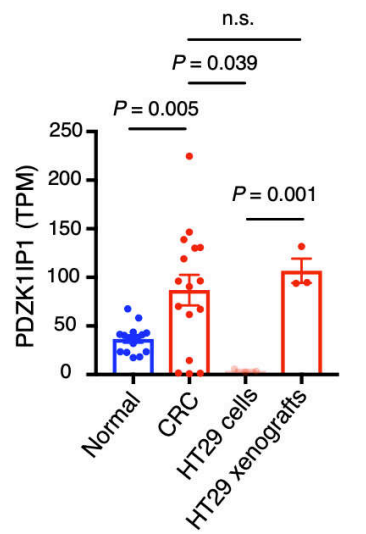

B

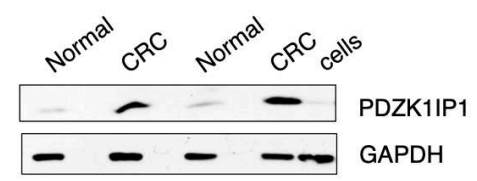

C

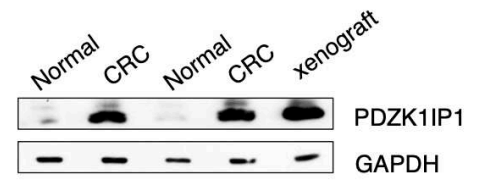

Figure S7. PDZK1IP1 expression levels in HT29 xenografts recapitulate those in primary CRC.

(A) PDZK1IP1 expression by RNA-seq, HT29 cells ( $n=3$ biological replicates), HT29 xenografts ( $n=3$ independent tumors), normal mucosa ( $n=15$ independent tissue samples), and primary CRC $(n=16)$ independent tumors Data presented as mean \pm s.e.m. Significance was determined using Student's $t$-test.

(B-C) PDZK1IP1 expression by immunoblot across four independent patient-matched CRCnormal colon pairs, versus HT29 cells or HT29 xenograft tumors. 
A

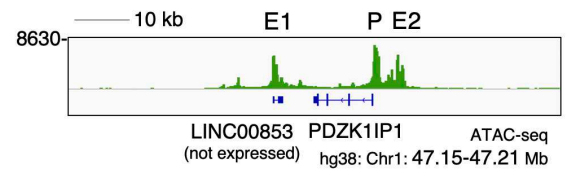

E

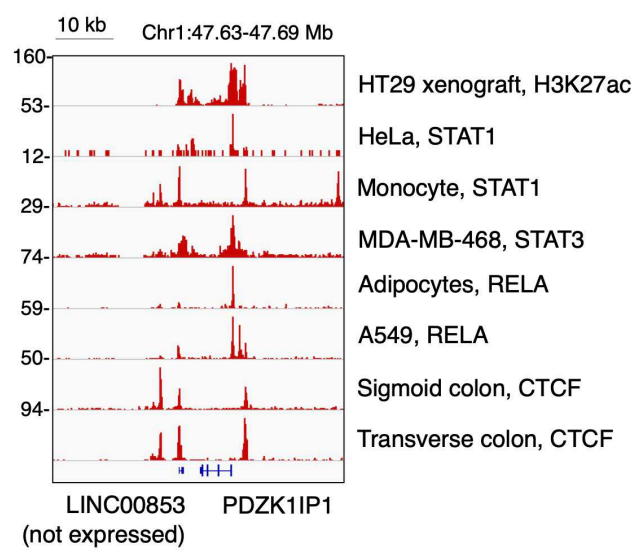

J

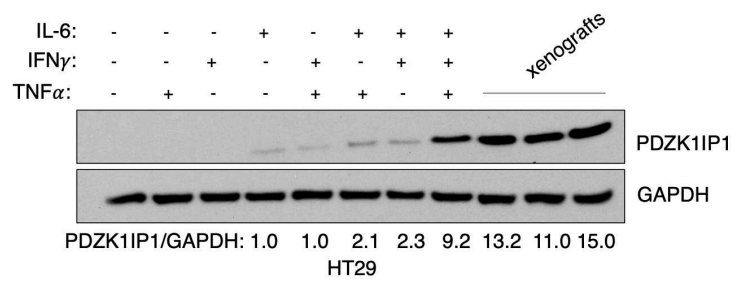

$\mathbf{L}$

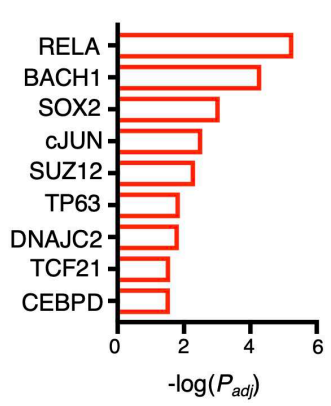

M
B

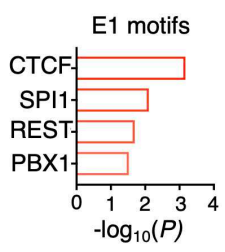

C

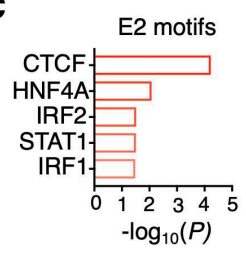

D

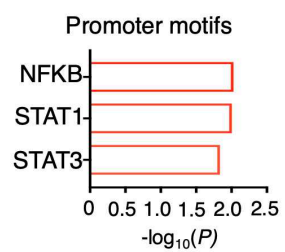

$\mathbf{F}$

Hallmark IFN-gamma response

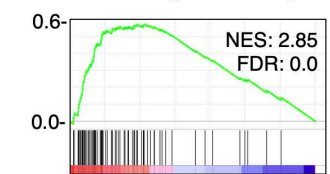

PDZK1IP1-high PDZK1IP1-low PDZK1IP1-high PDZK1IP1-low

H

Hallmark TNF-alpha signaling via NFKB Hallmark IL-6 JAK STAT3 signaling

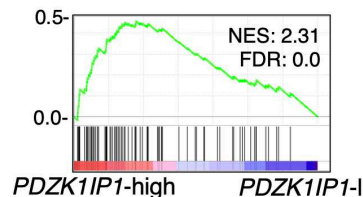

PDZK1IP1-low PDZK1IP1-high PDZK1IP1-low

K

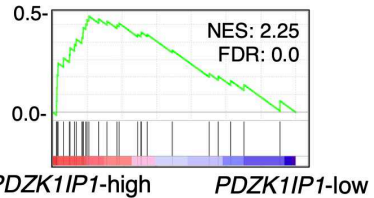

Hallmark inflammatory response

Hallmark $\mathrm{TNF} \alpha$ signaling via $\mathrm{NF} \kappa \mathrm{B}$
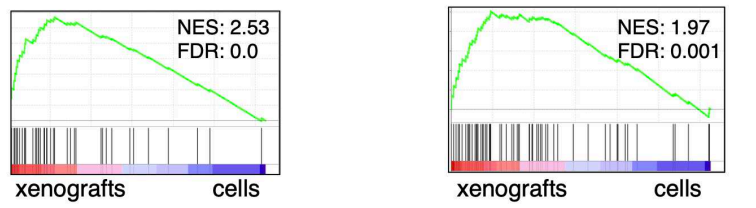

$\mathbf{N}$
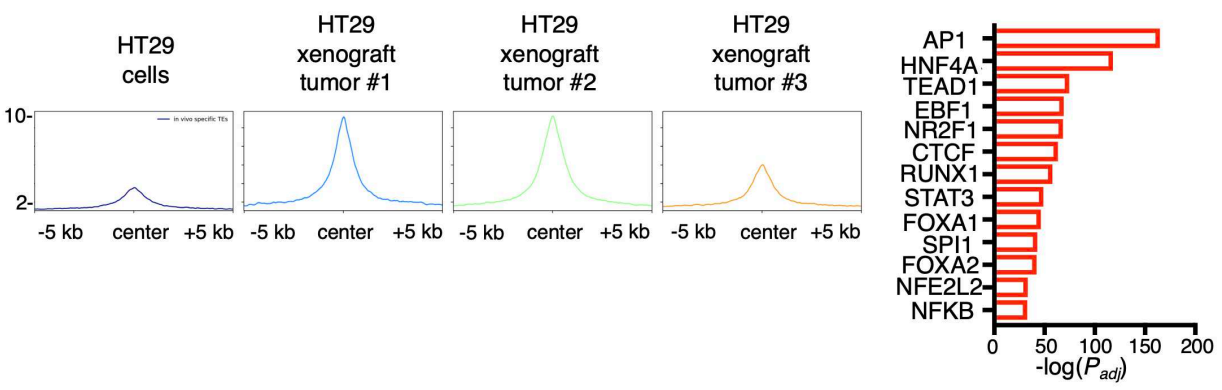

\section{Figure S8. PDZK1IP1 is regulated by inflammation.}

(A) ATAC-seq track at the PDZK1IPI SE in primary CRCs from TCGA $(n=81$ independent tumors, merged into one track).

(B-D) TRAP motif analysis at consensus open chromatin regions from (A) at the PDZK1IP1 SE in primary CRC. 
(E) H3K27ac, STAT1, STAT3, RELA, and CTCF ChIP-seq tracks at the PDZK1IP1 SE. See Methods for accessions.

(F-I) Hallmarks of Cancer GSEA enrichment signatures from PDZK1IP1-high (top 50\% mRNA expression) versus PDZK1IP1-low (bottom 50\% mRNA expression) primary CRCs from TCGA ( $n=342$ independent tumors).

(J) PDZK1IP1 expression levels by immunoblot in cytokine stimulated HT29 cells (10 ng/mL, 16 hours) or HT29 subcutaneous xenografts in nude mice.

(K) Hallmarks of Cancer GSEA performed on differentially expressed genes from RNA-seq between HT29 xenograft tumors ( $n=3$ independent tumors) and HT29 parental cells maintained 855 in culture ( $n=3$ biological replicates).

(L) ChEA TF predictions upstream of up-regulated genes $\left(\log _{2}\right.$ fold change $\left.>2\right)$ from RNA-seq data in HT29 xenograft tumors over HT29 parental cells in culture.

(M) Metagene of up-regulated H3K27ac enhancer peaks (mean $\log _{2}$ fold change $>1$ ) in HT29 xenograft tumors ( $n=3$ independent tumors) over HT29 parental cells maintained in culture.

860 (N) TRAP TF motif analysis output for H3K27ac enhancers shown in (M). 
A

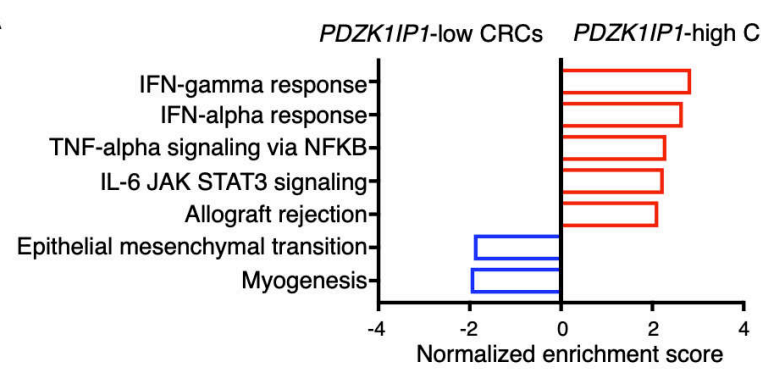

C

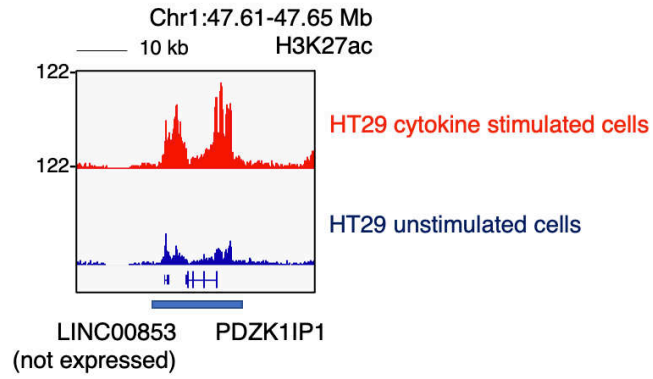

$\mathbf{B}$

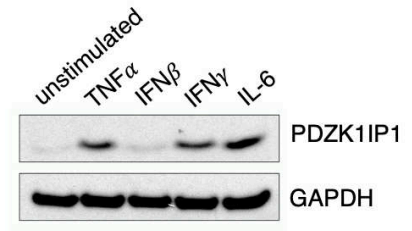

Figure 5. The PDZK1IP1 super-enhancer is regulated by inflammation.

(A) Hallmarks of Cancer GSEA of RNA-seq expression data from PDZK1IP1-high (top 50\% mRNA expression) versus PDZK1IP1-low (bottom 50\% mRNA expression) primary CRCs from TCGA ( $n=342$ independent tumors).

875 (B) PDZK1IP1 protein levels by immunoblot in HT29 cells following 16-hour stimulation with the indicated recombinant human cytokine in culture media at $10 \mathrm{ng} / \mathrm{mL}$.

(C) H3K27ac ChIP-seq track of the PDZK1IP1 SE (underlined) in unstimulated or TNF $\alpha$, IFN $\gamma$, and IL-6 co-stimulated HT29 cells at $10 \mathrm{ng} / \mathrm{mL}$ for 16 hours. 
A

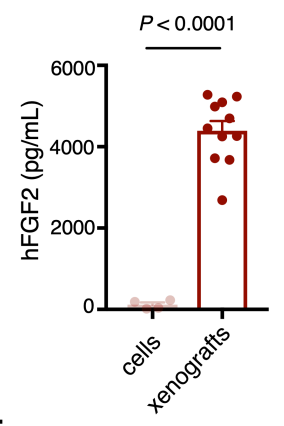

F

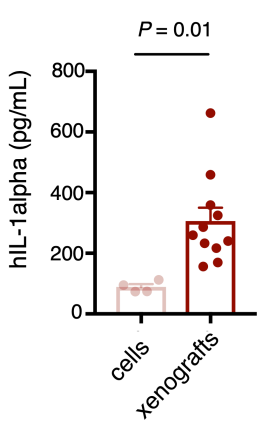

K

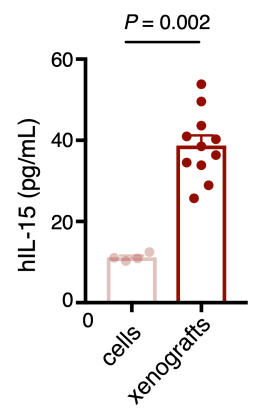

P

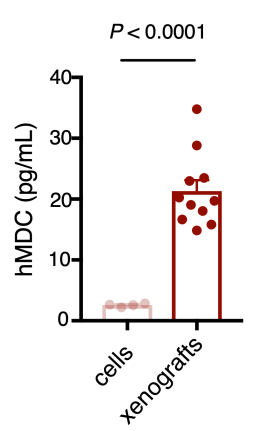

B

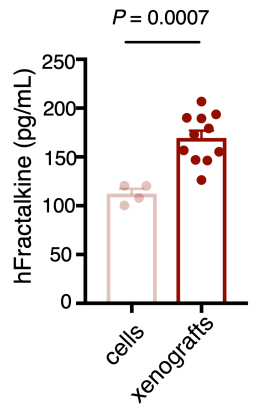

G

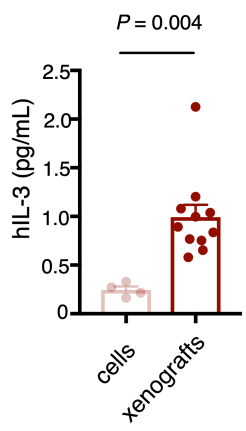

L

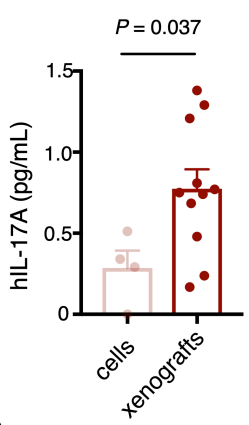

$\mathbf{Q}$

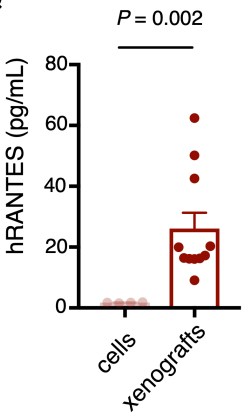

C

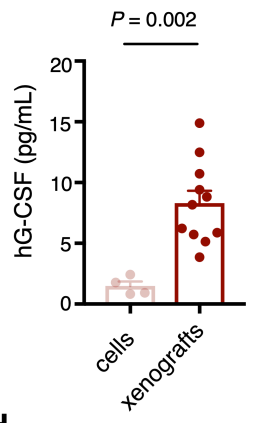

H

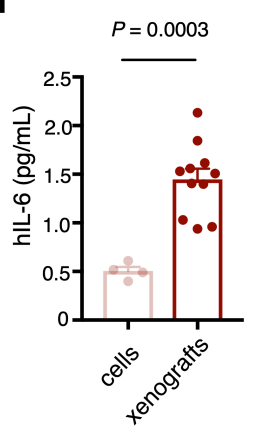

M

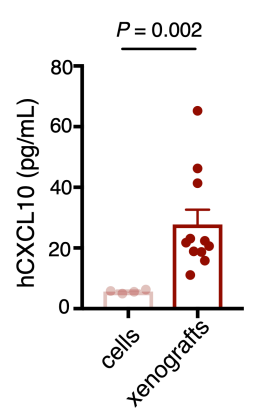

R

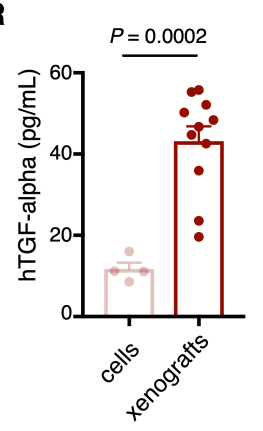

D

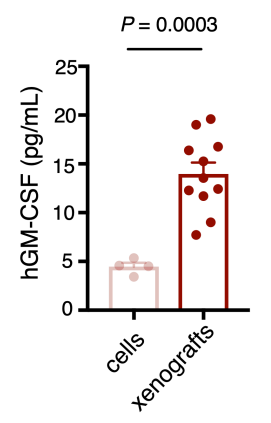

I

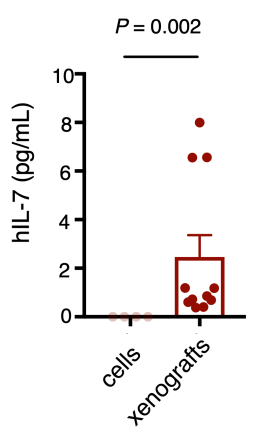

$\mathbf{N}$
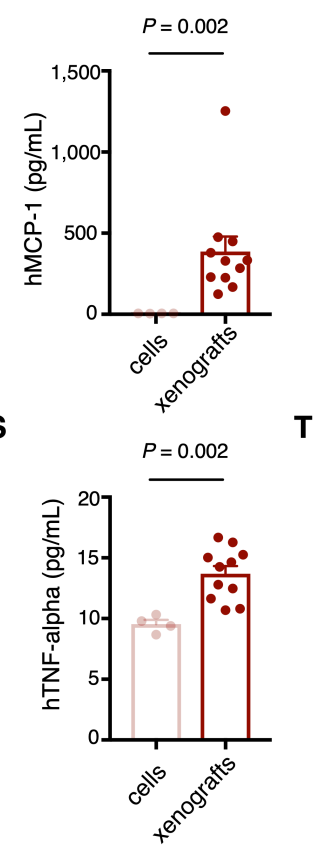

E

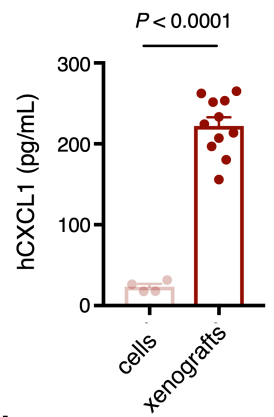

J

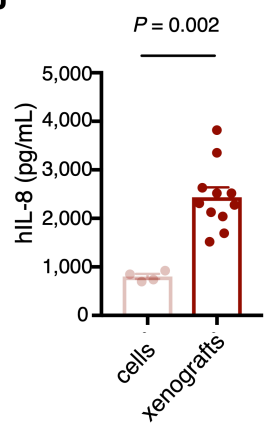

0

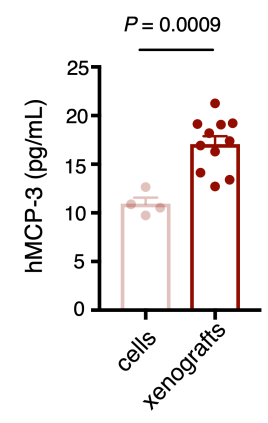

T

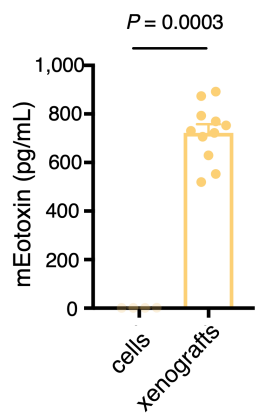


U

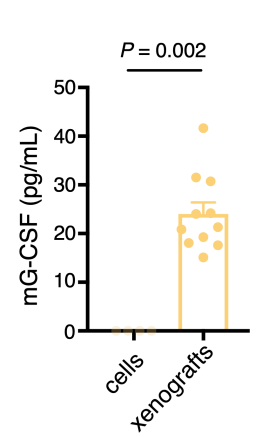

Z

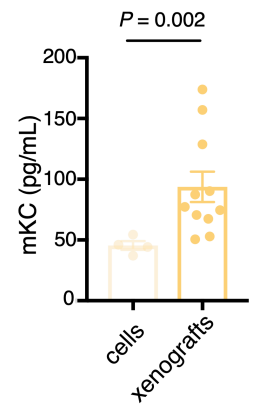

EE

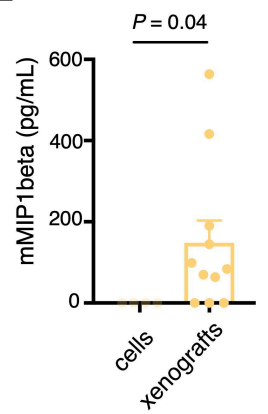

II
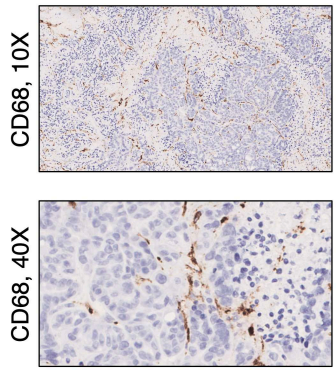

V

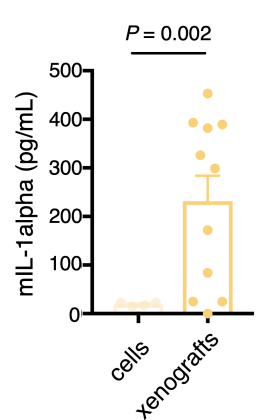

AA

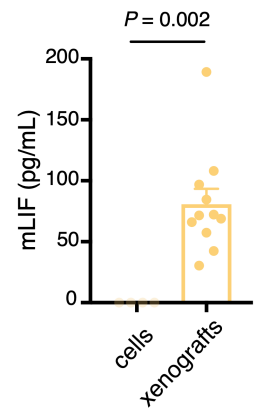

FF

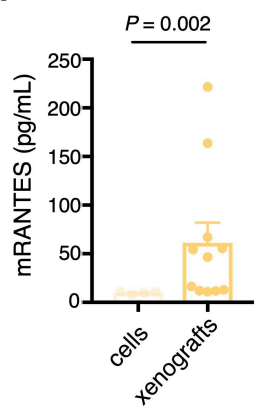

JJ
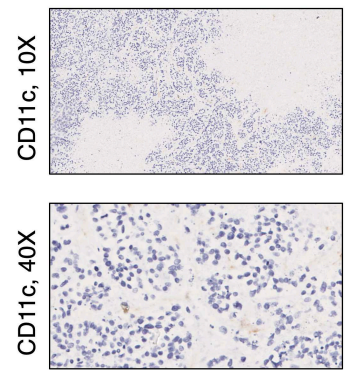

W

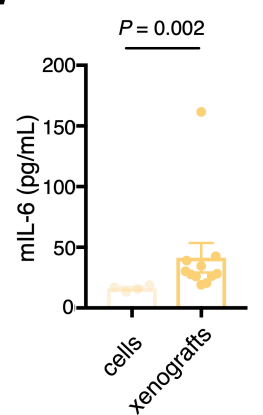

BB

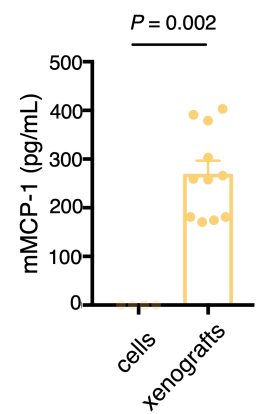

GG

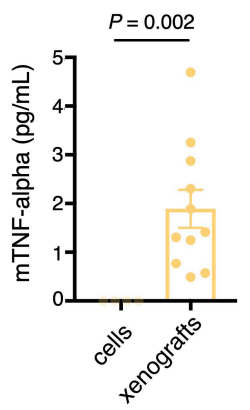

KK
X

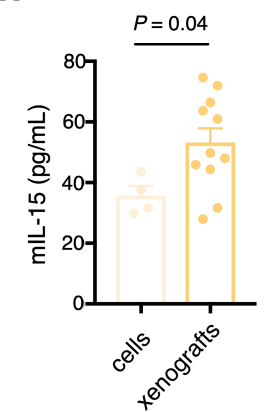

CC

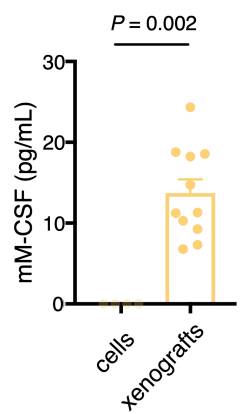

$\mathbf{Y}$

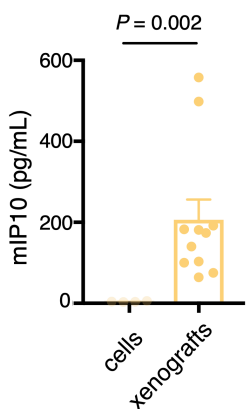

DD

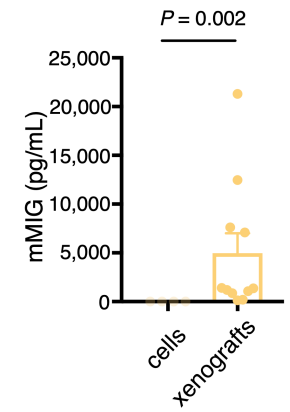

HH

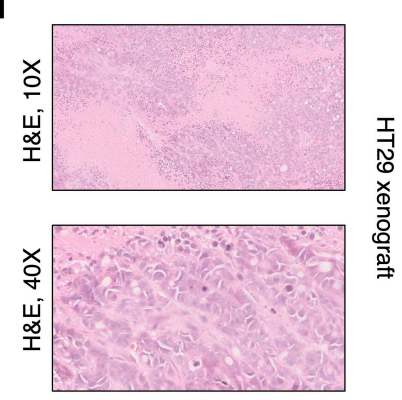

LL
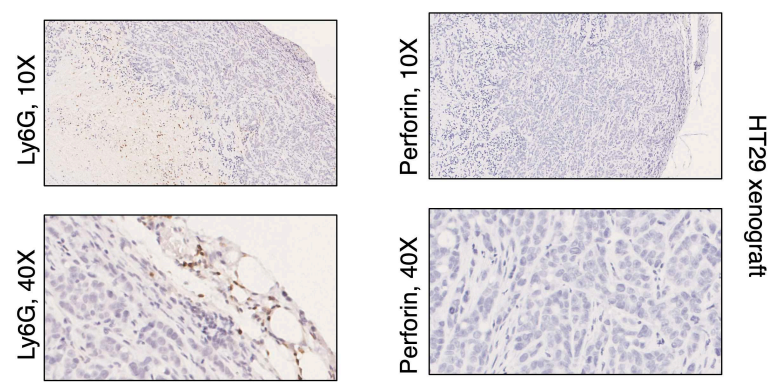

Figure S9. Xenograft tumors exhibit increased pro-inflammatory cytokines, chemokines, and growth factors upstream of $P D Z K 1 I P 1$.

(A-S) Luminex-based human (prefixed with "h" on the y-axis, with cayenne red bars) cytokine profiling of HT29 xenograft tumor lysates ( $n=11$ biological replicates) and HT29 parental cells 
( $n=4$ biological replicates) in culture (performed by EveTechnologies). Data presented as mean

$890 \pm$ s.e.m. Significance was determined using Student's $t$-test or Mann-Whitney $t$-test.

(T-GG) Luminex-based mouse (prefixed with "m" on the y-axis, with cantaloupe yellow bars) cytokine profiling of HT29 xenograft tumor lysates and HT29 parental cells in culture as above (performed by EveTechnologies). Data presented as mean \pm s.e.m. Significance was determined using Student's $t$-test or Mann-Whitney $t$-test.

895 (HH-LL) IHC staining of immune cell markers in HT29 xenograft tumors. 
A

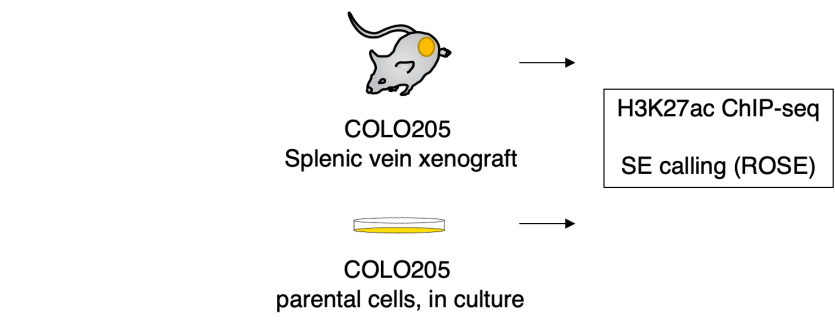

B

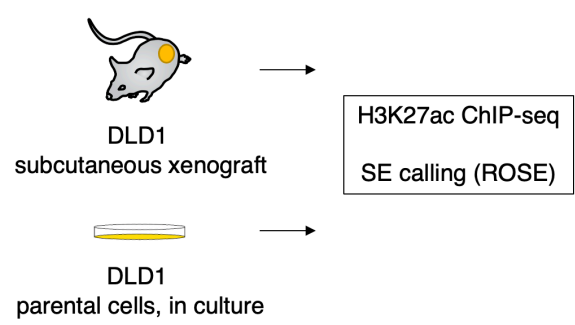

C

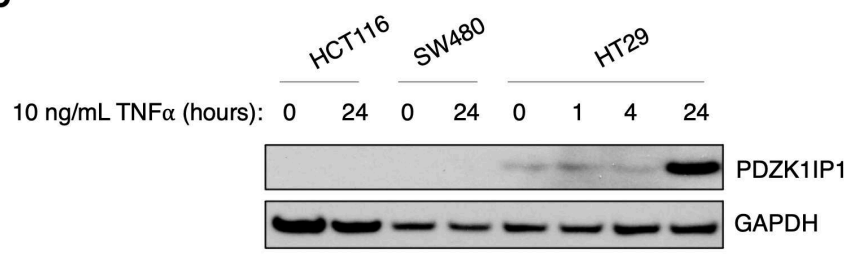

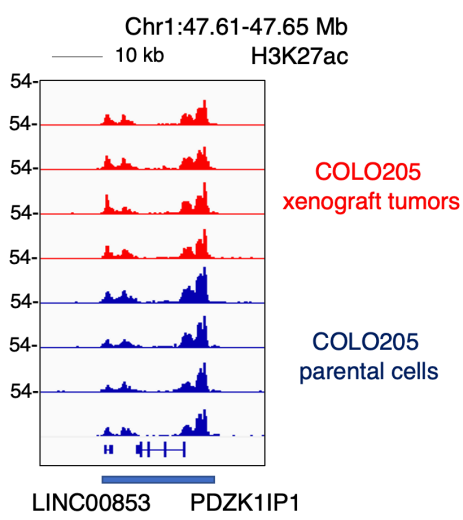

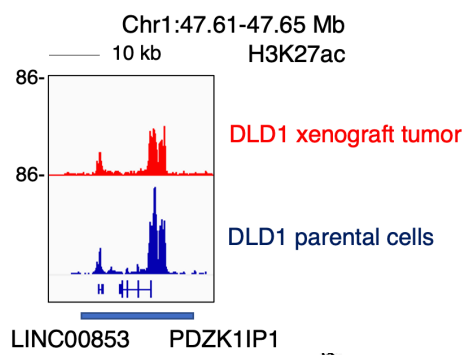

D

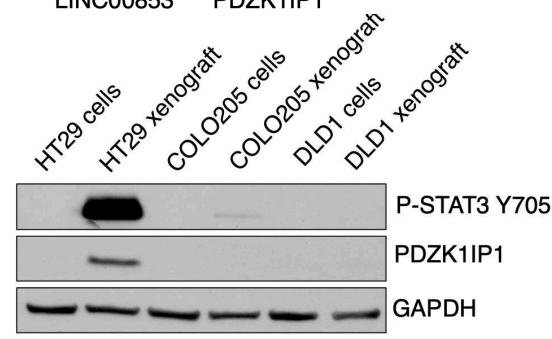

Figure S10. Cell-specific super-enhancer reprogramming in response to microenvironment.

(A) Experiment overview. A xenograft model of COLO205 liver metastases in nude mice via splenic vein injection. H3K27ac ChIP-seq of COLO205 xenograft tumors in nude mice $(n=4$ independent tumors) and COLO205 parental cells maintained in culture $(n=4$ biological replicates).

(B) Experiment overview. A subcutaneous xenograft tumor model of DLD1 cells in nude mice. H3K27ac ChIP-seq of DLD1 xenograft tumors or DLD1 parental cells maintained in culture.

(C) PDZK1IP1 protein levels by immunoblot with or without TNF $\alpha$ stimulation in HCT116, SW480, or HT29 cells. 
(D) PDZK1IP1 protein levels correlated with phosphorylation of STAT3 at the Y705 residue in parental cells maintained in culture or subcutaneous xenografts in nude mice.

925 
A

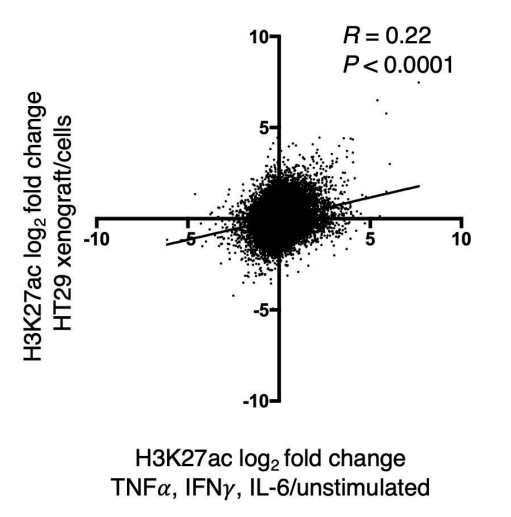

B

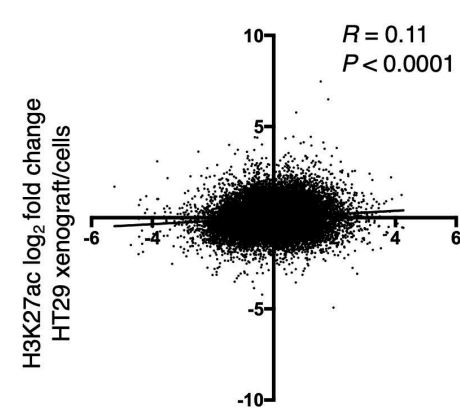

H3K27ac $\log _{2}$ fold change CRC/normal
C

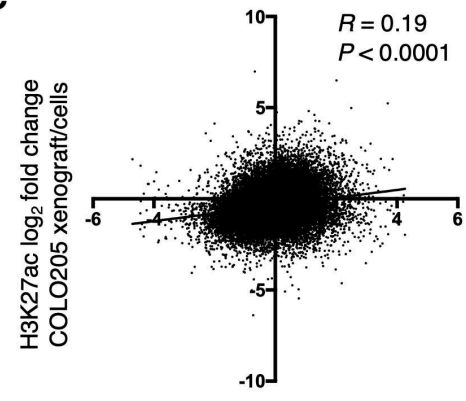

H3K27ac $\log _{2}$ fold change CRC/normal

Figure S11. The tumor microenvironment recapitulates enhancer reprogramming in cancer. (A) Linear correlation between $\log _{2}$ fold change H3K27ac signal in HT29 nude mice subcutaneous xenografts ( $n=3$ independent tumors) over parental cells in vitro, and TNF $\alpha$, IFN $\gamma$, IL-6 stimulated cells (10 ng/mL, 16 hours) over unstimulated cells. Each dot represents a unique typical enhancer, called in our primary CRC tumors using ROSE. For HT29 xenografts

(B) Linear correlation between $\log _{2}$ fold change H3K27ac signal in HT29 xenografts/parental cells and CRC/normal mucosa.

(C) Linear correlation between $\log _{2}$ fold change H3K27ac signal correlation in COLO205 splenic

955 vein injection xenografts ( $n=7$ independent tumors, 4 in nude mice, 3 in NSG mice) over parental cells against CRC ( $n=15$ independent tumors) over normal mucosa $(n=15$ normal colon tissue samples). 
A

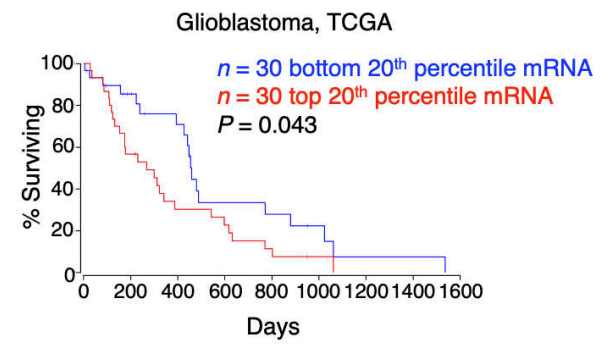

C

Cervical Squamous Carcinoma, TCGA

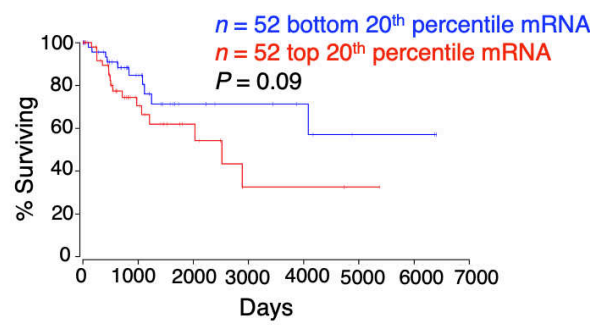

B

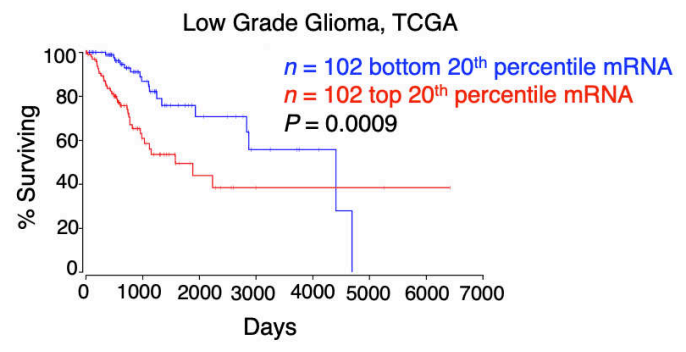

D

Pancreatic adenocarcinoma, TCGA

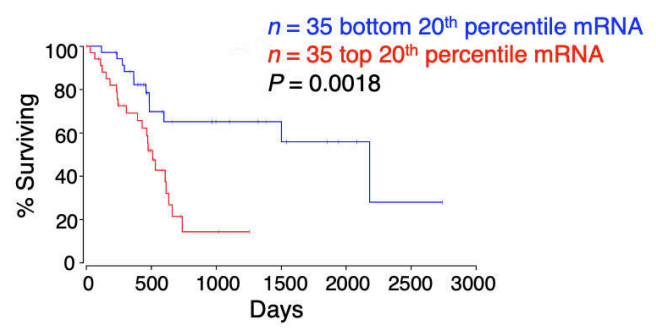

Figure S12. High PDZK1IP1 expression negatively prognosticates patient survival in multiple cancers.

(A-D) Kaplan-Meier survival curves of PDZK1IP1 high (top 20\% mRNA, in red) and low (bottom $20 \%$ mRNA, in blue) cancer cases. Patient survival and gene mRNA expression data from TCGA, visualized using OncoLnc. 
A

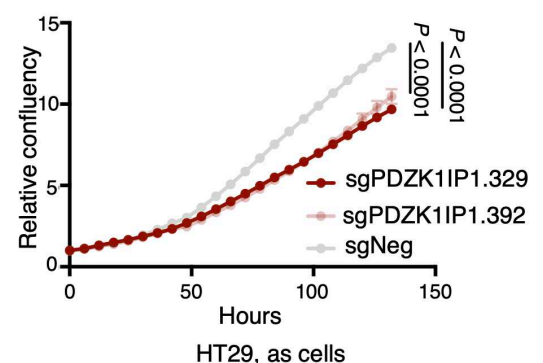

HT29, as cells

D

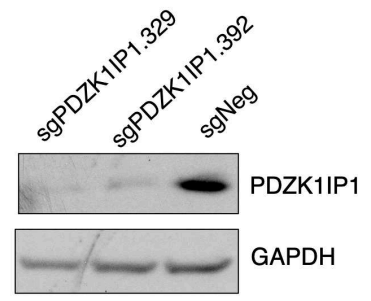

DLD1

G

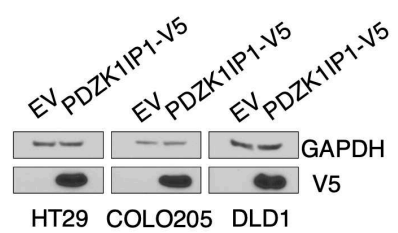

HT29 COLO205 DLD1

J

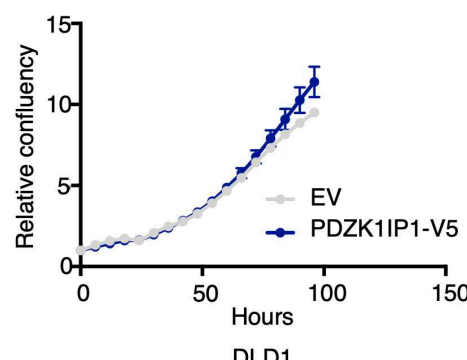

E

H
B

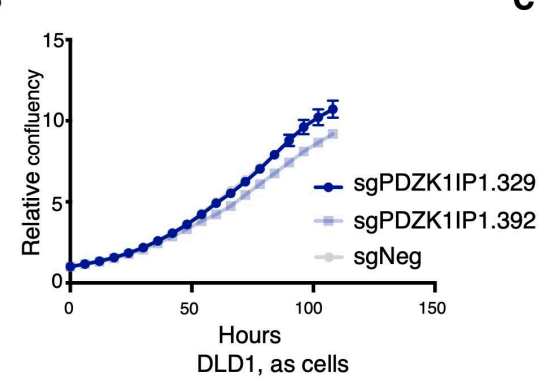

F

C
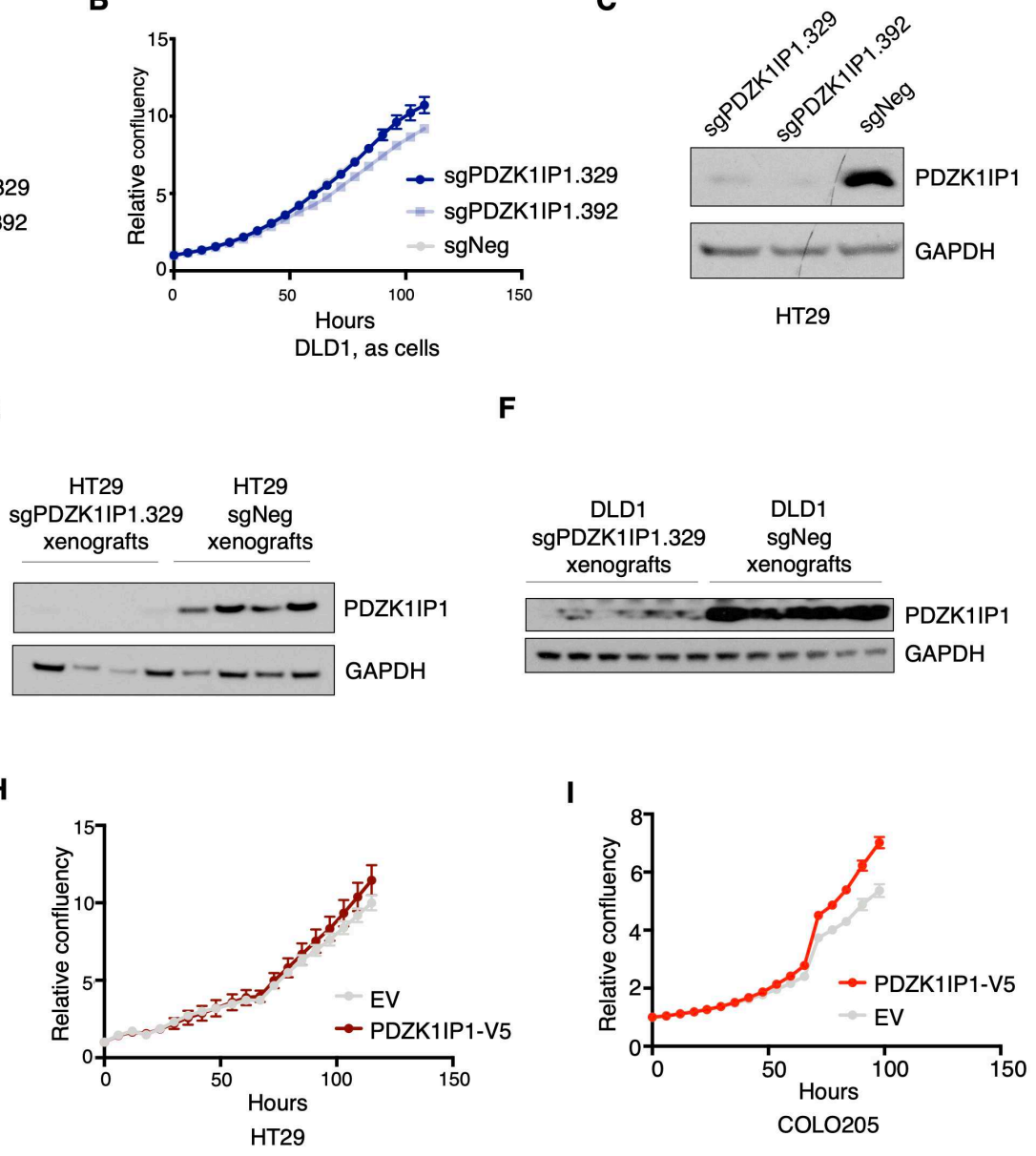

980

K

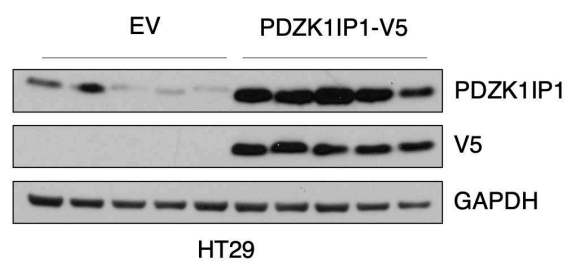

Figure S13. PDZK1IP1 does not affect CRC proliferation in culture.

(A-B) Incucyte 2D growth curves of sgNeg or sgPDZK1IP1 cells $(n=6$ biological replicates per group). Data presented as mean \pm s.e.m. Significance was determined using Student's $t$-test.

(C-D) PDZK1IP1 protein levels by immunoblot in HT29 and DLD1 cells between sgPDZK1IP1 and sgNeg. Data presented as mean \pm s.e.m. 
(E-F) PDZK1IP1 protein levels by immunoblot in HT29 and DLD1 subcutaneous xenograft tumors in nude mice between sgPDZK1IP1 and $\mathrm{sgNeg}$.

(G) Re-introducing exogenous PDZK1IP1 expression in vitro.

(H-J) Incucyte 2D growth curves of EV or PDZK1IP1-V5 expressing cells in HT29, COLO205, 990 or DLD1 ( $n=4-6$ biological replicates per group). Data presented as mean \pm s.e.m.

(K) PDZK1IP1 protein levels by immunoblot in HT29 subcutaneous xenograft tumors in nude mice between EV and PDZK1IP1-V5 expressing cells. 
A

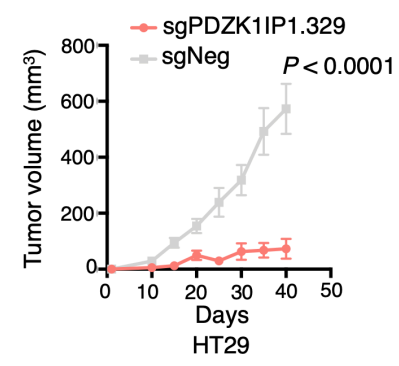

D

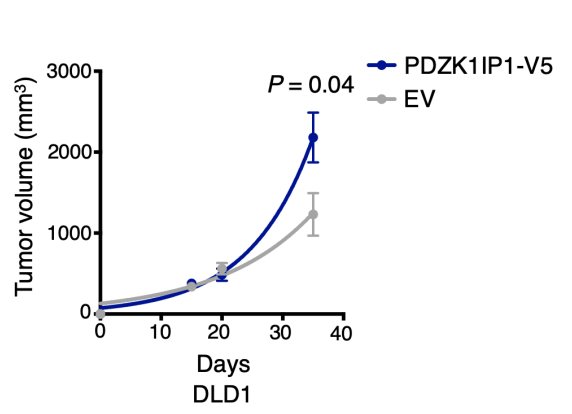

B

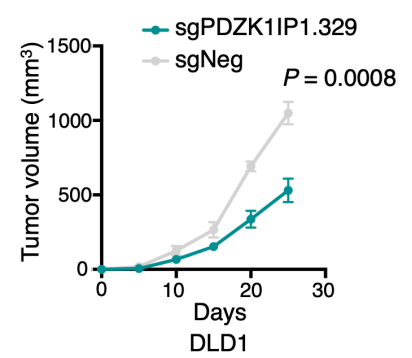

E
C
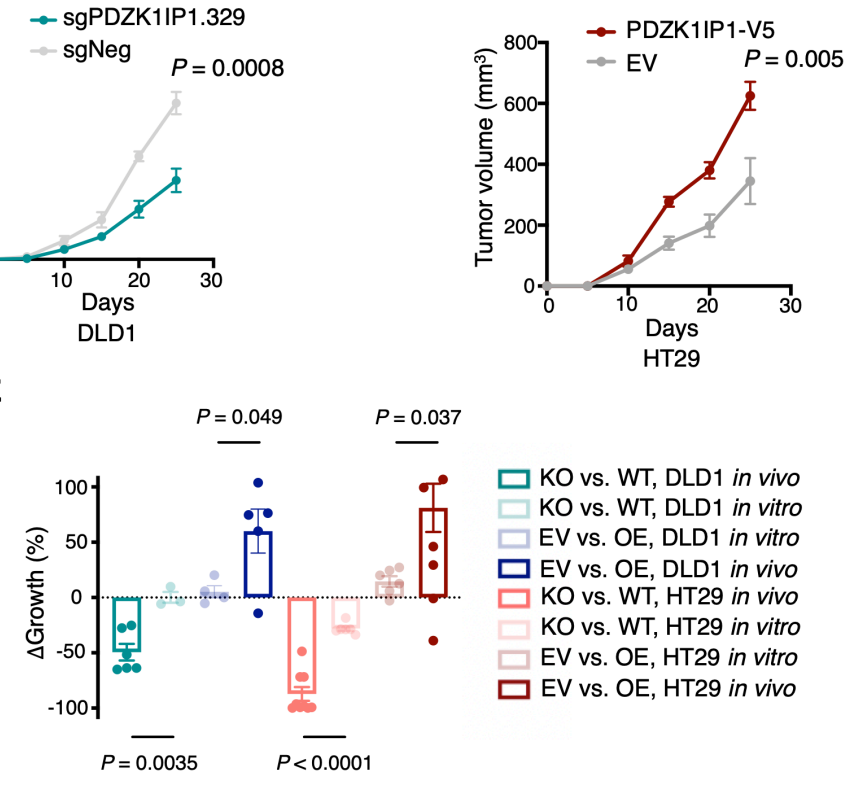

Figure 6. PDZK1IP1 is a novel context-dependent regulator of $\mathrm{CRC}$ tumor growth.

(A-B) Growth curves, sgPDZK1IP1.329 and sgNeg subcutaneous xenograft tumors in nude mice. HT29 $n=9$ mice per group, DLD1 $n=6$ mice per group. 1 million cells injected per mouse for both HT29 and DLD1. Data presented as mean \pm s.e.m. Significance was determined using Student's $t$-test.

(C-D) Growth curves, PDZK1IP1-V5 and EV xenograft tumors. HT29 $n=10$ mice per group, DLD1 $n=5$ mice for PDZK1IP1-V5, $n=8$ mice for EV. 3-5 million cells injected for both HT29 and DLD1. Data presented as mean \pm s.e.m. Significance was determined using Student's $t$-test. (E) Meta-comparison of 2D Incucyte growth curves in vitro with xenograft tumor growth in vivo. KO - sgPDZK1IP1.329, WT - sgNeg, EV - empty vector, OE - PDZK1IP1-V5. $\Delta$ Growth presented as (KO-WT) as percentage of WT, or (OE-EV) as a percentage of EV. Data presented as mean \pm s.e.m. Significance was determined using Student's $t$-test. 
A

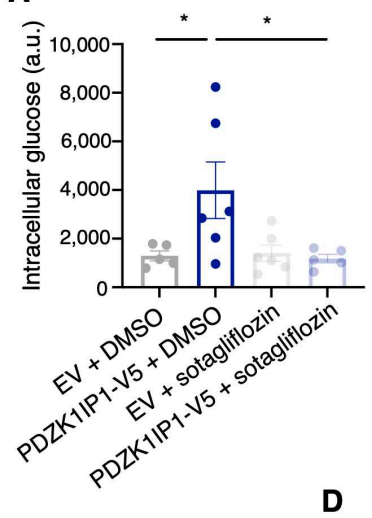

D

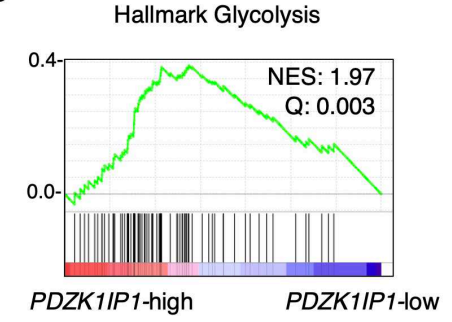

C

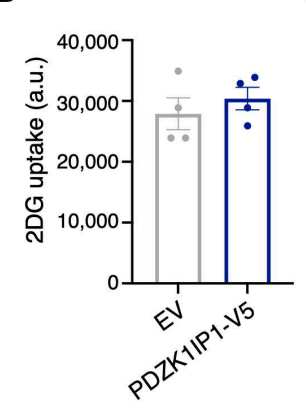

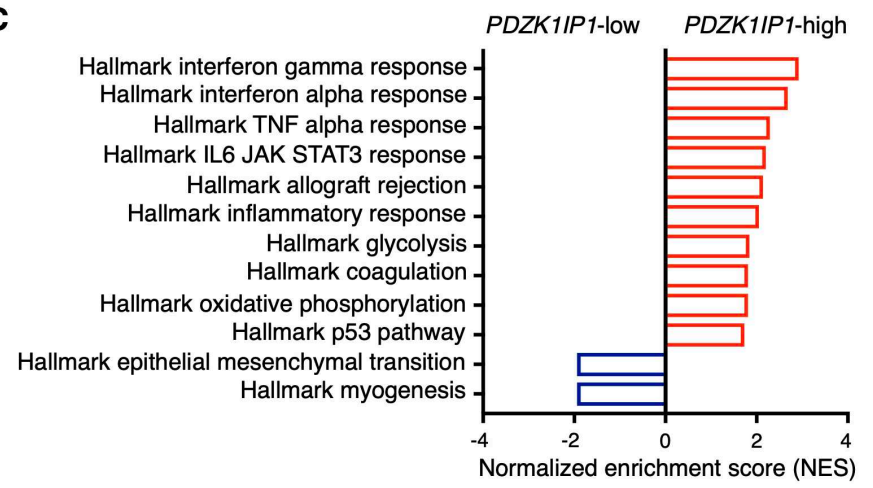

Hallmark Oxidative Phosphorylation

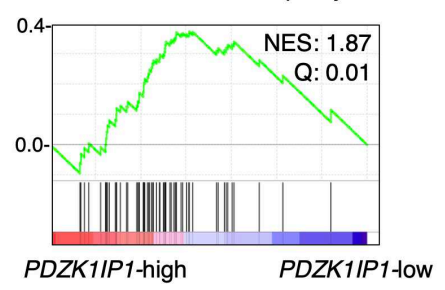

Figure S14. PDZK1IP1 increases glucose uptake and is linked to cancer metabolism.

(A) Cellular glucose levels by fluorometric assay in DLD1 cell lysates in the presence or absence of $25 \mu \mathrm{M}$ sotagliflozin. Data presented as mean \pm s.e.m. Significance was determined using Student's $t$-test.

(B) 2DG uptake by luminescent assay in DLD1 cell lysates. Data presented as mean \pm s.e.m. TCGA ( $n=342$ independent tumors). 
A

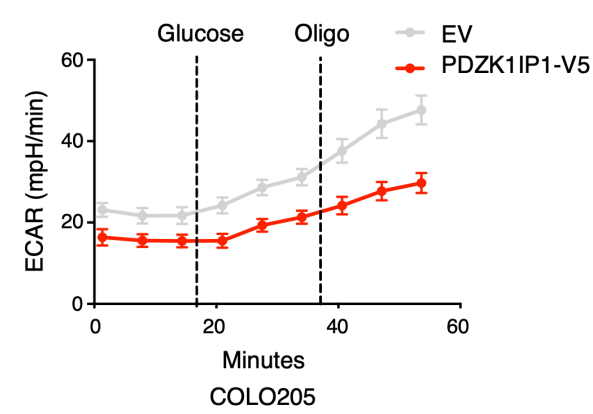

C
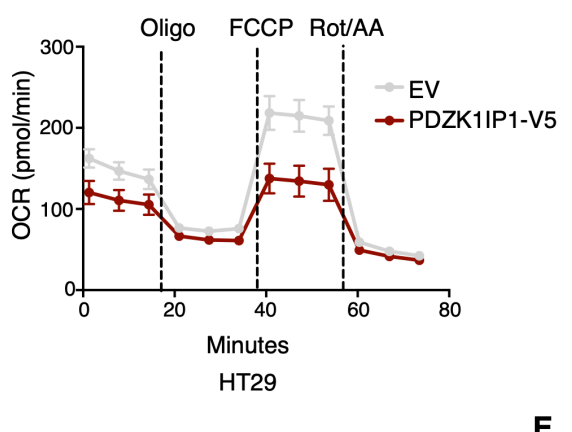

G

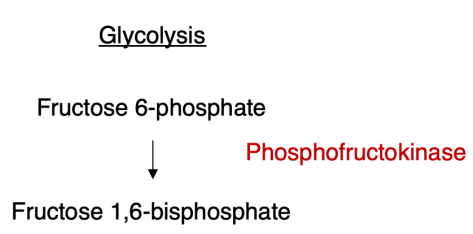

1040

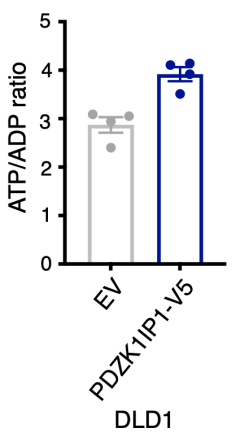

B

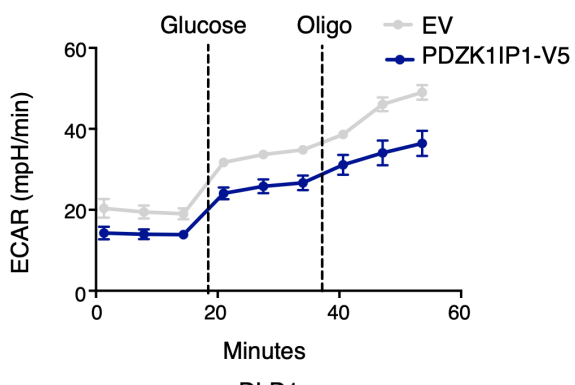

D

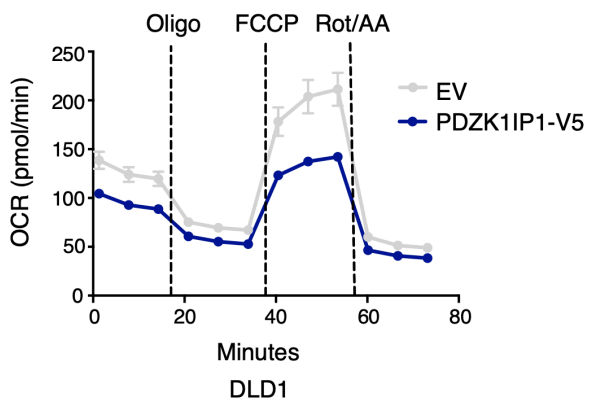

F

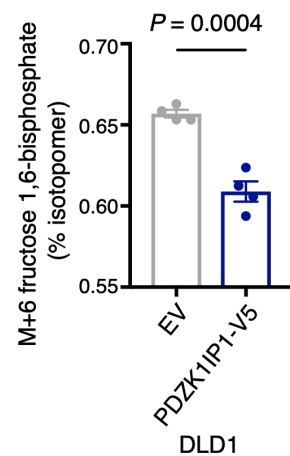

Figure S15. PDZK1IP1 decreases glycolytic and mitochondrial respiration rate.

(A-B) Seahorse glycolytic stress test. ECAR - extracellular acidification rate, a readout of glycolysis rate ( $n=6$ biological replicates per group). Data presented as mean \pm s.e.m.

1045 (C-D) Seahorse mitochondrial stress test. OCR - oxygen consumption rate, a readout of oxidative respiration rate ( $n=6$ biological replicates per group). Oligo - oligomycin, an ATP synthase 
inhibitor which decreases OCR and increase ECAR. FCCP - trifluoromethoxy carbonylcyanide phenylhydrazone, an inner mitochondrial membrane gradient decoupler that increases OCR. Rot/AA - Rotenone and antimycin A, complex I and complex III inhibitors, respectively, which decrease OCR. Data presented as mean \pm s.e.m.

(E-F) Relative peak area of uniformly labeled fructose 1,6-bisphopshate, reported as \% of M+6 isotopomer of total labeled and unlabeled metabolite, from $\mathrm{U}^{-\mathrm{C}^{13}}$ glucose tracing $(n=4$ biological replicates per group) as a readout of phosphofructokinase enzyme live-cell activity. Data presented as mean \pm s.e.m. Significance was determined using Student's $t$-test.

(G-H) ATP/ADP ratio from total polar metabolite peak area in HT29 and DLD1 cells $(n=4$ biological replicates per group). Data presented as mean \pm s.e.m. Significance was determined using Student's $t$-test. 


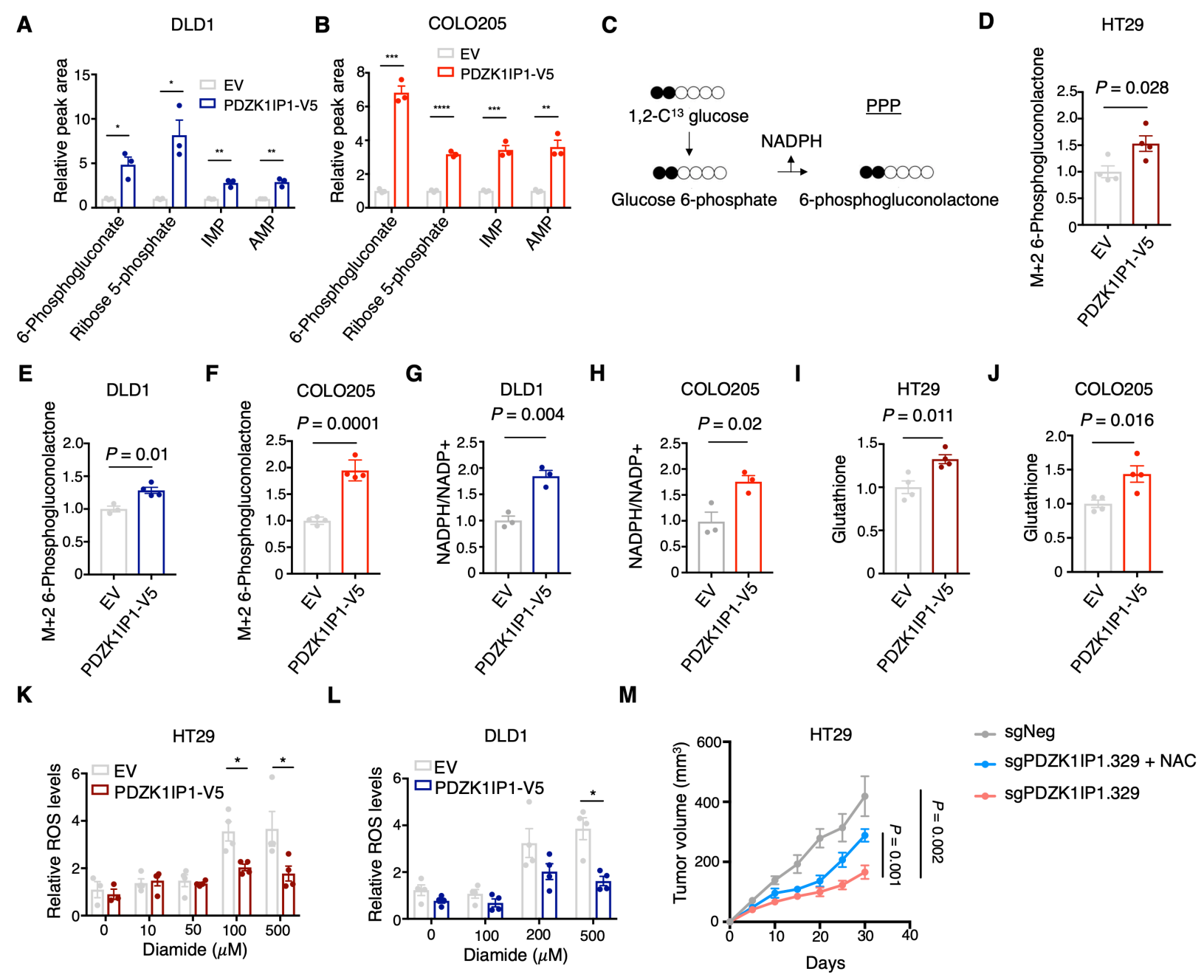

Figure 7. PDZK1IP1 regulates cancer metabolism.

(A-B) Steady state levels (total peak are) of PPP intermediates and downstream metabolites $(n=$ 3 per group). Data presented as mean \pm s.e.m. Significance was determined using Student's $t$-test.

$* P<0.05, * * P<0.01, * * * P<0.001, * * * * P<0.0001$.

(C) Schematic of PPP entry from glycolysis.

(D-F) Total peak area of labeled 6-phosphogluconolactone ( $n=4$ per group), 1,2C $\mathrm{C}^{13}$-glucose tracing. Data presented as mean \pm s.e.m. Significance was determined using Student's $t$-test.

1080 (G-H) Steady state NADPH/NADP+ ratios from total metabolite peak area ( $n=3$ per group). Data presented as mean \pm s.e.m. Significance was determined using Student's $t$-test. 
(I-J) Steady state levels of total glutathione peak area ( $n=4$ per group). Data presented as mean \pm s.e.m. Significance was determined using Student's $t$-test.

(K-L) Cellular ROS levels by luminescent assay following diamide treatment for 1 hour at the 1085 indicated concentrations ( $n=4$ per group). Data presented as mean \pm s.e.m. Significance was determined using Student's $t$-test.

(M) Growth curves of sgNeg and sgPDZK1IP1.329 xenograft tumors with or without $30 \mathrm{mM} \mathrm{N}$ acetylcysteine in drinking water ( $n=9$ mice per group, 4 million cells injected). Data presented as mean \pm s.e.m. Significance was determined using Student's $t$-test. 

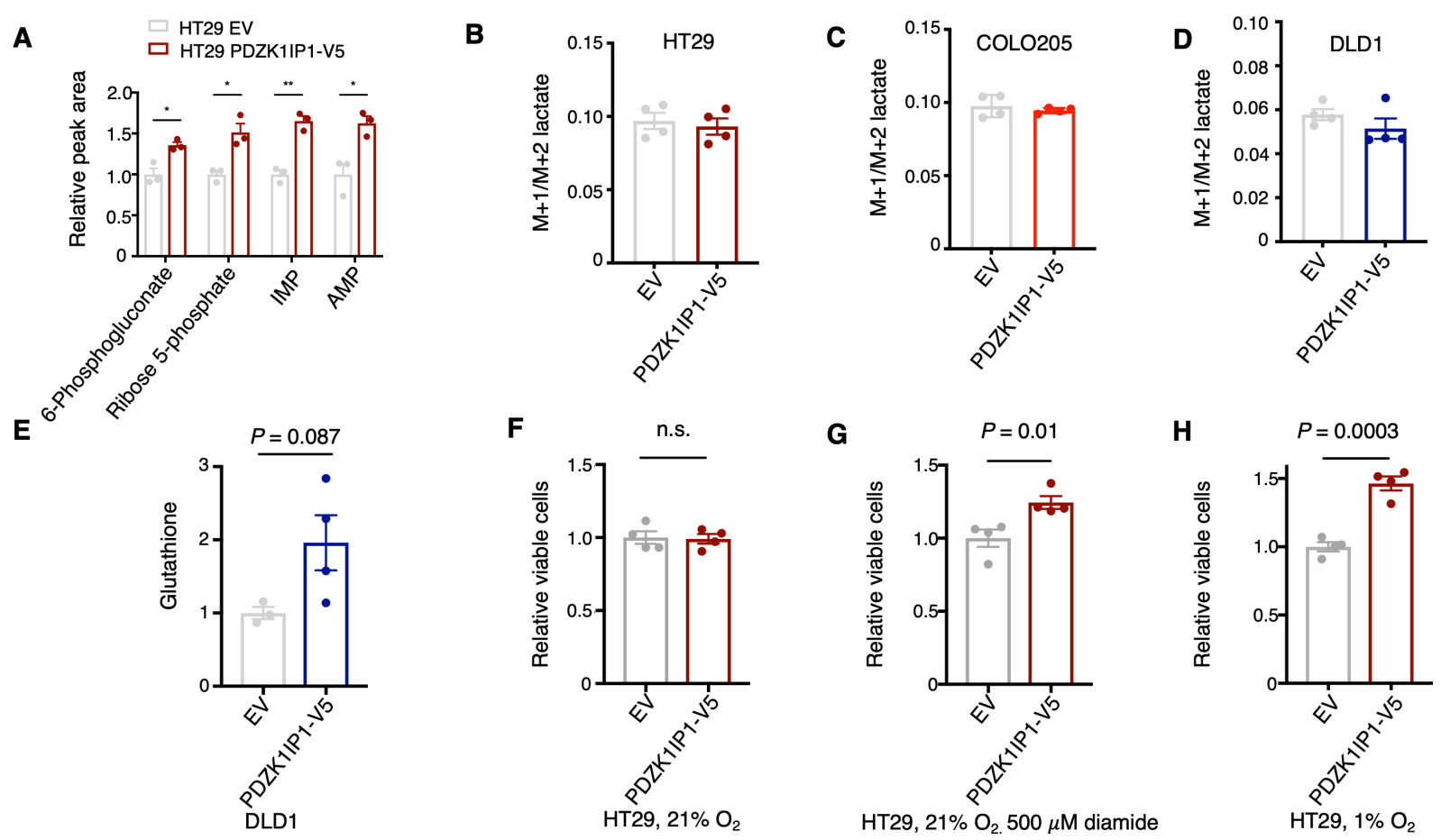

Figure S16. PDZK1IP1 maintains redox homeostasis.

(A) Steady state levels (total peak are) of PPP intermediates and downstream metabolites $(n=3$ per group). Data presented as mean \pm s.e.m. Significance was determined using Student's $t$-test. $* P<0.05, * * P<0.01$.

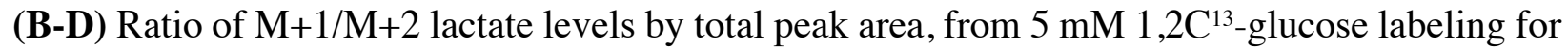
4 hours. Data presented as mean \pm s.e.m.

(E) Steady state levels of total glutathione peak area ( $n=4$ per group). Data presented as mean \pm s.e.m. Significance was determined using Student's $t$-test.

(F-H) Cell viability by colorimetric MTT assay under normoxia, hypoxia for 48 hours, or with 30 minutes of diamide treatment. Data presented as mean \pm s.e.m. Significance was determined using Student's $t$-test. 


\section{Materials and Methods}

\section{Patient samples and power analysis}

All human subjects work was approved by the Mount Sinai Hospital Institutional Review Board (IRB) under Protocol IRB-19-01860. Patient surgical specimens were resected by the Department of Colon and Rectal Surgery at Mount Sinai Hospital followed by pathologist separation into matched tumor and adjacent normal pairs. All samples were de-identified by The Mount Sinai Biorepository. For power analysis, total unique SEs for 15 primary CRCs and 15 adjacent normal mucosae were tallied. The percentage of total unique discovered SEs contributed by the acquisition of each patient sample, cumulative in the order in which the patient samples were received, was plotted.

\section{Cell lines}

HT29, COLO205, DLD1, and HEK293T cells were purchased from the American Type Culture Collection (ATCC) and grown according to their specifications, supplemented with $10 \%$ fetal bovine serum (Thermo Fisher), $1 \%$ penicillin/streptomycin (Corning), and $5 \mu \mathrm{g} / \mathrm{mL}$ plasmocin prophylactic against mycoplasma (Invivogen). Furthermore, cells were tested for mycoplasma contamination at regular intervals to ensure mycoplasma-negative status (Lonza). All cell lines were maintained at 37 degrees Celsius and $5 \% \mathrm{CO}_{2}$. Recombinant human TNF $\alpha$, IFN- $\beta$, IFN- $\gamma$, and IL-6 were purchased from Peprotech. For cytokine stimulation experiments, cells were 1135 stimulated overnight for 16 hours.

\section{Animal experiments}

6-8 week old male nude mice $\left(F o x n 1^{n u}\right)$ were purchased from The Jackson Laboratory. Male mice were used to better recapitulate CRC demographics. For HT29 xenograft experiments, 1 million cells suspended in 100uL serum-free RPMI media were injected per nude mouse. During the HT29 
experiments, 2 million cells suspended in 100uL serum-free RPMI media were injected per nude mouse. For animal studies involving $\mathrm{N}$-acetylcysteine (Sigma), drinking water supplemented with $30 \mathrm{mM}$ NAC was used as the only drinking source. NAC solution was $\mathrm{pH}$ adjusted to 7.0 and refreshed weekly. Tumors were measured using calipers every 5 days, with volume calculated using the following formula: volume $=0.523($ length $)\left(\right.$ width $\left.^{2}\right)$. All animal experiments were approved by the Mount Sinai Institutional Animal Care and Use Committee (IACUC) (protocol \#IACUC-2019-0048 \& LA13-00024). For mouse studies, no statistical method was used to predetermine sample size, mice were randomly distributed among the treatment groups and no blinding was performed during data collection.

\section{Intracellular ROS and cell death}

5,000 to 10,000 cells were plated in a 96-well plate overnight. Media containing $100 \mathrm{ng} / \mathrm{mL}$ doxycycline was refreshed the next day to induce expression of PDZK1IP1-V5 or empty vector (EV) for 48 hours. Cells were treated with media containing diamide (Sigma) at the indicated concentrations for one hour. Intracellular ROS levels were determined using the ROS-Glo $\mathrm{H}_{2} \mathrm{O}_{2}$ assay (Promega) assay according to manufacturer's instructions before being read on a spectrophotometer. Viable cells after diamide treatment were assessed using the CellTiter 96 NonRadioactive Cell Proliferation MTT Assay (Promega) according to manufacturer's instructions.

\section{Hypoxia chamber}

For experiments involving hypoxia, 5,000 to 10,000 cells were plated in a 96-well plate. Media containing $100 \mathrm{ng} / \mathrm{mL}$ doxycycline was refreshed the next day and the plate was moved into a HypOxystation H35 hypoxia chamber. The hypoxia chamber was maintained at 37 degrees, humified, $5 \% \mathrm{CO}_{2}, 1 \% \mathrm{O}_{2}$, and $94 \% \mathrm{~N}_{2}$. Cells were kept in the hypoxia chamber for 96 hours. Media containing $100 \mathrm{ng} / \mathrm{mL}$ doxycycline was maintained and refreshed every 48 hours for EV or PDZK1IP1-V5 cells. Cellular assays were performed at this time point. 


\section{Quantitative real-time PCR}

RNA was isolated using the RNeasy Mini Kit (Qiagen). cDNA synthesis was performed using the iScript cDNA Synthesis Kit (Bio-Rad) according to manufacturer's instructions and analyzed by qPCR using SYBR green master mix (Life Technologies) on an ABI Prism 7500 instrument. 10 ng of cDNA was used per reaction. Relative expression was calculated using the $2^{-\Delta \Delta C t}$ method as previously described(Livak and Schmittgen, 2001). For a list of primers used in this study, see Supplementary Figure 2.

\section{Immunoblot}

Cell and tissue lysates were collected in RIPA buffer supplemented with with PhosSTOP and cOmplete protease inhibitors (Roche). Tissue samples were homogenized using a handheld TissueRuptor (QIAGEN). Samples were sonicated with a probe sonicator for 12 pulses before spinning down cellular debris at 14,000 RPM in a 4-degree centrifuge. Total protein concentrations were determined and normalized using a BCA assay (Thermo Fisher). Lysates were mixed 1:1 with 2x sample buffer $(125 \mathrm{mM}$ Tris- $\mathrm{HCl}$ at $\mathrm{pH} 6.8,10 \% \beta$-mercaptoethanol, $2 \%$ SDS, $20 \%$ glycerol, $0.05 \%$ Bromophenol Blue, $8 \mathrm{M}$ urea) and boiled for 5 minutes. Protein lysates were resolved by electrophoresis using 4-12\% Bis-Tris gels (Thermo Fisher). Samples were blotted on PVDF membrane (Millipore) by wet transfer. Membranes were blocked in 5\% milk or 5\% BSA in TBST for 1 hour prior to overnight staining with primary antibody at 4 degrees Celsius with agitation. Membranes were rinsed three times with TBST followed by incubation with horseradish peroxidase-conjugated secondary antibodies in 5\% milk for 1 hour, and then rinsed again in TBST three times. Membranes were visualized using chemiluminescence (Thermo Fisher) and autoradiography film (Denville). The following primary antibodies were used for immunoblot: anti-PDZK1IP1 (Sigma \#HPA014907), anti-GAPDH (Cell Signaling Technologies, CST \#2118), 
anti-V5 (CST \#13202), anti-phosphorylated STAT3 at Y705 (CST \#9145). Band exposure was quantified using ImageJ.

\section{CRISPR-cas9 gene silencing}

LentiCRISPRv2-puro (Plasmid \#52961) and lentiCRISPRv2-blast (Plasmid \#98293) were purchased from Addgene. Sense and antisense sgRNA oligos were synthesized using Fisher Scientific Eurofins, annealed, phosphorylated, and ligated into BsmBI (NEB) digested plasmids according to depositor's instructions as previously described(Sanjana et al., 2014). The Quick Ligation Kit (NEB) was used to ligate DNA into the digested vectors. DNA was transformed into Stbl3 competent cells (Thermo Fisher) and ampicillin-resistant colonies were picked and screened for successful sgRNA integration by Sanger Sequencing (Genewiz) using the hU6-F primer (5'GAGGGCCTATTTCCCATGATT-3'). For a list of sgRNAs used in this study, please see Supplementary Figure 3.

\section{Ectopic overexpression of V5-tagged PDZK1IP1}

The consensus coding sequence of PDZK1IPI was acquired from NCBI and PCR amplified from HT29 cell cDNA, derived as above. Inserts were cloned into the doxycycline-inducible pTRI-blas vector, a gift from Dr. Poulikos Poulikakos and Dr. Stuart Aaronson using the EcoR1 and BamH1 restriction enzyme sites (both from NEB). The PDZK1IP1 carboxy-terminus comprises a PDZ binding domain. To minimize disruption of this domain which may require a free carboxyterminus, the V5 peptide tag (GKPIPNPLLGLDST) was inserted in-frame immediately upstream of the PDZ binding domain. For a list of primers used in this study, see Supplementary Figure 2. The Quick Ligation Kit (NEB) was used to ligate DNA into the digested vectors. DNA was transformed into Stbl3 competent cells (Thermo Fisher) and ampicillin-resistant colonies were picked and screened for successful sgRNA integration by Sanger Sequencing (Genewiz) using the pTRIPZ_seq_F primer (5'-GGCCATGGTGGCCCTCCTATAGTGA-3'). For doxycycline- 
induction of PDZK1IP1-V5 expression, cells were incubated with $100 \mathrm{ng} / \mathrm{mL}$ doxycycline for 48 hours prior to assay.

\section{Lentivirus production and cell transduction}

1215 Packaging plasmids psPAX2 (Plasmid \# 12260) and pMD2.G (Plasmid \# 12259) were purchased from Addgene. Lentiviral plasmids and packaging plasmids were assembled in Opti-MEM media (Corning) and transfected into HEK293T cells using the TransIT-Lenti Transfection Reagent (Mirus) according to the manufacturer's instructions. The mass ratio of psPAX2 to pMD2.G used for packaging was 3:1. Media was collected 48 hours after transfection and passed through a 0.45 $\mu \mathrm{m}$ filter and concentrated using Amicon Ultra-15 centrifugal filter (30 kDa, Millipore). Cells were transduced for 16 hours followed by 48-72 hours of puromycin selection or 6 days of blasticidin selection, depending on the vector. For puromycin, $2 \mu \mathrm{g} / \mathrm{mL}$ was used for HT29 cells and $3 \mu \mathrm{g} / \mathrm{mL}$ was used for DLD1 cells. For blasticidin, $5 \mu \mathrm{g} / \mathrm{mL}$ was used for HT29, COLO205, and DLD1 cells, refreshed every 72 hours. We aimed for low MOI infections by empirically determining lentivirus dilution factors to achieve $<50 \%$ cell survival during antibiotic selection.

\section{Chromatin immunoprecipitation followed by deep sequencing (ChIP-seq)}

Xenograft tumors and patient surgical specimens were digested with 1X collagenase/hyaluronidase (Stem Cell Technologies), minced, and passed through a $100 \mu \mathrm{m}$ filter. Cells were double crosslinked with $0.25 \mathrm{M}$ disuccinimidyl glutarate followed by $1 \%$ formaldehyde. ChIP-seq was performed as previously described(Fontanals-Cirera et al., 2017). Briefly, 2X crosslinked chromatin was sonicated on a Diagenode Bioruptor for 15 cycles 30s ON/30s OFF on the low power setting. Cells were precleared using $100 \mu \mathrm{L}$ of Magna-ChIP Protein A+G magnetic bead slurry (Millipore) before overnight incubation with $10 \mu \mathrm{g}$ ChIP antibody conjugated to $100 \mu \mathrm{L}$ beads. Beads were washed once with IP Wash Buffer I, twice with High Salt 
Wash Buffer, once with IP Wash Buffer II, and twice with TE buffer. For buffer recipes refer to Fontanals-Cirera, Hasson et al(Fontanals-Cirera et al., 2017). Beads were eluted with $1 \%$ SDS at 65 degrees Celsius with agitation and reverse crosslinked overnight with high salt with RNase treatment (Roche). The next day, DNA underwent Proteinase K treatment at 42 degrees Celsius before elution using QIAquick PCR purification kit (QIAGEN). DNA was run on an Agilent High Sensitivity DNA chip using an Agilent Technologies 2100 Bioanalyzer for quality control. H3K27ac ChIP-seq antibodies were purchased from abcam (\#ab177178).

\section{Incucyte in vitro cell proliferation assay}

10,000 cells were plated in a 48-well plate (Corning Falcon). Cells were monitored for 5-6 days using an Incucyte live cell imaging system (Essen Bioscience), which is placed in a cell culture incubator operated at 37 degrees Celsius and $5 \% \mathrm{CO}_{2}$. For relevant experiments, $100 \mathrm{ng} / \mathrm{mL}$ doxycycline containing media was refreshed every 48 hours.

\section{DNA library construction and sequencing}

DNA library construction was performed as previously described(Fontanals-Cirera et al., 2017). ChIP DNA was prepared as above. Briefly DNA underwent end repair, poly-adenylation, and barcoding using enzymes from New England Biolabs. ChIP libraries were amplified 12-15 PCR cycles using the $2 \mathrm{X}$ KAPA HiFi DNA HotStart ReadyMix before quality assessment by running on a High Sensitivity chip using a Bioanalyzer 2100 (Agilent) followed by a Qubit fluorometer (Thermo Fisher). The Mount Sinai Oncological Sciences Sequencing Core Facility prepared polyA-capture RNA-seq libraries using the TruSeq RNA Library Prep Kit v2 (Illumina) according to manufacturer's instructions. All libraries were sequenced as $75 \mathrm{bp}$ single end reads by the Mount Sinai Oncological Sciences Sequencing Core Facility on an Illumina NextSeq instrument.

\section{ChIP-seq data analysis and super-enhancer calling}


Adapter sequences were removed from reads using Cutadapt. Reads were mapped to the hg19 human genome using bowtie. Duplicate reads were removed using samtools. Matching input control was used to call peaks. Peak calling was performed using MACS2. For H3K27ac, a $P$ value cutoff of $10^{-10}$ was used for peak calling. Bigwig tracks were generated using deepTools bamCoverage with RPKM normalization. H3K27ac ChIP-seq tracks were promoter normalized prior to direct comparison within and between patients. Blacklisted regions (Duke_Hg19SignalRepeatArtifactRegions.bed, downloaded from the Broad Institute) were excluded from called peaks using bedtools. Super-enhancer and enhancer calling were performed using Rank Ordering of Super-Enhancers (ROSE) on H3K27ac enrichment(Loven et al., 2013) using default parameters. Principal component analysis was performed using deepTools multiBigwigSummary and plotPCA functions. Summary plots were generated using deepTools computeMatrix and plotProfile. Pearson correlation heatmap and unsupervised hierarchical clustering analysis was performed using deepTools plotCorrelation. Student's t-test was used to call significant differentially expressed super-enhancers among the 2026 total identified between 15 primary CRCs and 15 patient-matched adjacent normal colon mucosa, using normalized H3K27ac RPKM as input. These significantly differential super-enhancers were visualized as a heatmap in Figure 1 using the R package pheatmap on $\mathrm{R}$ version 4.0.3 and RStudio version 1.1.463. Please see Supplementary Table 8 for quality control metrics for ChIP-seq datasets generated in this study.

\section{RNA-seq data analysis}

Sequenced reads were mapped to the hg38 transcriptome using Salmon quasi-mapping under the default parameters and expression output in TPM was extracted(Patro et al., 2017). Output files (expression in TPM) were directly integrated into the R package DESeq2 for differential gene expression analysis, again under default parameters(Love et al., 2014). Genes with expression $>2$ 
TPM were used for downstream analyses. Pathway analyses were performed using pre-ranked Gene Set Enrichment Analysis (GSEA), using the pre-ranked (by $\log _{2}$ fold change gene expression) function, as well as Enrichr (which includes many tools including ChEA)(Kuleshov et al., 2016; Subramanian et al., 2005). $\log _{2}$ fold change cut-offs for differentially expressed genes used in downstream analyses are stated in the text. For epithelial, immune, and stromal cell population de-convolution from bulk CRC tumor RNA-seq data, xCell was used with Salmon output and gene expression in TPM(Aran et al., 2017). Out of the 15 CRC tumors, 11 had samplematched RNA-seq data, for which xCell was performed to assess non-epithelial cell contribution to $\mathrm{H} 3 \mathrm{~K} 27$ ac signal from the bulk tumor ChIP-seq. The ratio of epithelial cell, immune cell, and stroma scores for each independent CRC is reported.

\section{Prediction of super-enhancer target genes}

Sample-matched RNA-seq and H3K27ac ChIP-seq across multiple patient cohorts were utilized to predict SE target genes. For a list of patient samples with sample matched RNA-seq and H3K27ac ChIP-seq used in this analysis, please see Supplementary Fig. 5. For each of the 2026 SEs identified in this study, a linear regression analysis was performed, comparing natural variation of H3K27ac signal at the SE with sample-matched mRNA expression from RNA-seq for each protein coding gene with a transcriptional start site within $500 \mathrm{~kb}$ of the center of the SE. The gene with the most significant expression correlation $(P<0.05)$ is assigned as the most confident target gene. Several SEs have multiple target genes with significant correlation.

\section{ATAC-seq data and motif analysis}

Previously generated ATAC-seq bigwig files mapped to human genome hg38 from primary colorectal carcinomas were downloaded, with permission, from TCGA(Corces et al., 2018). LiftOver (UCSC) was used to convert coordinates between hg38 and hg19 human genomes. Tracks were visualized using the IGV browser(Robinson et al., 2011). Accessible chromatin 
regions of interest were subject to motif analysis using Transcription Factor Affinity Prediction (TRAP) web tools(Thomas-Chollier et al., 2011). <500bp regions were analyzed using Jaspar vertebrates as the matrix file, human promoters as the background model, and BenjaminiHochberg as the multiple test correction. For TRAP motif analysis on multiple sequences, only the top 3000 sequences were analyzed per program input requirements.

\section{Single cell RNA-seq analysis}

Single cell 3' mRNA sequencing data from a cohort of 23 CRC patients (SMC cohort) was obtained from GSE132465(Lee et al., 2020). R package Seurat (v.4.0) was used to analyze the data, using built in functions for normalization, dimensionality reduction, and visualization. To display cell clusters in UMAP plots and dotplots we colored and grouped cells by the annotations provided by the study, where malignant and non-malignant epithelial cells were combined into one category called epithelial cells. A customized version of the Seurat dotplot was used to display PDZK1IP1 expression across cell types and patients.

\section{Mutation analysis of $P D Z K 1 I P 1$ super-enhancer}

H3K27ac ChIP-seq bam files for 15 patient tumor normal pairs were loaded into the IGV genome browser where the PDZK1IP1 super-enhancer locus (chr1:47644434-47659486, hg19 coordinates) was visualized. Single nucleotide polymorphisms (SNPs), insertions, and deletions against the hg19 reference human genome within the super-enhancer locus were highlighted and assessed for specificity in CRC tumors over patient-matched normal in all 15 patients.

\section{Seahorse assays}

Cellular glycolysis was measured using the XF Glycolysis stress test kit and XP Mitochondrial stress test kit (Agilent) according to the manufacturer's instructions. Briefly, PDZK1IP1-V5 and EV cells were seeded in XFe96 well plates (8000-10,000/well). The next day, media containing $100 \mathrm{ng} / \mathrm{mL}$ doxycycline was added to the cells for 48 hours to induce PDZK1IP1-V5 or EV 
expression. The next day, growth media was aspirated and replaced with Seahorse media (DMEM supplemented with $2 \mathrm{mM}$ glutamine, $\mathrm{pH} 7.4$ ) and cells were incubated in a were incubated at $37^{\circ} \mathrm{C}$ in the absence of $\mathrm{CO}_{2}$ for $1 \mathrm{hr}$. Extracellular acidification rates (ECAR) and oxygen consumption rate (OCR) were measured using the XFe96 Extracellular Flux Analyzer. Baseline ECAR measurements were determined before administration of glucose $(10 \mathrm{mM})$ and oligomycin $(1 \mu \mathrm{M})$. Baseline OCR measurements were determined before administration of any drug. At the end of the assay, cells were stained with methylene blue, de-stained, and the absorbance was measured at 668nm using a plate reader (Synergy H1 Hybrid multi-mode micro-plate reader, Biotek). ECAR and OCR measurements were normalized against the cell densities and all data analysis was conducted with the Seahorse Wave software version 2.6.1.53 (Agilent).

\section{Medical illustrations}

Figure 1a contains medical illustrations from SMART Servier Medical Art, reproduced with permission.

\section{Cytokine profiling}

Cell line and tumor lysates were collected in RIPA buffer as described above, without the addition

of $2 \mathrm{X}$ sample buffer. Supernatant lysates were diluted 1:1 with PBS supplemented with protease inhibitors. Cytokine profiling performed by Eve Technologies using the Human Cytokine Array/Chemokine Array 48-plex platform and Mouse Cytokine Array/Chemokine Array 31-plex panels. Cytokine concentrations were normalized to protein levels determined by BCA assay (Thermo Fisher).

\section{Targeted metabolomics and data analysis}

For steady state polar metabolite profiling, full RPMI media was refreshed on cells for two hours. Polar metabolites were extracted from cancer cells in vitro using $80 \%$ (v/v) aqueous methanol as described before(Yuan et al., 2012). Targeted liquid chromatography-tandem mass spectrometry 
(LC-MS/MS) was performed using a 6500 or 5500 QTRAP triple quadrupole mass spectrometer (AB/SCIEX) coupled to a Prominence UFLC HPLC system (Shimadzu) with Amide HILIC chromatography (Waters). Data were acquired in selected reaction monitoring (SRM) mode using positive/negative ion polarity switching for steady-state polar profiling of greater than 260 molecules. Peak areas from the total ion current for each metabolite SRM transition were integrated using MultiQuant v2.0 software (AB/SCIEX). The original data were normalized to protein concentration determined by BCA assay.

\section{$1,2 \mathrm{C}^{13}$ glucose carbon labeling}

For carbon labeling experiments to assess the pentose phosphate pathway, cells were plated and PDZK1IP1-V5 induced in full RPMI. 24 hours prior to extraction, media was changed to RPMI with $5 \mathrm{mM}$ glucose, $2 \mathrm{mM}$ glutamine, and 10\% dialyzed FBS as previously described(Yi et al., 2012). Media was refreshed using RPMI with 5mM glucose, $2 \mathrm{mM}$ glutamine, and $10 \%$ dialyzed FBS for three hours to normalize metabolism. Media was then changed to RPMI with $5 \mathrm{mM} 1,2 \mathrm{C}^{13}$ glucose (Cambridge Isotope Laboratories), 2mM glutamine, and 10\% dialyzed FBS to allow carbon labeling for 4 hours. Polar metabolites were extracted as above.

\section{Uniform $\mathrm{C}^{13}$ glucose carbon labeling}

For carbon labeling experiments to assess glycolysis, cells were plated and PDZK1IP1-V5 induced in full RPMI. 24 hours prior to extraction, media was changed to RPMI with 5mM glucose, $2 \mathrm{mM}$ glutamine, and 10\% dialyzed FBS as previously described(Yi et al., 2012). Media was refreshed using RPMI with 5mM glucose, $2 \mathrm{mM}$ glutamine, and $10 \%$ dialyzed FBS for three hours to normalize metabolism. Media was then changed to RPMI with $5 \mathrm{mM} \mathrm{U- \textrm {C } ^ { 1 3 }}$ glucose (Cambridge Isotope Laboratories), 2mM glutamine, and 10\% dialyzed FBS to allow carbon labeling for 15 minutes. Polar metabolites were extracted as above.

\section{Immunohistochemistry}


Xenograft tumors were fixed in $10 \%$ formalin (Thermo Fisher). IHC was performed by the Oncological Sciences Core Facility. Paraffin sections were dewaxed as previously described. Antigen retrieval was performed using a Dako pressure cooker in Antigen Unmasking Solution (Vector Laboratories). Briefly, sections were boiled in $0.01 \mathrm{M}$ sodium citrate, $\mathrm{pH}$ 6.0, 0.05\% Tween-20 twice for $10 \mathrm{~min}$ and cooled at room temperature for $20 \mathrm{~min}$. Sections were washed with $\mathrm{ddH}_{2} \mathrm{O} 3$ times for $5 \mathrm{~min}$, followed by a PBS wash for $5 \mathrm{~min}$. HRP conjugated secondary antibody was used to detect signal. Endogenous $\mathrm{HRP}$ was blocked with $3 \% \mathrm{H}_{2} \mathrm{O}_{2}$ in $\mathrm{PBS}$ or methanol for $10 \mathrm{~min}$. The slide was washed in PBS three times for 5 minutes. The following primary antibodies were used for IHC: anti-CD11c (CST \#97585), anti-CD68 (CST \#97778), antiperforin (CST \#31647), and anti-Ly-6G (CST \#87048).

Glucose 6-phosphate dehydrogenase (G6PD) and 6-phosphogluconate (6PGD) activity assays

1390 In vitro enzyme activity assays were performed as previously described(Stanton et al., 1991). Briefly, for glucose 6-phosphate dehydrogenase activity, the following substrates were reconstituted in vitro in PPP activity buffer (50 mM Tris, $1 \mathrm{mM} \mathrm{MgCl}_{2}$ ): $200 \mu \mathrm{M}$ glucose 6phosphate (Sigma) and $100 \mu \mathrm{M}$ NADP+ (Roche). $10 \mu \mathrm{g}$ of protein lysate from PDZK1IP1-V5 or EV expressing cells were added to the reaction mixture. Reduction of NADP+ to NADPH was read by absorption at $340 \mathrm{~nm}$ on a spectrophotometer as a readout of glucose 6-phosphate dehydrogenase activity. For 6-phosphogluconate dehydrogenase activity, the following substrates were re-constituted in vitro in. PPP activity buffer: $200 \mu \mathrm{M}$ 6-phosphogluconate (Sigma) and 100 $\mu \mathrm{M}$ NADP+ (Roche). $10 \mu \mathrm{g}$ of protein lysate from PDZK1IP1-V5 or EV expressing cells were added to the reaction mixture. Reduction of NADP+ to NADPH was read by absorption at $340 \mathrm{~nm}$ on a spectrophotometer as a readout of 6-phosphogluconate dehydrogenase activity.

\section{Statistics and data reproducibility}


Statistical analyses were performed using Microsoft Excel for Mac Version 16 and Prism Graphpad Version 7. Data are expressed as mean with standard error of the mean unless otherwise noted. A Student's $t$-test (two-tailed with equal variance) was used when comparing two groups. When unequal variance was noted (for example, in some cytokine profiling measurements detectable in one group but not the other in fig. S4), a Mann-Whitney test was used instead. A $P$ value of $<0.05$ was considered statistically significant. No statistical method was used to predetermine sample size. We were not blinded to allocation during experiments and outcome assessment. Experiments presented in Fig. 2G,I,K,L,N, 3A,M,N, and in fig. S2G-I,M, 4HH-LL, 6G, 7A,D-F,I-K, 8A-F, 9A-G were independently repeated and similar results were obtained.

\section{Data availability}

H3K27ac ChIP-seq and RNA-seq datasets performed in this study are deposited at the NCBI Gene Expression Omnibus under the accession GSE166254. H3K27ac ChIP-seq datasets previously performed in FAP adenomas and normal colon crypts presented in Fig. 1b-c, fig. S6A were accessed from the Gene Expression Omnibus under the accession GSE77737(Cohen et al., 2017). Broad Institute Cancer Cell Line Encyclopedia (CCLE) RNA-seq datasets for CRC cell lines presented in Fig. 2g, fig. S4C-F were accessed from the Gene Expression Omnibus under the accession PRJNA523380(Ghandi et al., 2019). COLO205 in vitro and orthotopic tumor H3K27ac ChIP-seq datasets presented in fig. S2C-E, 3A-B were accessed under the accession GSE126188(Hung et al., 2019). The following datasets are presented in fig. S2I: RELA ChIP-seq datasets from adipocytes were accessed under the accession GSM1566735(Schmidt et al., 2015); RELA ChIP-seq datasets from A549 cells were accessed under the accession GSM847876(Raskatov et al., 2012); STAT1 ChIP-seq datasets from HeLa cells were accessed under the accession GSM385505(Robertson et al., 2007); STAT1 ChIP-seq datasets from 
datasets from MDA-MB-468 cells were accessed under the accession GSM2278003(McDaniel et al., 2017); CTCF ChIP-seq from normal colon tissue was accessed from ENCODE(Davis et al., 2018). Cancer H3K27ac datasets presented in the heatmap in fig. S1D contains the following: osteosarcoma H3K27ac ChIP-seq datasets accessed under accession GSE74230(Morrow et al., 2018); gastric cancer H3K27ac ChIP-seq datasets accessed under accession GSE76153 \& GSE75898(Ooi et al., 2016); luminal breast cancer H3K27ac ChIP-seq datasets accessed at the ENA under accession PRJEB22757(Patten et al., 2018); prostate cancer H3K27ac ChIP-seq datasets accessed under accession GSE96652(Kron et al., 2017); GBM H3K27ac ChIP-seq datasets accessed under accession GSE119834(Mack et al., 2019); chordoma H3K27ac ChIP-seq datasets accessed under accession GSE109794(Sharifnia et al., 2019); ccRCC H3K27ac ChIP-seq datasets accessed under accession GSE86095(Yao et al., 2017); DLBCL H3K27ac ChIP-seq datasets accessed under accession GSE46663(Chapuy et al., 2013). OncoLnc was used to generate Kaplan Meier curves for PDZK1IP1-high and -low mRNA expression cases based off TCGA data. ATAC-seq data presented in Fig. 3a and RNA-seq data presented in fig. S6C accessed from TCGA. RNA-seq datasets from CRC GEMMs with reversible $A p c$ silencing using an endogenous doxycycline-inducible shRNA in the presence of absence of $K R A S^{G 12 D}$ mutations accessed under accession GSE67186(Dow et al., 2015). Single-cell RNA-seq data from primary CRC and normal colon epithelium was accessed under the accession EGAS00001003779 and EGAS00001003769 from the European Genome-phenome Archive database(Lee et al., 2020). Raw H3K27ac ChIP1445 seq sequencing data from primary CRC and matched human colon organoids, also referred to in the manuscript as the Milan cohort, were accessed under E-MTAB-8416, and raw RNA-seq sequencing data was accessed under E-MTAB-8448(Della Chiara et al., 2021). Raw H3K27ac ChIP-seq sequencing data from commercially available human CRC cell lines were accessed under 
GSE96069, GSE73319, GSE126188, and GSE77737(Cohen et al., 2017; Hung et al., 2019;

$1450 \quad$ McCleland et al., 2016; Nakamura et al., 2017).

1455

1460

1465

1470 


\section{References}

1495

Adam, R.C., Yang, H., Rockowitz, S., Larsen, S.B., Nikolova, M., Oristian, D.S., Polak, L., Kadaja, M., Asare, A., Zheng, D., et al. (2015). Pioneer factors govern super-enhancer dynamics in stem cell plasticity and lineage choice. Nature 521, 366-370.

Akhtar-Zaidi, B., Cowper-Sal-lari, R., Corradin, O., Saiakhova, A., Bartels, C.F., Balasubramanian, D., Myeroff, L., Lutterbaugh, J., Jarrar, A., Kalady, M.F., et al. (2012). Epigenomic enhancer profiling defines a signature of colon cancer. Science 336, 736-739. Al Hasawi, N., Alkandari, M.F., and Luqmani, Y.A. (2014). Phosphofructokinase: a mediator of glycolytic flux in cancer progression. Crit Rev Oncol Hematol 92, 312-321.

Alonso-Curbelo, D., Ho, Y.J., Burdziak, C., Maag, J.L.V., Morris, J.P.t., Chandwani, R., Chen, H.A., Tsanov, K.M., Barriga, F.M., Luan, W., et al. (2021). A gene-environment-induced epigenetic program initiates tumorigenesis. Nature.

Aran, D., Hu, Z., and Butte, A.J. (2017). xCell: digitally portraying the tissue cellular heterogeneity landscape. Genome Biol 18, 220.

Babeu, J.P., and Boudreau, F. (2014). Hepatocyte nuclear factor 4-alpha involvement in liver and intestinal inflammatory networks. World J Gastroenterol 20, 22-30.

Bhatt, D.L., Szarek, M., Steg, P.G., Cannon, C.P., Leiter, L.A., McGuire, D.K., Lewis, J.B., Riddle, M.C., Voors, A.A., Metra, M., et al. (2021). Sotagliflozin in Patients with Diabetes and Recent Worsening Heart Failure. N Engl J Med 384, 117-128.

Blasco, T., Aramayona, J.J., Alcalde, A.I., Catalan, J., Sarasa, M., and Sorribas, V. (2003). Rat kidney MAP17 induces cotransport of Na-mannose and Na-glucose in Xenopus laevis oocytes. Am J Physiol Renal Physiol 285, F799-810.

Bradner, J.E., Hnisz, D., and Young, R.A. (2017). Transcriptional Addiction in Cancer. Cell 168, 629-643.

Brown, J.D., Lin, C.Y., Duan, Q., Griffin, G., Federation, A., Paranal, R.M., Bair, S., Newton, G., Lichtman, A., Kung, A., et al. (2014). NF-kappaB directs dynamic super enhancer formation in inflammation and atherogenesis. Mol Cell 56, 219-231.

Calado, J., Santos, A.R., Aires, I., Lebre, F., Nolasco, F., Rueff, J., and Ramalho, J. (2018). The $\mathrm{Na}(+)$-coupled glucose transporter SGLT2 interacts with its accessory unit MAP17 in vitro and their expressions overlap in the renal proximal tubule. FEBS Lett 592, 3317-3326.

Cancer Genome Atlas, N. (2012). Comprehensive molecular characterization of human colon and rectal cancer. Nature 487, 330-337.

Chapuy, B., McKeown, M.R., Lin, C.Y., Monti, S., Roemer, M.G., Qi, J., Rahl, P.B., Sun, H.H., Yeda, K.T., Doench, J.G., et al. (2013). Discovery and characterization of super-enhancerassociated dependencies in diffuse large B cell lymphoma. Cancer Cell 24, 777-790.

Coady, M.J., El Tarazi, A., Santer, R., Bissonnette, P., Sasseville, L.J., Calado, J., Lussier, Y., Dumayne, C., Bichet, D.G., and Lapointe, J.Y. (2017). MAP17 Is a Necessary Activator of Renal Na+/Glucose Cotransporter SGLT2. J Am Soc Nephrol 28, 85-93.

Cohen, A.J., Saiakhova, A., Corradin, O., Luppino, J.M., Lovrenert, K., Bartels, C.F., Morrow, J.J., Mack, S.C., Dhillon, G., Beard, L., et al. (2017). Hotspots of aberrant enhancer activity punctuate the colorectal cancer epigenome. Nat Commun $8,14400$.

Corces, M.R., Granja, J.M., Shams, S., Louie, B.H., Seoane, J.A., Zhou, W., Silva, T.C., Groeneveld, C., Wong, C.K., Cho, S.W., et al. (2018). The chromatin accessibility landscape of primary human cancers. Science 362.

Corvinus, F.M., Orth, C., Moriggl, R., Tsareva, S.A., Wagner, S., Pfitzner, E.B., Baus, D., Kaufmann, R., Huber, L.A., Zatloukal, K., et al. (2005). Persistent STAT3 activation in colon cancer is associated with enhanced cell proliferation and tumor growth. Neoplasia 7, 545-555. 
Coussens, L.M., and Werb, Z. (2002). Inflammation and cancer. Nature 420, 860-867.

Daley, J.M., Thomay, A.A., Connolly, M.D., Reichner, J.S., and Albina, J.E. (2008). Use of Ly6G-specific monoclonal antibody to deplete neutrophils in mice. J Leukoc Biol 83, 64-70. Davis, C.A., Hitz, B.C., Sloan, C.A., Chan, E.T., Davidson, J.M., Gabdank, I., Hilton, J.A., Jain, K., Baymuradov, U.K., Narayanan, A.K., et al. (2018). The Encyclopedia of DNA elements (ENCODE): data portal update. Nucleic Acids Res 46, D794-D801.

Della Chiara, G., Gervasoni, F., Fakiola, M., Godano, C., D'Oria, C., Azzolin, L., Bonnal, R.J.P., Moreni, G., Drufuca, L., Rossetti, G., et al. (2021). Epigenomic landscape of human colorectal cancer unveils an aberrant core of pan-cancer enhancers orchestrated by YAP/TAZ. Nat Commun 12, 2340.

Dienstmann, R., Vermeulen, L., Guinney, J., Kopetz, S., Tejpar, S., and Tabernero, J. (2017).

Consensus molecular subtypes and the evolution of precision medicine in colorectal cancer. Nat Rev Cancer 17, 79-92.

1555 Dong, F., Li, R., Wang, J., Zhang, Y., Yao, J., Jiang, S.H., Hu, X., Feng, M., and Bao, Z. (2021). Hypoxia-dependent expression of MAP17 coordinates the Warburg effect to tumor growth in hepatocellular carcinoma. J Exp Clin Cancer Res 40, 121.

Dow, L.E., O'Rourke, K.P., Simon, J., Tschaharganeh, D.F., van Es, J.H., Clevers, H., and Lowe, S.W. (2015). Apc Restoration Promotes Cellular Differentiation and Reestablishes Crypt

1560 Homeostasis in Colorectal Cancer. Cell 161, 1539-1552.

Field, M. (2003). Intestinal ion transport and the pathophysiology of diarrhea. J Clin Invest 111, 931-943.

Fontanals-Cirera, B., Hasson, D., Vardabasso, C., Di Micco, R., Agrawal, P., Chowdhury, A., Gantz, M., de Pablos-Aragoneses, A., Morgenstern, A., Wu, P., et al. (2017). Harnessing BET Inhibitor Sensitivity Reveals AMIGO2 as a Melanoma Survival Gene. Mol Cell 68, 731-744 e739.

Garcia-Heredia, J.M., Lucena-Cacace, A., Verdugo-Sivianes, E.M., Perez, M., and Carnero, A. (2017). The Cargo Protein MAP17 (PDZK1IP1) Regulates the Cancer Stem Cell Pool Activating the Notch Pathway by Abducting NUMB. Clin Cancer Res 23, 3871-3883. Ghaleb, A.M., and Yang, V.W. (2017). Kruppel-like factor 4 (KLF4): What we currently know. Gene 611, 27-37.

Ghandi, M., Huang, F.W., Jane-Valbuena, J., Kryukov, G.V., Lo, C.C., McDonald, E.R., 3rd, Barretina, J., Gelfand, E.T., Bielski, C.M., Li, H., et al. (2019). Next-generation characterization of the Cancer Cell Line Encyclopedia. Nature 569, 503-508.

1575 Gong, Y., Lazaris, C., Sakellaropoulos, T., Lozano, A., Kambadur, P., Ntziachristos, P., Aifantis, I., and Tsirigos, A. (2018). Stratification of TAD boundaries reveals preferential insulation of super-enhancers by strong boundaries. Nat Commun 9, 542.

Greten, F.R., and Grivennikov, S.I. (2019). Inflammation and Cancer: Triggers, Mechanisms, and Consequences. Immunity 51, 27-41.

1580 Grivennikov, S.I., and Karin, M. (2010). Dangerous liaisons: STAT3 and NF-kappaB collaboration and crosstalk in cancer. Cytokine Growth Factor Rev 21, 11-19.

Guijarro, M.V., Castro, M.E., Romero, L., Moneo, V., and Carnero, A. (2007a). Large scale genetic screen identifies MAP17 as protein bypassing TNF-induced growth arrest. J Cell Biochem 101, 112-121.

1585 Guijarro, M.V., Leal, J.F., Blanco-Aparicio, C., Alonso, S., Fominaya, J., Lleonart, M., Castellvi, J., Ramon y Cajal, S., and Carnero, A. (2007b). MAP17 enhances the malignant behavior of tumor cells through ROS increase. Carcinogenesis 28, 2096-2104. 
Guijarro, M.V., Leal, J.F., Fominaya, J., Blanco-Aparicio, C., Alonso, S., Lleonart, M., Castellvi, J., Ruiz, L., Ramon, Y.C.S., and Carnero, A. (2007c). MAP17 overexpression is a common characteristic of carcinomas. Carcinogenesis 28, 1646-1652.

Guijarro, M.V., Link, W., Rosado, A., Leal, J.F., and Carnero, A. (2007d). MAP17 inhibits Mycinduced apoptosis through PI3K/AKT pathway activation. Carcinogenesis 28, 2443-2450.

Guinney, J., Dienstmann, R., Wang, X., de Reynies, A., Schlicker, A., Soneson, C., Marisa, L., Roepman, P., Nyamundanda, G., Angelino, P., et al. (2015). The consensus molecular subtypes of colorectal cancer. Nat Med 21, 1350-1356.

Guo, R.J., Suh, E.R., and Lynch, J.P. (2004). The role of Cdx proteins in intestinal development and cancer. Cancer Biol Ther 3, 593-601.

He, T.C., Sparks, A.B., Rago, C., Hermeking, H., Zawel, L., da Costa, L.T., Morin, P.J., Vogelstein, B., and Kinzler, K.W. (1998). Identification of c-MYC as a target of the APC pathway. Science 281, 1509-1512.

Hnisz, D., Abraham, B.J., Lee, T.I., Lau, A., Saint-Andre, V., Sigova, A.A., Hoke, H.A., and Young, R.A. (2013). Super-enhancers in the control of cell identity and disease. Cell 155, 934947.

Hnisz, D., Schuijers, J., Lin, C.Y., Weintraub, A.S., Abraham, B.J., Lee, T.I., Bradner, J.E., and Young, R.A. (2015). Convergence of developmental and oncogenic signaling pathways at transcriptional super-enhancers. Mol Cell 58, 362-370.

Holness, C.L., and Simmons, D.L. (1993). Molecular cloning of CD68, a human macrophage marker related to lysosomal glycoproteins. Blood 81, 1607-1613.

Hopkins, B.D., Pauli, C., Du, X., Wang, D.G., Li, X., Wu, D., Amadiume, S.C., Goncalves, M.D., Hodakoski, C., Lundquist, M.R., et al. (2018). Suppression of insulin feedback enhances the efficacy of PI3K inhibitors. Nature 560, 499-503.

Hung, S., Saiakhova, A., Faber, Z.J., Bartels, C.F., Neu, D., Bayles, I., Ojo, E., Hong, E.S., Pontius, W.D., Morton, A.R., et al. (2019). Mismatch repair-signature mutations activate gene enhancers across human colorectal cancer epigenomes. Elife 8.

1615 Huynh, J., Chand, A., Gough, D., and Ernst, M. (2019). Therapeutically exploiting STAT3 activity in cancer - using tissue repair as a road map. Nat Rev Cancer 19, 82-96.

Ikeno, S., Nakano, N., Sano, K., Minowa, T., Sato, W., Akatsu, R., Sakata, N., Hanagata, N., Fujii, M., Itoh, F., et al. (2019). PDZK1-interacting protein 1 (PDZK1IP1) traps Smad4 protein and suppresses transforming growth factor-beta (TGF-beta) signaling. J Biol Chem 294, 49664980.

Inagaki-Ohara, K., Kondo, T., Ito, M., and Yoshimura, A. (2013). SOCS, inflammation, and cancer. JAKSTAT 2, e24053.

Jang, C., Chen, L., and Rabinowitz, J.D. (2018). Metabolomics and Isotope Tracing. Cell 173, 822-837.

1625 Keenan, A.B., Torre, D., Lachmann, A., Leong, A.K., Wojciechowicz, M.L., Utti, V., Jagodnik, K.M., Kropiwnicki, E., Wang, Z., and Ma'ayan, A. (2019). ChEA3: transcription factor enrichment analysis by orthogonal omics integration. Nucleic Acids Res 47, W212-W224.

Kocher, O., Cheresh, P., Brown, L.F., and Lee, S.W. (1995). Identification of a novel gene, selectively up-regulated in human carcinomas, using the differential display technique. Clin

$1630 \quad$ Cancer Res 1, 1209-1215.

Kocher, O., Cheresh, P., and Lee, S.W. (1996). Identification and partial characterization of a novel membrane-associated protein (MAP17) up-regulated in human carcinomas and modulating cell replication and tumor growth. Am J Pathol 149, 493-500. 
Kocher, O., Comella, N., Tognazzi, K., and Brown, L.F. (1998). Identification and partial characterization of PDZK1: a novel protein containing PDZ interaction domains. Lab Invest 78, 117-125.

Kron, K.J., Murison, A., Zhou, S., Huang, V., Yamaguchi, T.N., Shiah, Y.J., Fraser, M., van der Kwast, T., Boutros, P.C., Bristow, R.G., et al. (2017). TMPRSS2-ERG fusion co-opts master transcription factors and activates NOTCH signaling in primary prostate cancer. Nat Genet 49 , 1336-1345.

Kuleshov, M.V., Jones, M.R., Rouillard, A.D., Fernandez, N.F., Duan, Q., Wang, Z., Koplev, S., Jenkins, S.L., Jagodnik, K.M., Lachmann, A., et al. (2016). Enrichr: a comprehensive gene set enrichment analysis web server 2016 update. Nucleic Acids Res 44, W90-97.

Lachmann, A., Torre, D., Keenan, A.B., Jagodnik, K.M., Lee, H.J., Wang, L., Silverstein, M.C., and Ma'ayan, A. (2018). Massive mining of publicly available RNA-seq data from human and mouse. Nat Commun 9, 1366.

Laurent, C., Valet, F., Planque, N., Silveri, L., Maacha, S., Anezo, O., Hupe, P., Plancher, C., Reyes, C., Albaud, B., et al. (2011). High PTP4A3 phosphatase expression correlates with metastatic risk in uveal melanoma patients. Cancer Res 71, 666-674.

Lee, H.O., Hong, Y., Etlioglu, H.E., Cho, Y.B., Pomella, V., Van den Bosch, B., Vanhecke, J., Verbandt, S., Hong, H., Min, J.W., et al. (2020). Lineage-dependent gene expression programs influence the immune landscape of colorectal cancer. Nat Genet 52, 594-603.

Lim, J.K.M., Delaidelli, A., Minaker, S.W., Zhang, H.F., Colovic, M., Yang, H., Negri, G.L., von Karstedt, S., Lockwood, W.W., Schaffer, P., et al. (2019). Cystine/glutamate antiporter xCT (SLC7A11) facilitates oncogenic RAS transformation by preserving intracellular redox balance. Proc Natl Acad Sci U S A 116, 9433-9442.

Lin, C.Y., Erkek, S., Tong, Y., Yin, L., Federation, A.J., Zapatka, M., Haldipur, P., Kawauchi, D., Risch, T., Warnatz, H.J., et al. (2016). Active medulloblastoma enhancers reveal subgroupspecific cellular origins. Nature 530, 57-62.

1660 Livak, K.J., and Schmittgen, T.D. (2001). Analysis of relative gene expression data using realtime quantitative PCR and the 2(-Delta Delta C(T)) Method. Methods 25, 402-408.

Love, M.I., Huber, W., and Anders, S. (2014). Moderated estimation of fold change and dispersion for RNA-seq data with DESeq2. Genome Biol 15, 550.

Loven, J., Hoke, H.A., Lin, C.Y., Lau, A., Orlando, D.A., Vakoc, C.R., Bradner, J.E., Lee, T.I., and Young, R.A. (2013). Selective inhibition of tumor oncogenes by disruption of superenhancers. Cell 153, 320-334.

Mack, S.C., Pajtler, K.W., Chavez, L., Okonechnikov, K., Bertrand, K.C., Wang, X., Erkek, S., Federation, A., Song, A., Lee, C., et al. (2018). Therapeutic targeting of ependymoma as informed by oncogenic enhancer profiling. Nature 553, 101-105.

1670 Mack, S.C., Singh, I., Wang, X., Hirsch, R., Wu, Q., Villagomez, R., Bernatchez, J.A., Zhu, Z., Gimple, R.C., Kim, L.J.Y., et al. (2019). Chromatin landscapes reveal developmentally encoded transcriptional states that define human glioblastoma. J Exp Med 216, 1071-1090.

Mansour, M.R., Abraham, B.J., Anders, L., Berezovskaya, A., Gutierrez, A., Durbin, A.D., Etchin, J., Lawton, L., Sallan, S.E., Silverman, L.B., et al. (2014). Oncogene regulation. An oncogenic super-enhancer formed through somatic mutation of a noncoding intergenic element. Science 346, 1373-1377.

McCleland, M.L., Mesh, K., Lorenzana, E., Chopra, V.S., Segal, E., Watanabe, C., Haley, B., Mayba, O., Yaylaoglu, M., Gnad, F., et al. (2016). CCAT1 is an enhancer-templated RNA that predicts BET sensitivity in colorectal cancer. J Clin Invest 126, 639-652. 
McDaniel, J.M., Varley, K.E., Gertz, J., Savic, D.S., Roberts, B.S., Bailey, S.K., Shevde, L.A., Ramaker, R.C., Lasseigne, B.N., Kirby, M.K., et al. (2017). Genomic regulation of invasion by STAT3 in triple negative breast cancer. Oncotarget 8, 8226-8238.

Morrow, J.J., Bayles, I., Funnell, A.P.W., Miller, T.E., Saiakhova, A., Lizardo, M.M., Bartels, C.F., Kapteijn, M.Y., Hung, S., Mendoza, A., et al. (2018). Positively selected enhancer elements endow osteosarcoma cells with metastatic competence. Nat Med 24, 176-185.

Morton, A.R., Dogan-Artun, N., Faber, Z.J., MacLeod, G., Bartels, C.F., Piazza, M.S., Allan, K.C., Mack, S.C., Wang, X., Gimple, R.C., et al. (2019). Functional Enhancers Shape Extrachromosomal Oncogene Amplifications. Cell 179, 1330-1341 e1313.

Nakamura, Y., Hattori, N., Iida, N., Yamashita, S., Mori, A., Kimura, K., Yoshino, T., and Ushijima, T. (2017). Targeting of super-enhancers and mutant BRAF can suppress growth of BRAF-mutant colon cancer cells via repression of MAPK signaling pathway. Cancer Lett 402, 100-109.

Oldridge, D.A., Wood, A.C., Weichert-Leahey, N., Crimmins, I., Sussman, R., Winter, C., McDaniel, L.D., Diamond, M., Hart, L.S., Zhu, S., et al. (2015). Genetic predisposition to neuroblastoma mediated by a LMO1 super-enhancer polymorphism. Nature 528, 418-421. Ooi, W.F., Xing, M., Xu, C., Yao, X., Ramlee, M.K., Lim, M.C., Cao, F., Lim, K., Babu, D., Poon, L.F., et al. (2016). Epigenomic profiling of primary gastric adenocarcinoma reveals superenhancer heterogeneity. Nat Commun 7, 12983.

Patra, K.C., and Hay, N. (2014). The pentose phosphate pathway and cancer. Trends Biochem Sci 39, 347-354.

Patro, R., Duggal, G., Love, M.I., Irizarry, R.A., and Kingsford, C. (2017). Salmon provides fast and bias-aware quantification of transcript expression. Nat Methods 14, 417-419.

Patten, D.K., Corleone, G., Gyorffy, B., Perone, Y., Slaven, N., Barozzi, I., Erdos, E., Saiakhova, A., Goddard, K., Vingiani, A., et al. (2018). Enhancer mapping uncovers phenotypic heterogeneity and evolution in patients with luminal breast cancer. Nat Med 24, 1469-1480. Perez, M., Praena-Fernandez, J.M., Felipe-Abrio, B., Lopez-Garcia, M.A., Lucena-Cacace, A., Garcia, A., Lleonart, M., Roncador, G., Marin, J.J., and Carnero, A. (2013). MAP17 and SGLT1 protein expression levels as prognostic markers for cervical tumor patient survival. PLoS One 8 , e56169.

1710 Pomerantz, M.M., Li, F., Takeda, D.Y., Lenci, R., Chonkar, A., Chabot, M., Cejas, P., Vazquez, F., Cook, J., Shivdasani, R.A., et al. (2015). The androgen receptor cistrome is extensively reprogrammed in human prostate tumorigenesis. Nat Genet 47, 1346-1351.

Qiao, Y., Giannopoulou, E.G., Chan, C.H., Park, S.H., Gong, S., Chen, J., Hu, X., Elemento, O., and Ivashkiv, L.B. (2013). Synergistic activation of inflammatory cytokine genes by interferon-

1715 gamma-induced chromatin remodeling and toll-like receptor signaling. Immunity 39, 454-469. Rajamaki, K., Taira, A., Katainen, R., Valimaki, N., Kuosmanen, A., Plaketti, R.M., Seppala, T.T., Ahtiainen, M., Wirta, E.V., Vartiainen, E., et al. (2021). Genetic and epigenetic characteristics of inflammatory bowel disease associated colorectal cancer. Gastroenterology. Raskatov, J.A., Meier, J.L., Puckett, J.W., Yang, F., Ramakrishnan, P., and Dervan, P.B. (2012). Modulation of NF-kappaB-dependent gene transcription using programmable DNA minor groove binders. Proc Natl Acad Sci U S A 109, 1023-1028.

Robertson, G., Hirst, M., Bainbridge, M., Bilenky, M., Zhao, Y., Zeng, T., Euskirchen, G., Bernier, B., Varhol, R., Delaney, A., et al. (2007). Genome-wide profiles of STAT1 DNA association using chromatin immunoprecipitation and massively parallel sequencing. Nat Methods 4, 651-657.

Robinson, J.T., Thorvaldsdottir, H., Winckler, W., Guttman, M., Lander, E.S., Getz, G., and Mesirov, J.P. (2011). Integrative genomics viewer. Nat Biotechnol 29, 24-26. 
Roe, J.S., Hwang, C.I., Somerville, T.D.D., Milazzo, J.P., Lee, E.J., Da Silva, B., Maiorino, L., Tiriac, H., Young, C.M., Miyabayashi, K., et al. (2017). Enhancer Reprogramming Promotes

$1730 \quad$ Pancreatic Cancer Metastasis. Cell 170, 875-888 e820.

Ross-Innes, C.S., Stark, R., Teschendorff, A.E., Holmes, K.A., Ali, H.R., Dunning, M.J., Brown, G.D., Gojis, O., Ellis, I.O., Green, A.R., et al. (2012). Differential oestrogen receptor binding is associated with clinical outcome in breast cancer. Nature 481, 389-393.

Rowland, B.D., Bernards, R., and Peeper, D.S. (2005). The KLF4 tumour suppressor is a transcriptional repressor of p53 that acts as a context-dependent oncogene. Nat Cell Biol 7, 10741082.

Sanjana, N.E., Shalem, O., and Zhang, F. (2014). Improved vectors and genome-wide libraries for CRISPR screening. Nat Methods 11, 783-784.

Sansom, O.J., Meniel, V.S., Muncan, V., Phesse, T.J., Wilkins, J.A., Reed, K.R., Vass, J.K., 1740 Athineos, D., Clevers, H., and Clarke, A.R. (2007). Myc deletion rescues Apc deficiency in the small intestine. Nature 446, 676-679.

Santer, R., and Calado, J. (2010). Familial renal glucosuria and SGLT2: from a mendelian trait to a therapeutic target. Clin J Am Soc Nephrol 5, 133-141.

Sayin, V.I., Ibrahim, M.X., Larsson, E., Nilsson, J.A., Lindahl, P., and Bergo, M.O. (2014). Antioxidants accelerate lung cancer progression in mice. Sci Transl Med 6, $221 \mathrm{ra} 215$. Scafoglio, C., Hirayama, B.A., Kepe, V., Liu, J., Ghezzi, C., Satyamurthy, N., Moatamed, N.A., Huang, J., Koepsell, H., Barrio, J.R., et al. (2015). Functional expression of sodium-glucose transporters in cancer. Proc Natl Acad Sci U S A 112, E4111-4119.

Scafoglio, C.R., Villegas, B., Abdelhady, G., Bailey, S.T., Liu, J., Shirali, A.S., Wallace, W.D., Magyar, C.E., Grogan, T.R., Elashoff, D., et al. (2018). Sodium-glucose transporter 2 is a diagnostic and therapeutic target for early-stage lung adenocarcinoma. Sci Transl Med 10.

Schmidt, S.F., Larsen, B.D., Loft, A., Nielsen, R., Madsen, J.G., and Mandrup, S. (2015). Acute TNF-induced repression of cell identity genes is mediated by NFkappaB-directed redistribution of cofactors from super-enhancers. Genome Res 25, 1281-1294. Schuijers, J., Junker, J.P., Mokry, M., Hatzis, P., Koo, B.K., Sasselli, V., van der Flier, L.G., Cuppen, E., van Oudenaarden, A., and Clevers, H. (2015). Ascl2 acts as an R-spondin/Wntresponsive switch to control stemness in intestinal crypts. Cell Stem Cell 16, 158-170. Segovia, M., Russo, S., Jeldres, M., Mahmoud, Y.D., Perez, V., Duhalde, M., Charnet, P., Rousset, M., Victoria, S., Veigas, F., et al. (2019). Targeting TMEM176B Enhances Antitumor Immunity and Augments the Efficacy of Immune Checkpoint Blockers by Unleashing Inflammasome Activation. Cancer Cell 35, 767-781 e766.

Sengupta, S., and George, R.E. (2017). Super-Enhancer-Driven Transcriptional Dependencies in Cancer. Trends Cancer 3, 269-281.

Sharifnia, T., Wawer, M.J., Chen, T., Huang, Q.Y., Weir, B.A., Sizemore, A., Lawlor, M.A., Goodale, A., Cowley, G.S., Vazquez, F., et al. (2019). Small-molecule targeting of brachyury transcription factor addiction in chordoma. Nat Med 25, 292-300.

Shaw, A.T., Winslow, M.M., Magendantz, M., Ouyang, C., Dowdle, J., Subramanian, A., Lewis, T.A., Maglathin, R.L., Tolliday, N., and Jacks, T. (2011). Selective killing of K-ras mutant cancer cells by small molecule inducers of oxidative stress. Proc Natl Acad Sci U S A 108, 87738778.

Shin, H.Y. (2019). The structural and functional roles of CTCF in the regulation of cell typespecific and human disease-associated super-enhancers. Genes Genomics 41, 257-265. Siegel, R.L., Miller, K.D., Goding Sauer, A., Fedewa, S.A., Butterly, L.F., Anderson, J.C., Cercek, A., Smith, R.A., and Jemal, A. (2020). Colorectal cancer statistics, 2020. CA Cancer J Clin 70, 145-164. 
Silberg, D.G., Swain, G.P., Suh, E.R., and Traber, P.G. (2000). Cdx1 and cdx2 expression during intestinal development. Gastroenterology 119, 961-971.

Stanton, R.C., Seifter, J.L., Boxer, D.C., Zimmerman, E., and Cantley, L.C. (1991). Rapid release of bound glucose-6-phosphate dehydrogenase by growth factors. Correlation with increased enzymatic activity. J Biol Chem 266, 12442-12448.

Subramanian, A., Tamayo, P., Mootha, V.K., Mukherjee, S., Ebert, B.L., Gillette, M.A., Paulovich, A., Pomeroy, S.L., Golub, T.R., Lander, E.S., et al. (2005). Gene set enrichment analysis: a knowledge-based approach for interpreting genome-wide expression profiles. Proc Natl Acad Sci U S A 102, 15545-15550. Takeda, D.Y., Spisak, S., Seo, J.H., Bell, C., O'Connor, E., Korthauer, K., Ribli, D., Csabai, I., Solymosi, N., Szallasi, Z., et al. (2018). A Somatically Acquired Enhancer of the Androgen Receptor Is a Noncoding Driver in Advanced Prostate Cancer. Cell 174, 422-432 e413. Taniguchi, K., and Karin, M. (2018). NF-kappaB, inflammation, immunity and cancer: coming of age. Nat Rev Immunol 18, 309-324. Thomas-Chollier, M., Hufton, A., Heinig, M., O'Keeffe, S., Masri, N.E., Roider, H.G., Manke, T., and Vingron, M. (2011). Transcription factor binding predictions using TRAP for the analysis of ChIP-seq data and regulatory SNPs. Nat Protoc 6, 1860-1869.

Vahedi, G., Takahashi, H., Nakayamada, S., Sun, H.W., Sartorelli, V., Kanno, Y., and O'Shea, J.J. (2012). STATs shape the active enhancer landscape of T cell populations. Cell 151, 981-993. Wang, Q., Li, W., Zhang, Y., Yuan, X., Xu, K., Yu, J., Chen, Z., Beroukhim, R., Wang, H., Lupien, M., et al. (2009). Androgen receptor regulates a distinct transcription program in androgen-independent prostate cancer. Cell 138, 245-256.

Whyte, W.A., Orlando, D.A., Hnisz, D., Abraham, B.J., Lin, C.Y., Kagey, M.H., Rahl, P.B., Lee, T.I., and Young, R.A. (2013). Master transcription factors and mediator establish superenhancers at key cell identity genes. Cell 153, 307-319.

Wyckoff, J., Wang, W., Lin, E.Y., Wang, Y., Pixley, F., Stanley, E.R., Graf, T., Pollard, J.W., Segall, J., and Condeelis, J. (2004). A paracrine loop between tumor cells and macrophages is required for tumor cell migration in mammary tumors. Cancer Res 64, 7022-7029.

Xia, Y., Shen, S., and Verma, I.M. (2014). NF-kappaB, an active player in human cancers. Cancer Immunol Res 2, 823-830.

Yao, X., Tan, J., Lim, K.J., Koh, J., Ooi, W.F., Li, Z., Huang, D., Xing, M., Chan, Y.S., Qu, J.Z., et al. (2017). VHL Deficiency Drives Enhancer Activation of Oncogenes in Clear Cell Renal Cell Carcinoma. Cancer Discov 7, 1284-1305.

Yi, W., Clark, P.M., Mason, D.E., Keenan, M.C., Hill, C., Goddard, W.A., 3rd, Peters, E.C., Driggers, E.M., and Hsieh-Wilson, L.C. (2012). Phosphofructokinase 1 glycosylation regulates cell growth and metabolism. Science 337, 975-980.

Yu, H., Lee, H., Herrmann, A., Buettner, R., and Jove, R. (2014). Revisiting STAT3 signalling in cancer: new and unexpected biological functions. Nat Rev Cancer 14, 736-746.

Yuan, M., Breitkopf, S.B., Yang, X., and Asara, J.M. (2012). A positive/negative ion-switching, targeted mass spectrometry-based metabolomics platform for bodily fluids, cells, and fresh and fixed tissue. Nat Protoc 7, 872-881.

Yun, J., Mullarky, E., Lu, C., Bosch, K.N., Kavalier, A., Rivera, K., Roper, J., Chio, II, Giannopoulou, E.G., Rago, C., et al. (2015). Vitamin C selectively kills KRAS and BRAF mutant colorectal cancer cells by targeting GAPDH. Science 350, 1391-1396.

1820 Zhang, X., Choi, P.S., Francis, J.M., Gao, G.F., Campbell, J.D., Ramachandran, A., Mitsuishi, Y., Ha, G., Shih, J., Vazquez, F., et al. (2018). Somatic Superenhancer Duplications and Hotspot Mutations Lead to Oncogenic Activation of the KLF5 Transcription Factor. Cancer Discov 8, 108-125. 
Zhang, X., Choi, P.S., Francis, J.M., Imielinski, M., Watanabe, H., Cherniack, A.D., and 1825 Meyerson, M. (2016). Identification of focally amplified lineage-specific super-enhancers in human epithelial cancers. Nat Genet 48, 176-182. 
Supplementary Table 1: List of commercially available CRC cell lines commonly used in laboratory studies.

HCT15

$1830 \quad$ HCT116

COLO320

$\mathrm{CACO} 2$

HT29

DLD1

1835 LS180

RKO

SW480

SW620

COLO741

$1840 \quad$ SW480

COLO205 
Supplementary Table 2: Hg19 coordinates of super-enhancers identified in primary CRC and normal colon tissue that are over- or under-represented in 13 commercial CRC cell lines.

\begin{tabular}{|c|c|c|c|c|}
\hline 'chr' & 'start' 'end' & \multicolumn{2}{|c|}{$\log 2$ cell lines/primary CRC } & P-value \\
\hline $\operatorname{chr} 2$ & 219921304 & 219926326 & -3.933334181 & 4.7453E-06 \\
\hline $\operatorname{chr} 19$ & 12827411294598 & $8-3.032709913$ & 7.59682E-05 & \\
\hline chr16 & 49886677 & 49893398 & -2.949821466 & 0.000519631 \\
\hline $\operatorname{chr} 19$ & 42210448 & 42221456 & -2.898911644 & 0.004772279 \\
\hline $\operatorname{chr} 11$ & 312970318010 & -2.894756705 & $1.76456 \mathrm{E}-05$ & \\
\hline chr8 & 142422272 & 142429622 & -2.644337941 & 0.001276849 \\
\hline chr19 & 950367958117 & -2.495988143 & 0.007449326 & \\
\hline $\operatorname{chr} 5$ & 149539500 & 149568866 & -2.335044971 & $1.37598 \mathrm{E}-06$ \\
\hline chr7 & 27226673 & 27235671 & -2.171925116 & 0.002112967 \\
\hline chr7 & 100607523 & 100631215 & -2.158768857 & 7.52654E-06 \\
\hline $\operatorname{chr} 11$ & 76773786 & 76787721 & -2.116481306 & $9.32179 \mathrm{E}-10$ \\
\hline chr3 & 38025920 & 38036323 & -2.084897042 & $1.80235 \mathrm{E}-06$ \\
\hline chr1 & 47644434 & 47659486 & -2.078868512 & 1.73654E-06 \\
\hline chr7 & 113722871 & 113728455 & -2.054225966 & 0.003951842 \\
\hline chr16 & 31137030 & 31147852 & -2.037706389 & 1.65113E-08 \\
\hline $\operatorname{chr} 19$ & 11292401134649 & $9-2.035016076$ & $5.13254 \mathrm{E}-09$ & \\
\hline $\operatorname{chr} 17$ & 38564963892930 & $0-2.015277075$ & $9.50179 \mathrm{E}-07$ & \\
\hline $\operatorname{chr} 11$ & 76796563 & 76803020 & -2.005698624 & $1.14188 \mathrm{E}-06$ \\
\hline $\operatorname{chr} 10$ & 85918778 & 85965078 & -1.956797767 & 6.89249E-07 \\
\hline $\operatorname{chr} 16$ & 67460809 & 67504574 & -1.945311673 & 1.21339E-07 \\
\hline $\operatorname{chr} 9$ & 130905976 & 130914424 & -1.91203976 & 0.000189521 \\
\hline $\operatorname{chr} 14$ & 94848020 & 94862793 & -1.890862615 & 0.009692258 \\
\hline $\operatorname{chr} 20$ & 22548732 & 22567099 & -1.887185684 & 0.001244224 \\
\hline $\operatorname{chrX}$ & 70835396 & 70848211 & -1.868040926 & 0.000105237 \\
\hline $\operatorname{chr} 17$ & 74485442 & 74490614 & -1.851351981 & $2.512 \mathrm{E}-05$ \\
\hline
\end{tabular}




\begin{tabular}{|c|c|c|c|c|c|}
\hline & chr7 & 70158103 & 70166365 & -1.815465956 & 2.41185E-05 \\
\hline & $\operatorname{chr} 7$ & 73180110 & 73189479 & -1.810669041 & $1.09706 \mathrm{E}-05$ \\
\hline \multirow[t]{5}{*}{1885} & $\operatorname{chr} 2$ & 14762896 & 14776676 & -1.803198778 & 0.000146674 \\
\hline & chr8 & 142315603 & 142357428 & -1.803098563 & 0.00033056 \\
\hline & chr1 & 205532653 & 205568500 & -1.800685286 & 0.000129067 \\
\hline & chr8 & 48646118 & 48651966 & -1.760217332 & $6.43184 \mathrm{E}-08$ \\
\hline & $\operatorname{chr} 7$ & 156393561 & 156419142 & -1.759424939 & 0.000451767 \\
\hline \multirow[t]{5}{*}{1890} & $\operatorname{chr} 7$ & 150477778 & 150505955 & -1.753099976 & $1.77004 \mathrm{E}-05$ \\
\hline & $\operatorname{chr} 16$ & 85449100 & 85526770 & -1.752547912 & 0.000214569 \\
\hline & chr16 & 582919587823 & -1.75068509 & 5.44416E-06 & \\
\hline & $\operatorname{chr} 4$ & 15002818 & 15007221 & -1.704048064 & 8.80386E-08 \\
\hline & $\operatorname{chr} 19$ & 18611824 & 18621473 & -1.694070408 & 8.10599E-07 \\
\hline \multirow[t]{5}{*}{1895} & chr19 & 40419549 & 40457265 & -1.692289026 & 0.000447315 \\
\hline & chr9 & 140186990 & 140203083 & -1.674837677 & 8.93647E-05 \\
\hline & $\operatorname{chr} 1$ & 33342282 & 33373754 & -1.670767379 & 3.25312E-06 \\
\hline & $\operatorname{chr} 4$ & 149348610 & 149367220 & -1.66504665 & 4.70202E-07 \\
\hline & $\operatorname{chr} 17$ & 73634586 & 73644264 & -1.663655009 & 0.000271978 \\
\hline \multirow[t]{5}{*}{1900} & chr8 & 76314903 & 76322046 & -1.663653639 & 0.000200429 \\
\hline & $\operatorname{chr} 4$ & 160023546 & 160026111 & -1.660029638 & $2.20781 \mathrm{E}-06$ \\
\hline & chr19 & 50668992 & 50738128 & -1.654229726 & $1.38886 \mathrm{E}-05$ \\
\hline & $\operatorname{chr} 20$ & 60979569 & 60991115 & -1.651679206 & 0.001274464 \\
\hline & $\operatorname{chr} 16$ & 31487207 & 31500133 & -1.646142188 & 2.01116E-05 \\
\hline \multirow[t]{5}{*}{1905} & chr1 & \multicolumn{2}{|c|}{$10563061073787-1.625633377$} & $4.36938 \mathrm{E}-05$ & \\
\hline & $\operatorname{chr} 7$ & 27140197 & 27149295 & -1.590910353 & 0.002221693 \\
\hline & $\operatorname{chr} 15$ & 68479899 & 68503417 & -1.588524898 & 3.10799E-08 \\
\hline & $\operatorname{chr} 22$ & 31666929 & 31694556 & -1.583014828 & $6.12579 \mathrm{E}-07$ \\
\hline & $\operatorname{chr} 19$ & 33723635 & 33815979 & -1.576082011 & 4.14475E-06 \\
\hline 1910 & $\operatorname{chr} 16$ & 53163214 & 53168804 & -1.562522215 & 0.001147531 \\
\hline
\end{tabular}




\begin{tabular}{|c|c|c|c|c|c|}
\hline & $\operatorname{chr} 16$ & 68384973 & 68432029 & -1.562204677 & $1.67925 \mathrm{E}-07$ \\
\hline & chr17 & 37779956 & 37790775 & -1.552808833 & 3.35556E-05 \\
\hline & chr21 & 43718828 & 43759283 & -1.549372024 & 0.000136642 \\
\hline & chr22 & 38493842 & 38517899 & -1.539972117 & $5.67556 \mathrm{E}-07$ \\
\hline 1915 & chr20 & 17902067 & 17921342 & -1.522326512 & $2.29737 \mathrm{E}-06$ \\
\hline & $\operatorname{chr} 16$ & 30123335 & 30135353 & -1.518808525 & 9.5405E-06 \\
\hline & chr2 & 241540948 & 241546332 & -1.517004878 & 0.000736344 \\
\hline & chr8 & 144938952 & 144989216 & -1.503213086 & $6.16809 \mathrm{E}-06$ \\
\hline & chr19 & 35599346 & 35623141 & -1.500696097 & 0.000173606 \\
\hline 1920 & chr22 & 50319146 & 50364826 & -1.495054142 & 2.28937E-06 \\
\hline & chr9 & 92263575 & 92302155 & -1.49031086 & $1.82918 \mathrm{E}-06$ \\
\hline & chr18 & 28676993 & 28682939 & -1.489553055 & 0.001023615 \\
\hline & chr11 & 293016829 & $7-1.486304394$ & $1.33944 \mathrm{E}-05$ & \\
\hline & chr9 & 130864490 & 130880714 & -1.485125129 & $8.30681 \mathrm{E}-05$ \\
\hline 1925 & chr4 & 174818018 & -1.482977267 & 0.000172748 & \\
\hline & chr1 & 16059949 & 16070046 & -1.480374457 & 0.000183684 \\
\hline & chr9 & 95929205 & 96033139 & -1.480201283 & 3.42275E-06 \\
\hline & chr2 & 219148537 & 219162345 & -1.476482263 & 0.001992198 \\
\hline & chr19 & 41914345 & 41942398 & -1.473144331 & $1.3812 \mathrm{E}-07$ \\
\hline 1930 & $\operatorname{chr} 18$ & 19741865 & 19781074 & -1.464659281 & 0.000491763 \\
\hline & chr17 & 38327873 & 38351879 & -1.464426274 & $6.48712 \mathrm{E}-05$ \\
\hline & chr2 & 239169490 & 239219160 & -1.463708595 & 1.68293E-07 \\
\hline & chr7 & 29601890 & 29607677 & -1.452014835 & 0.001734837 \\
\hline & chr17 & 81005827 & 81069196 & -1.442303168 & $1.50685 \mathrm{E}-05$ \\
\hline 1935 & $\operatorname{chr} 2$ & 242704267 & 242763347 & -1.441783842 & 7.53839E-06 \\
\hline & chr13 & 27522316 & 27597035 & -1.42852943 & 0.008113301 \\
\hline & $\operatorname{chr} 15$ & 31616912 & 31698718 & -1.42833867 & $2.07408 \mathrm{E}-07$ \\
\hline & chr19 & 55756765 & 55767392 & -1.42726789 & 0.006850812 \\
\hline
\end{tabular}




\begin{tabular}{|c|c|c|c|c|c|}
\hline & chr10 & 134197375 & 134245029 & -1.427197048 & 5.09147E-09 \\
\hline \multirow[t]{5}{*}{1940} & chr1 & 61508480 & 61523688 & -1.412822061 & 2.24545E-05 \\
\hline & chr9 & 140087151 & 140096306 & -1.410234098 & 0.006737055 \\
\hline & chr16 & 67423853 & 67447927 & -1.407506127 & 1.03681E-05 \\
\hline & $\operatorname{chr} 17$ & 79763639 & 79788092 & -1.388498587 & 8.97146E-08 \\
\hline & chr10 & 134257773 & 134301784 & -1.380589018 & 7.23145E-06 \\
\hline \multirow[t]{5}{*}{1945} & chr1 & 199990289 & 200023200 & -1.374864468 & 0.002411763 \\
\hline & $\operatorname{chr} 3$ & 53166834 & 53230973 & -1.374491386 & 8.47178E-08 \\
\hline & chr8 & 142203985 & 142256046 & -1.372888112 & 6.06341E-05 \\
\hline & $\operatorname{chr} 3$ & 71612437 & 71634637 & -1.372196278 & 0.000179723 \\
\hline & chr19 & 54979246 & 54985496 & -1.363581356 & 0.000548464 \\
\hline \multirow[t]{5}{*}{1950} & chr14 & 38052216 & 38072548 & -1.363489967 & 0.002279186 \\
\hline & chr9 & 134496283 & 134555283 & -1.35721224 & 0.005416658 \\
\hline & chr22 & 37406071 & 37423323 & -1.357177296 & 4.84104E-05 \\
\hline & chr7 & 30322996 & 30327105 & -1.355003336 & 6.64456E-06 \\
\hline & chr12 & 6468473647 & -1.354950301 & 0.000145933 & \\
\hline \multirow[t]{5}{*}{1955} & $\operatorname{chr} 4$ & 140096935 & 140110107 & -1.354221017 & 1.09865E-07 \\
\hline & $\operatorname{chr} 4$ & 7957954798 & $5-1.340452856$ & $1.32515 \mathrm{E}-05$ & \\
\hline & chr17 & 26120397 & 26151772 & -1.335406068 & 0.000614658 \\
\hline & chr11 & 152503415 & -1.334335 & 6.89398E-06 & \\
\hline & $\operatorname{chr} 5$ & 40676729 & 40700663 & -1.333969521 & 0.005834136 \\
\hline \multirow[t]{5}{*}{1960} & $\operatorname{chr} 7$ & 27236867 & 27251265 & -1.333213185 & 0.008969102 \\
\hline & chr5 & 149586118 & 149597726 & -1.327771064 & 0.000134751 \\
\hline & chr1 & 155050463 & 155059415 & -1.32584885 & 0.000636383 \\
\hline & chr19 & 4034556415 & $4-1.318671308$ & 4.72375E-08 & \\
\hline & $\operatorname{chr} 17$ & 73568797 & 73577073 & -1.314979465 & $3.52102 \mathrm{E}-05$ \\
\hline \multirow[t]{2}{*}{1965} & chr14 & 55031455 & 55035147 & -1.314499318 & 0.00014642 \\
\hline & chr9 & 117124745 & 117165720 & -1.313797327 & 0.000198119 \\
\hline
\end{tabular}




\begin{tabular}{|c|c|c|c|c|c|}
\hline & $\operatorname{chr} 17$ & 37827160 & 37837462 & -1.311567369 & 0.000914851 \\
\hline & $\operatorname{chr} 7$ & 991118994980 & -1.306250732 & 0.006732574 & \\
\hline & chr8 & 19138901926709 & -1.295545411 & 0.000272981 & \\
\hline \multirow[t]{5}{*}{1970} & $\operatorname{chr} 12$ & 121650947 & 121685811 & -1.29244219 & 0.001279391 \\
\hline & chr19 & 12473171256284 & -1.290320659 & 7.93516E-05 & \\
\hline & chr7 & 25979727 & 26008574 & -1.288425537 & 0.005901451 \\
\hline & $\operatorname{chr} 16$ & 11290981 & 11360138 & -1.28593865 & $2.36031 \mathrm{E}-06$ \\
\hline & chr8 & 145536936 & 145562791 & -1.282480618 & 2.95262E-05 \\
\hline \multirow[t]{5}{*}{1975} & chr5 & 10735241188157 & -1.28018389 & 0.000552488 & \\
\hline & chr2 & 43035897 & 43038998 & -1.279825977 & 7.19543E-09 \\
\hline & chr9 & 139578763 & 139591286 & -1.278519633 & 5.51206E-05 \\
\hline & $\operatorname{chr} 1$ & 51761624 & 51802404 & -1.276336427 & 7.98952E-06 \\
\hline & chr19 & 35485150 & 35505427 & -1.273803969 & 2.20636E-06 \\
\hline \multirow[t]{5}{*}{1980} & $\operatorname{chr} 21$ & 42866102 & 42955540 & -1.271553665 & 0.003990368 \\
\hline & $\operatorname{chr} 9$ & 140203344 & 140212896 & -1.268492344 & 0.003718446 \\
\hline & $\operatorname{chr} 7$ & 948975956672 & -1.267631416 & 0.000589779 & \\
\hline & chr7 & 100482826 & 100510426 & -1.262130127 & 4.80322E-06 \\
\hline & chr11 & 64654508 & 64663543 & -1.26061998 & 0.001093014 \\
\hline \multirow[t]{5}{*}{1985} & chr9 & 110243788 & 110268173 & -1.251133259 & 0.000442417 \\
\hline & chr1 & 226288057 & 226325426 & -1.248226489 & $8.31645 \mathrm{E}-07$ \\
\hline & chr12 & 32543708 & 32556907 & -1.244848297 & $1.22568 \mathrm{E}-06$ \\
\hline & $\operatorname{chr} 18$ & 60381757 & 60385355 & -1.235852828 & $3.78748 \mathrm{E}-05$ \\
\hline & $\operatorname{chr} 20$ & 57463250 & 57471189 & -1.214365622 & 0.000611273 \\
\hline \multirow[t]{5}{*}{1990} & chr5 & 32433949 & 32447867 & -1.213848352 & 0.000267944 \\
\hline & $\operatorname{chr} 19$ & 923608929931 & -1.211890102 & 0.004619643 & \\
\hline & $\operatorname{chr} 21$ & 45658980 & 45670752 & -1.200354979 & 0.001115286 \\
\hline & chr17 & 76988200 & 76995813 & -1.19781147 & 0.002996369 \\
\hline & chr3 & 169375755 & 169387326 & -1.197762721 & 0.00030491 \\
\hline
\end{tabular}




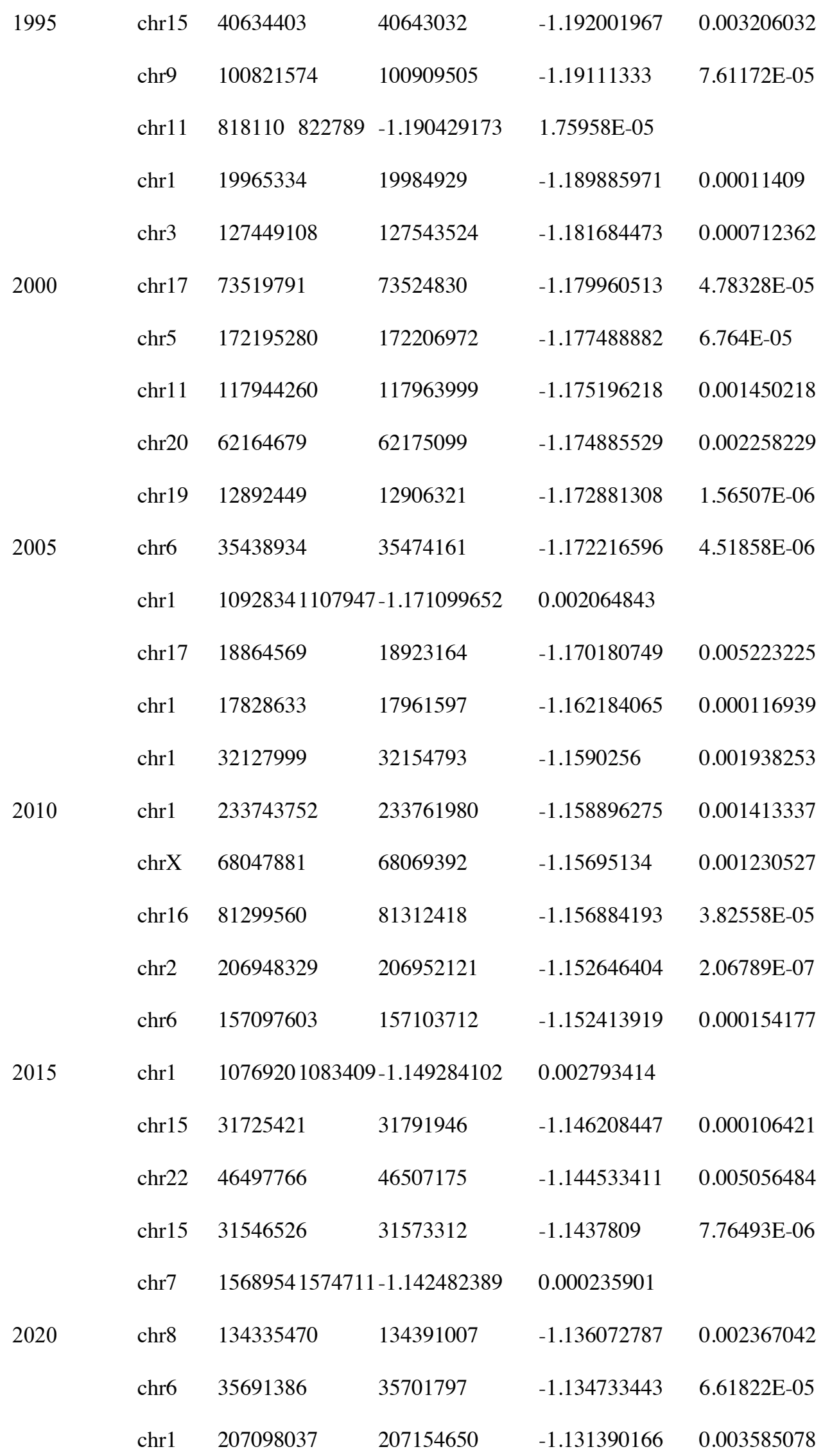




\begin{tabular}{|c|c|c|c|c|c|}
\hline & $\operatorname{chr} 11$ & 29223972926733 & $3-1.127961438$ & 0.000137631 & \\
\hline & chr9 & 14309511 & 14323573 & -1.125174648 & 0.002250256 \\
\hline 2025 & chr20 & 56104107 & 56204341 & -1.122036256 & 0.00336621 \\
\hline & chr20 & 56229753 & 56295325 & -1.118689646 & 0.004286441 \\
\hline & chr19 & 49178577 & 49202140 & -1.111287415 & 8.87727E-05 \\
\hline & chr17 & 73529524 & 73542716 & -1.109659761 & 0.008782904 \\
\hline & chr21 & 44858977 & 44873702 & -1.109649262 & 0.001078597 \\
\hline 2030 & chr9 & 20141952023271 & -1.108875373 & 7.58311E-06 & \\
\hline & chr14 & 105944150 & 105959031 & -1.106254332 & 0.002882295 \\
\hline & chr19 & 11353793 & 11380147 & -1.104940631 & $1.86943 \mathrm{E}-06$ \\
\hline & chr8 & 81397760 & 81421513 & -1.104026822 & 0.000173483 \\
\hline & chr8 & 145724875 & 145736551 & -1.102944841 & 0.000375006 \\
\hline 2035 & chr10 & 135156522 & 135179866 & -1.10253336 & 0.004821712 \\
\hline & $\operatorname{chr} 19$ & 45220249 & 45288652 & -1.101828316 & 0.000358198 \\
\hline & chr1 & 155161643 & 155165270 & -1.101255846 & 0.006195042 \\
\hline & chr11 & 25319692557416 & $5-1.099006162$ & 0.000600571 & \\
\hline & chr10 & 112562258 & 112639452 & -1.095353097 & 0.00213485 \\
\hline 2040 & chr16 & 88443224 & 88621560 & -1.094897966 & 0.002762185 \\
\hline & chr17 & 10676053 & 10719009 & -1.094674354 & 0.004648038 \\
\hline & chr11 & 606195622242 & -1.094121442 & $5.98525 \mathrm{E}-05$ & \\
\hline & chr5 & 172327125 & 172346151 & -1.093982888 & 2.61373E-05 \\
\hline & $\operatorname{chr} 22$ & 50962309 & 50971267 & -1.093835024 & 0.003064404 \\
\hline 2045 & chr6 & 168413323 & 168503148 & -1.09366734 & $2.40523 \mathrm{E}-05$ \\
\hline & chr8 & 145043674 & 145052590 & -1.093621486 & 0.000623648 \\
\hline & chr17 & 57442508 & 57459901 & -1.092540175 & 0.003262118 \\
\hline & chr1 & 228349132 & 228354871 & -1.091068244 & 0.000204448 \\
\hline & chr6 & 89788647 & 89793074 & -1.089729814 & 8.93332E-09 \\
\hline 2050 & $\operatorname{chr} 2$ & 28542414 & 28677214 & -1.088175117 & $9.13028 \mathrm{E}-05$ \\
\hline
\end{tabular}




\begin{tabular}{|c|c|c|c|c|c|}
\hline & chr22 & 46406761 & 46411260 & -1.088019864 & 0.000118634 \\
\hline & chr1 & 65530848 & 65534992 & -1.086156021 & 0.000454408 \\
\hline & chr13 & 41237892 & 41242018 & -1.08574238 & 0.000736638 \\
\hline & chr1 & 37936562 & 37964770 & -1.084054544 & 0.000176254 \\
\hline 2055 & chr1 & 20796697 & 20823686 & -1.080299094 & 0.004959933 \\
\hline & chr8 & 61811816 & 61840052 & -1.080121891 & 4.14865E-05 \\
\hline & chr12 & 106620916 & 106644657 & -1.079291391 & 3.6892E-05 \\
\hline & chr14 & 103367432 & 103415466 & -1.07815608 & 2.60995E-05 \\
\hline & chr3 & 169755228 & 169768436 & -1.072797034 & 7.40788E-06 \\
\hline 2060 & chr14 & 100569955 & 100660583 & -1.069741409 & 0.000293944 \\
\hline & chr2 & 208027703 & 208032208 & -1.068574986 & 0.00013338 \\
\hline & chr5 & 149941195 & 150017647 & -1.064230609 & $5.22559 \mathrm{E}-06$ \\
\hline & $\operatorname{chr} 4$ & 124315353 & 124341272 & -1.055196918 & 0.001277395 \\
\hline & chr9 & 139739767 & 139758297 & -1.045706755 & 4.37139E-05 \\
\hline 2065 & chr4 & 141157126 & 141174915 & -1.044484983 & 0.00687941 \\
\hline & chr1 & 226029826 & 226110273 & -1.037503403 & 7.20714E-06 \\
\hline & chr9 & 139683661 & 139691005 & -1.034391734 & $9.9218 \mathrm{E}-05$ \\
\hline & chr5 & 32298136 & 32333194 & -1.033402799 & 0.003793373 \\
\hline & chr16 & 57118390 & 57188393 & -1.032752273 & 2.17302E-05 \\
\hline 2070 & chr2 & 242280263 & 242316360 & -1.030467192 & 0.002928121 \\
\hline & chr1 & 48150864 & 48195520 & -1.024145926 & $2.274 \mathrm{E}-05$ \\
\hline & chr19 & 39887706 & 39902964 & -1.023371562 & 0.000581726 \\
\hline & chr2 & 238380339 & 238457019 & -1.019570375 & 0.00548691 \\
\hline & chr12 & 57519739 & 57575138 & -1.017545226 & 0.000325957 \\
\hline 2075 & $\operatorname{chr} 2$ & 241895868 & 241951777 & -1.014868666 & 0.004083038 \\
\hline & chr20 & 62150329 & 62155053 & -1.010226977 & 0.000818134 \\
\hline & chr19 & 49114785 & 49123342 & -1.009885182 & 0.000928071 \\
\hline & chr19 & 17875523 & 17914613 & -1.007297164 & $9.04413 \mathrm{E}-05$ \\
\hline
\end{tabular}




\begin{tabular}{|c|c|c|c|c|c|}
\hline & chr10 & 98337456 & 98394081 & 1.007035335 & 0.002355826 \\
\hline \multirow[t]{5}{*}{2080} & chr14 & 91817703 & 91881574 & 1.054473572 & 0.001319197 \\
\hline & chr2 & 242784751 & 242844988 & 1.055869807 & 0.000500672 \\
\hline & chr6 & 30691362 & 30762214 & 1.06354511 & 0.001788619 \\
\hline & chr8 & 27189458 & 27266603 & 1.105089489 & 0.006499779 \\
\hline & chr1 & 839207879441 & 1.23821519 & 0.008747137 & \\
\hline \multirow[t]{5}{*}{2085} & chr4 & 14928161584306 & 51.253051461 & 0.003244989 & \\
\hline & chr18 & 35832743626174 & 1.292623519 & 4.46798E-05 & \\
\hline & chr7 & 130567798 & 130646840 & 1.301600783 & 0.000842286 \\
\hline & chr12 & 46761555 & 46797433 & 1.368447694 & 0.00332708 \\
\hline & chr17 & 48176137 & 48195174 & 1.393480425 & 0.000480532 \\
\hline 2090 & chr17 & 17795500 & 17864058 & 1.41147405 & 0.007475802 \\
\hline
\end{tabular}


Supplementary Table 3: Gene signature downstream of tumor-enriched SEs. Genes are mRNA up-regulated in primary CRCs over CCLE cell lines.

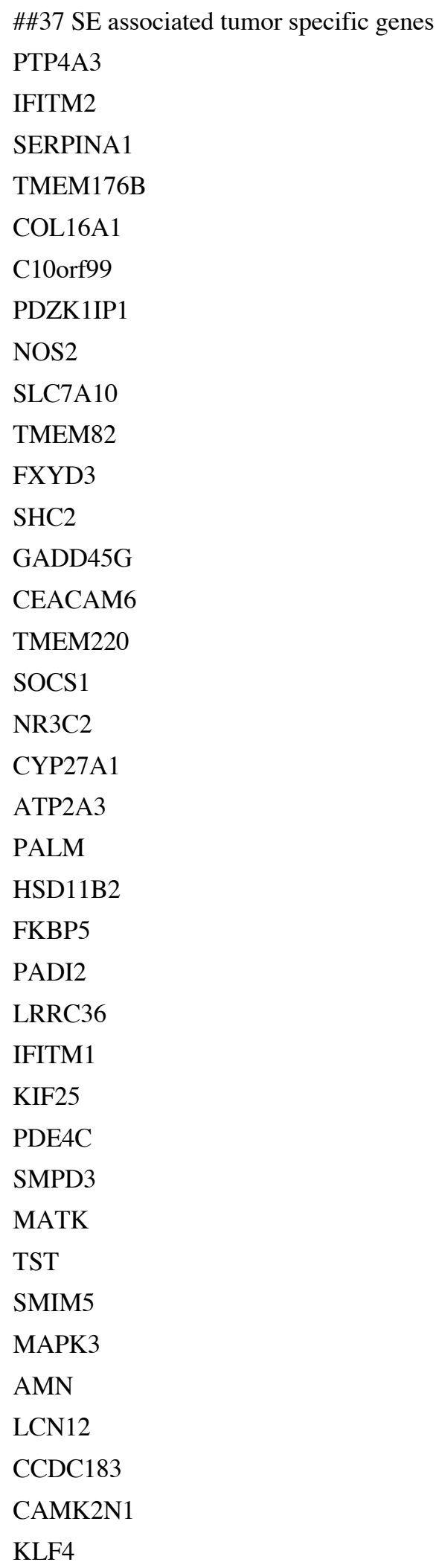


Supplementary Table 4: Super-enhancers up-regulated in primary CRC over patient-matched 2110 normal tissue, and also up-regulated in primary specimens over CRC cell lines.

$\begin{array}{llll}\text { 'chr' } & \text { 'start' 'end' } & \\ \text { chr11 } & 312970 & 318010 & \\ \text { chr8 } & 142422272 & 142429622 \\ \text { chr19 } & 950367 & 958117 & \\ \text { chr1 } & 47644434 & 47659486 \\ \text { chr17 } & 744854442 & 74490614 \\ \text { chr8 } & 142203985 & 142256046 \\ \text { chr19 } & 923608 & 929931 & \\ \text { chr20 } & 56229753 & 56295325 \\ \text { chr2 } & 208027703 & 208032208\end{array}$




\section{Supplementary Table 5: Juxtaposition of primary CRC cases with mutational status and $P D Z K 1 I P 1$ SE status. All patients for which data are available are shown.}

Patient PDZK1IP1 SE? Gene Mutation Variant_Classification Variant Allele Frequency

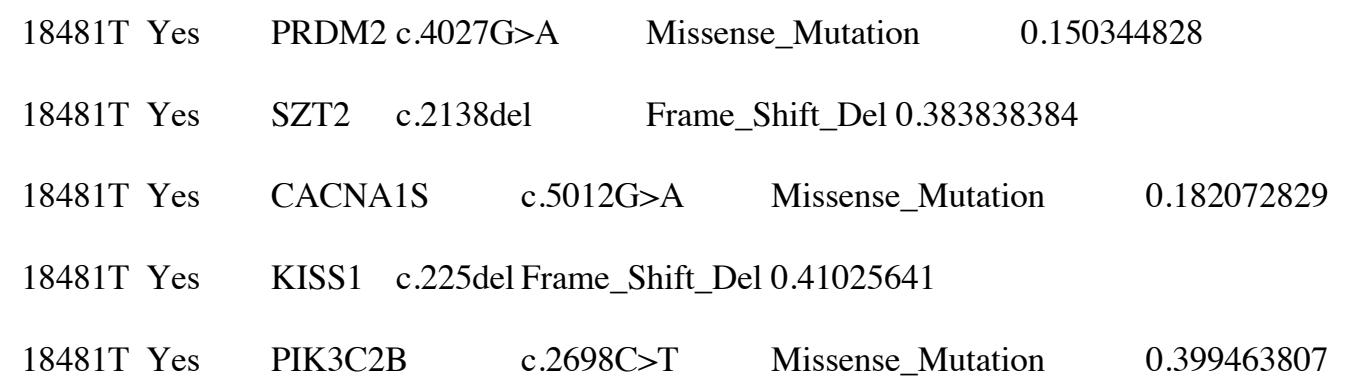

TGFBR2

PBRM1 c.1961A>G

Missense_Mutation

0.189873418

$18481 \mathrm{~T}$ Yes

PBRM1 c.518T>C

Missense_Mutation

0.390728477

$18481 \mathrm{~T}$ Yes

ATR c.7375C $>$ T

Missense_Mutation

0.155555556

18481T Yes

TET2 c.371A>G

Missense_Mutation

0.179447853

$18481 \mathrm{~T}$ Yes

TET2 c.4354C $>$ T

Nonsense_Mutation

0.377919321

2155

$18481 \mathrm{~T}$ Yes

TET2 c.4871A $>\mathrm{G}$

Missense_Mutation

0.208805031

$18481 \mathrm{~T}$ Yes

FAT1 c.12608G>A

Missense_Mutation

0.376744186

18481T Yes

FAT1 c.7366G $>$ A

Missense_Mutation

0.352859135

18481T Yes

ARID1B

c. $1988 \mathrm{~A}>\mathrm{G}$

Missense_Mutation

0.19895288

$18481 \mathrm{~T}$ Yes

EGFR c.2029C $>$ T

Missense_Mutation

0.193548387

$18481 \mathrm{~T}$ Yes

EGFR c.2930G>A

Missense_Mutation

0.393333333

18481T Yes

MET c.40C $>$ TMissense_Mutation

0.418390805

$18481 \mathrm{~T}$ Yes

KMT2C c.7238C >T

Missense_Mutation

0.18814433

18481T Yes

WRN c.2743T>C

Missense_Mutation

0.181081081

18481T Yes

ANK1 c. $1231 \mathrm{G}>\mathrm{A}$

Missense_Mutation

0.420454545 
$18481 \mathrm{~T}$ Yes SMARCA2 c.980G>A Missense_Mutation 0.33333333

$18481 T$ Yes GATA3 c.1134del Frame_Shift_Del 0.408333333

$18481 \mathrm{~T}$ Yes RET c.169C $>\mathrm{T} \quad$ Missense_Mutation 0.343023256

$18481 \mathrm{~T}$ Yes $\quad$ ADK $\quad$ c.731C $>\mathrm{T} \quad$ Missense_Mutation $\quad 0.152777778$

$18481 \mathrm{~T}$ Yes $\quad$ KAT6B c.4121G>A Missense_Mutation 0.37628866

$18481 \mathrm{~T}$ Yes

TCF7L2 c.1485del

Frame_Shift_Del 0.452830189

$18481 \mathrm{~T}$ Yes

FGFR2 c.181C $>$ T

Missense_Mutation

0.368512111

$18481 \mathrm{~T}$ Yes

DRD4 c.763del Frame_Shift_Del 0.344827586

$18481 \mathrm{~T}$ Yes

FAT3 c.971A>G

Missense_Mutation

0.158798283

$18481 \mathrm{~T}$ Yes

KMT2A c.5338del

Frame_Shift_Del 0.179824561

2175

$18481 \mathrm{~T}$ Yes

CHD4 c.2402T $>$ C

Missense_Mutation

0.338461538

$18481 \mathrm{~T}$ Yes

KMT2D c.9417del

Frame_Shift_Del 0.401574803

18481T Yes

KMT2D c.7061del

Frame_Shift_Del 0.25

$18481 \mathrm{~T}$ Yes

KMT2D c.1300del

Frame_Shift_Del 0.227272727

18481T Yes

ERBB3 c.2033G>A

Missense_Mutation

0.332129964

2180

18481T Yes

POLE c.1309G $>$ A

Missense_Mutation

0.370481928

$18481 \mathrm{~T}$ Yes

POLE c.1280C $>\mathrm{T}$

Missense_Mutation

0.341397849

18481T Yes

BRCA2 c.2957del

Frame_Shift_Del 0.33611691

18481T Yes

RB

c. $971 \mathrm{~T}>\mathrm{A}$

Missense_Mutation

0.333333333

18481T Yes

PCDH8 c.1975C $>$ T

Missense_Mutation

0.36

2185

$18481 \mathrm{~T}$ Yes

PCDH8 c.1432C > T

Missense_Mutation

0.413043478

18481T Yes

PCDH8 c.1397C>T

Missense_Mutation

0.295454545

18481T Yes

PCDH8 c. $277 \mathrm{G}>\mathrm{A}$

Missense_Mutation

0.371273713

18481T Yes

PCDH17

c. $1898 \mathrm{~A}>\mathrm{G}$

Missense_Mutation

0.394160584

18481T Yes

PCDH17

c. $2714 \mathrm{~A}>\mathrm{T}$

Missense_Mutation

0.364

18481T Yes

DICER1 c.4458del

Frame_Shift_Del 0.368088468

18481T Yes

DICER1 c.1859A >G

Missense_Mutation

0.123214286

18481T Yes

AXIN1 c.1565C>T

Missense_Mutation

0.28 


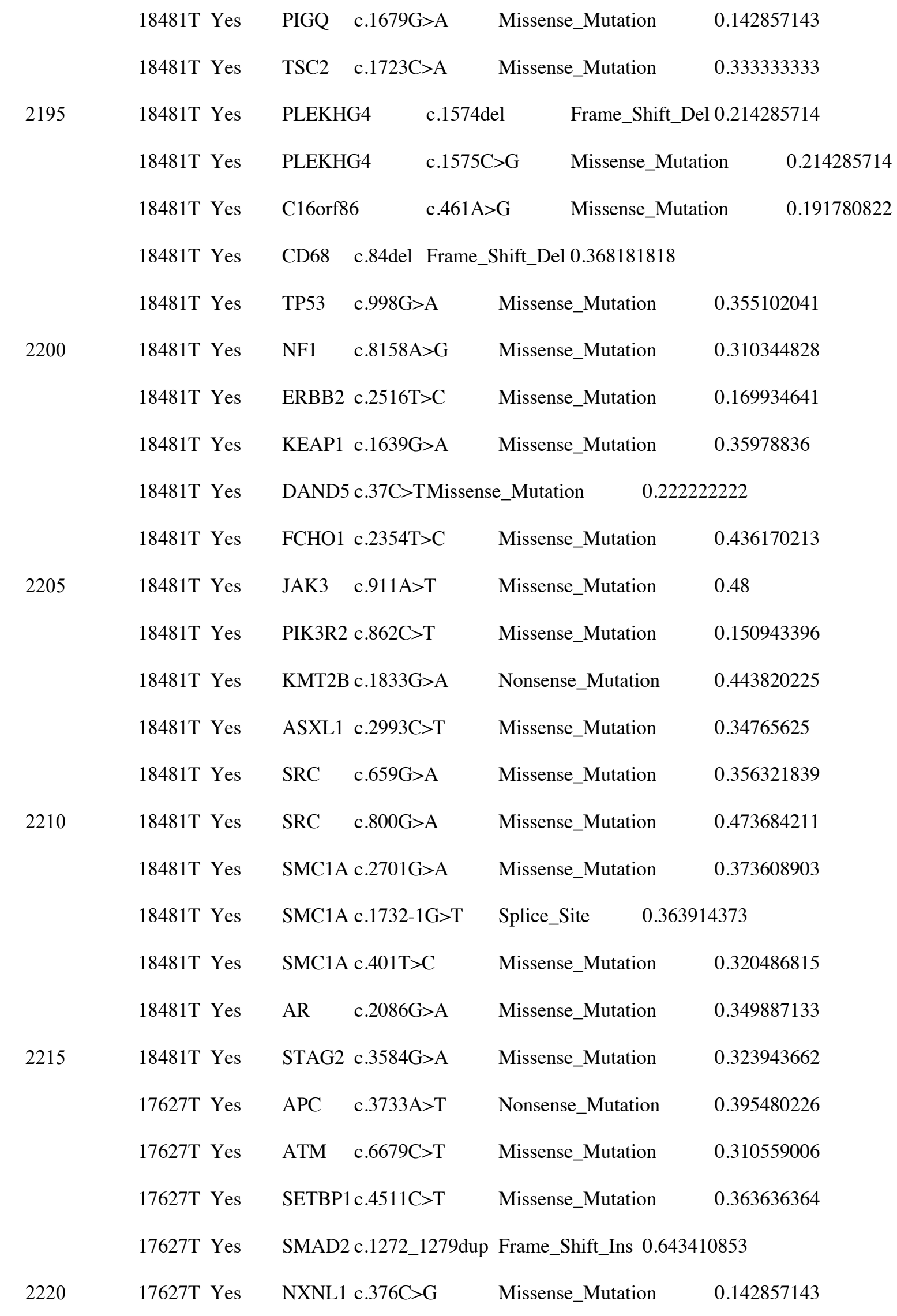




\begin{tabular}{|c|c|c|c|c|c|}
\hline & 18946T No & NRAS & c. $34 \mathrm{G}>\mathrm{TMissense}$ & _Mutation & 44186 \\
\hline & $18946 \mathrm{~T}$ No & APC & c. $1495 \mathrm{C}>\mathrm{T}$ & Nonsense_Mutation & 0.441201717 \\
\hline & 18946T No & APC & c.4339del & Frame_Shift_Del 0.4 & 82038 \\
\hline & $18946 \mathrm{~T}$ No & SMC3 & c. $212 \mathrm{C}>\mathrm{T}$ & Missense_Mutation & 0.41686747 \\
\hline 2225 & 18946T No & ATM & c. $2084 \mathrm{~T}>\mathrm{C}$ & Missense_Mutation & 0.45041816 \\
\hline & $18946 \mathrm{~T}$ No & ATM & c. $9022 \mathrm{C}>\mathrm{T}$ & Missense_Mutation & 0.443911793 \\
\hline & 18946T No & CHD4 & c. $4216 \mathrm{C}>\mathrm{T}$ & Missense_Mutation & 0.419981499 \\
\hline & $18946 \mathrm{~T}$ No & FLT3 & c. $106 \mathrm{G}>\mathrm{T}$ & Missense_Mutation & 0.620921802 \\
\hline & 18946T No & ERBB2 & c. $2033 \mathrm{G}>\mathrm{A}$ & Missense_Mutation & 0.550724638 \\
\hline 2230 & 19395T Yes & PIK3CA & c. $323 \mathrm{G}>\mathrm{A}$ & Missense_Mutation & 0.376528117 \\
\hline & 19395T Yes & PIK3CA & c. $1634 \mathrm{~A}>\mathrm{C}$ & Missense_Mutation & 0.251655629 \\
\hline & 19395T Yes & APC & c.2336dup & Frame_Shift_Ins 0.3 & 4808 \\
\hline & 19395T Yes & APC & c.4459_4460insT F & Frame_Shift_Ins 0.3 & 99204 \\
\hline & 19395T Yes & APC & c. $4460 \mathrm{C}>\mathrm{A}$ & Missense_Mutation & 0.394946809 \\
\hline 2235 & 19395T Yes & BRAF & c.1799T $>A$ & Missense_Mutation & 0.269349845 \\
\hline & 19395T Yes & FAT3 & c. $2762 \mathrm{C}>\mathrm{A}$ & Missense_Mutation & 0.3671875 \\
\hline & 19395T Yes & FAT3 & c. $4718 \mathrm{C}>\mathrm{T}$ & Missense_Mutation & 0.352380952 \\
\hline & 19395T Yes & KMT2D & c. $2021 \mathrm{C}>\mathrm{T}$ & Missense_Mutation & 0.307692308 \\
\hline & 19395T Yes & AGRP & c. $262 \mathrm{G}>\mathrm{A}$ & Missense_Mutation & 0.486631016 \\
\hline 2240 & 19395T Yes & TP53 & c. $743 \mathrm{G}>\mathrm{A}$ & Missense_Mutation & 0.6125 \\
\hline & 19395T Yes & SOX9 & c. $736 \mathrm{C}>\mathrm{T}$ & Nonsense_Mutation & 0.363888889 \\
\hline & 19395T Yes & SMAD2 & c. $1389 \mathrm{C}>\mathrm{A}$ & Nonsense_Mutation & 0.379496403 \\
\hline & 19395T Yes & SMAD2 & c. $904 \mathrm{~T}>\mathrm{C}$ & Missense_Mutation & 0.380514706 \\
\hline & 19395T Yes & KMT2B & c. $2732 \mathrm{C}>\mathrm{T}$ & Missense_Mutation & 0.41509434 \\
\hline 2245 & 19442T Yes & PRDM2 & c. $2933 \mathrm{C}>\mathrm{T}$ & Missense_Mutation & 0.121718377 \\
\hline & 19442T Yes & PRDM2 & c. $4184 \mathrm{G}>\mathrm{A}$ & Missense_Mutation & 0.170694864 \\
\hline & 19442T Yes & ARID1A & c.2402dup & Frame_Shif & 0.102857143 \\
\hline & 19442T Yes & IGFN1 & c. $10258 \mathrm{G}>\mathrm{A}$ & Missense_Mutation & 0.175 \\
\hline
\end{tabular}




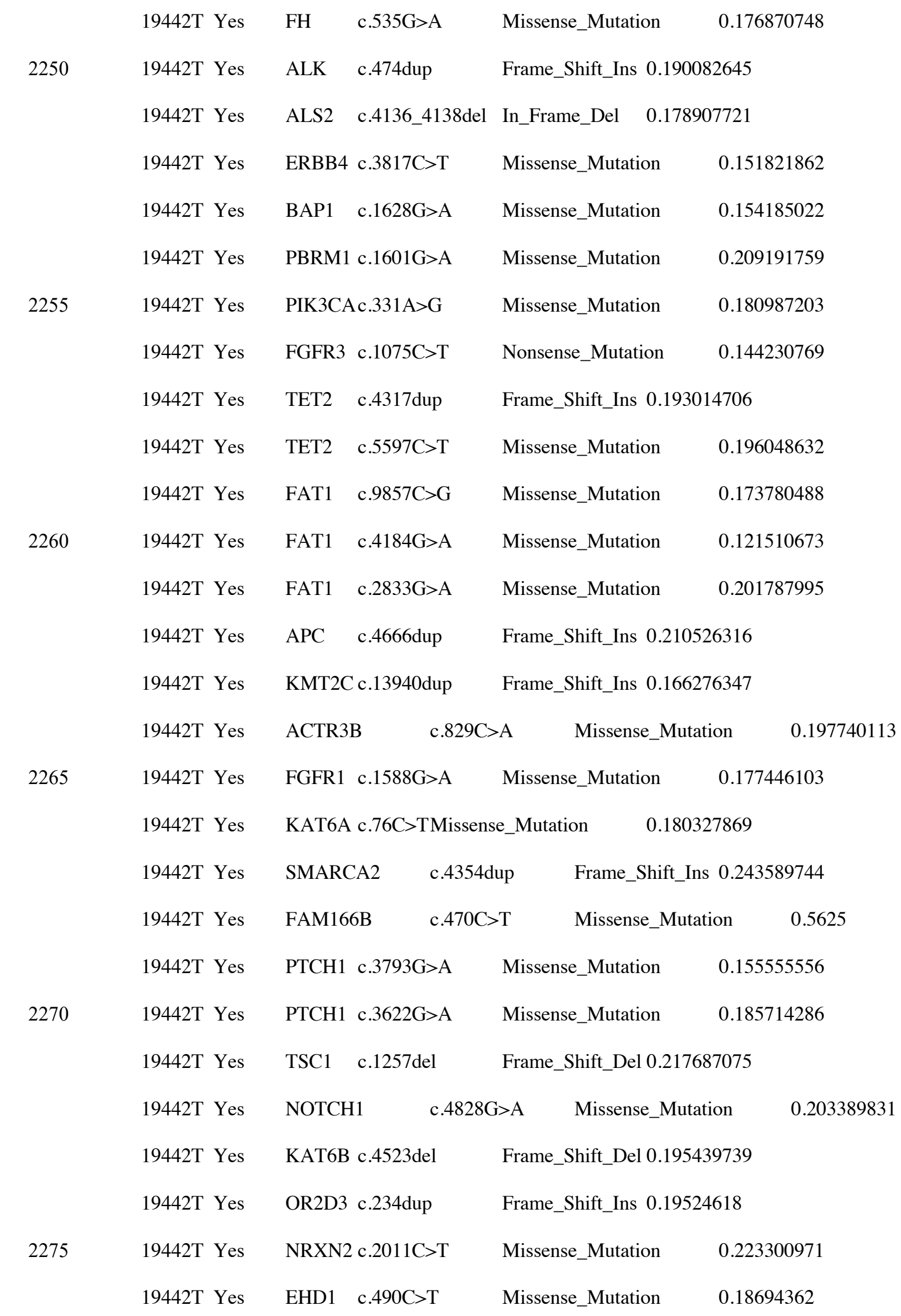




\begin{tabular}{|c|c|c|c|}
\hline $19442 \mathrm{~T}$ Yes & c. $3998 \mathrm{~A}>\mathrm{G}$ & Missense_Mutation & 0.244705882 \\
\hline 19442T Yes & c. $6679 \mathrm{C}>\mathrm{T}$ & Missense_Mutation & 0.12424608 \\
\hline $19442 \mathrm{~T}$ Yes & KMT2D c.7109G >A & Missense_Mutation & 0.216216216 \\
\hline 19442T Yes & KMT2D c.7061del & \multicolumn{2}{|c|}{ Frame_Shift_Del 0.351351351} \\
\hline 19442T Yes & KMT2D c. $4841 \mathrm{G}>\mathrm{A}$ & Missense_Mutation & 0.174563591 \\
\hline 19442T Yes & KMT2D c.2993del & \multicolumn{2}{|c|}{ Frame_Shift_Del 0.170731707} \\
\hline $19442 \mathrm{~T}$ Yes & NCOR2 c. $6923 \mathrm{C}>\mathrm{T}$ & Missense_Mutation & 0.141304348 \\
\hline 19442T Yes & c. $1478 \mathrm{~T}>\mathrm{A}$ & Missense_Mutation & 0.149797571 \\
\hline
\end{tabular}


17787T No KEAP1 c.1133G >A Missense_Mutation 0.663793103

$18081 \mathrm{~T}$ Yes APC $\quad$ c.646C $>\mathrm{T} \quad$ Nonsense_Mutation 0.635416667

18081T Yes PDE6A c.2302G>A Missense_Mutation 0.333333333

$18081 \mathrm{~T}$ Yes POLE c.5573G>A Missense_Mutation 0.381294964

19106T Yes PRDM16 c.1898C $>$ T $\quad$ Missense_Mutation 0.951612903

19106T Yes

PRDM16

c.3369_3371dup In_Frame_Ins 0.92

19106T Yes

IDH1 c. $532 \mathrm{G}>\mathrm{A}$

Missense_Mutation

0.302449414

19106T Yes

MLH1 c.655A>G

Missense_Mutation

0.372986369

19106T Yes

TACC 3 c.427G $>$ A

Missense_Mutation

0.358422939

19106T Yes

UGT2B7

c.801_802delinsTC

Missense_Mutation

0.319034853

19106T Yes

FAT1 c.8535G $>$ A

Missense_Mutation

0.355665025

19106T Yes

PNPLA1

c. $1268 \mathrm{C}>\mathrm{A}$

Missense_Mutation

0.914285714

19106T Yes

TSC

c. $1079 \mathrm{C}>\mathrm{A}$

Missense_Mutation

0.337777778

19106T Yes

ATE1 c.499C $>$ T

Missense_Mutation

0.378723404

19106T Yes

TACC 2 c. $2488 \mathrm{C}>\mathrm{T}$

Missense_Mutation

0.363043478

2320

19106T Yes

FAT3 c.8983C $>$ A

Missense_Mutation

0.290087464

19106T Yes

TECTA c. $1111 \mathrm{~A}>\mathrm{G}$

Missense_Mutation

0.33492823

19106T Yes

TP53BP1

c. $1074 \mathrm{C}>\mathrm{G}$

Missense_Mutation

0.949874687

19106T Yes

MPDU1 c.685G $>$ A

Missense_Mutation

0.969465649

19106T Yes

TP53 c.326dup

Frame_Shift_Ins 0.910714286

2325

19282T No

SMO c.2081del

Frame_Shift_Del 0.117021277

18607T Yes

ADCY3 c. $2387 \mathrm{G}>\mathrm{A}$

Missense_Mutation

0.167630058

18607T Yes

MSH6 c.2079del

Frame_Shift_Del 0.16286645

18607T Yes

CASP8 c.1596del

Frame_Shift_Del 0.121794872

18607T Yes

PIK3CAc.3140A $>$ G

Missense_Mutation

0.159292035

2330

18607T Yes

TET2 c.3157C > T

Nonsense_Mutation

0.166666667

$18607 \mathrm{~T}$ Yes

FAT1 c. $13717 \mathrm{G}>\mathrm{A}$

Missense_Mutation

0.153439153

18607T Yes

EGFR c.1282G $>$ A

Missense_Mutation

0.174208145 


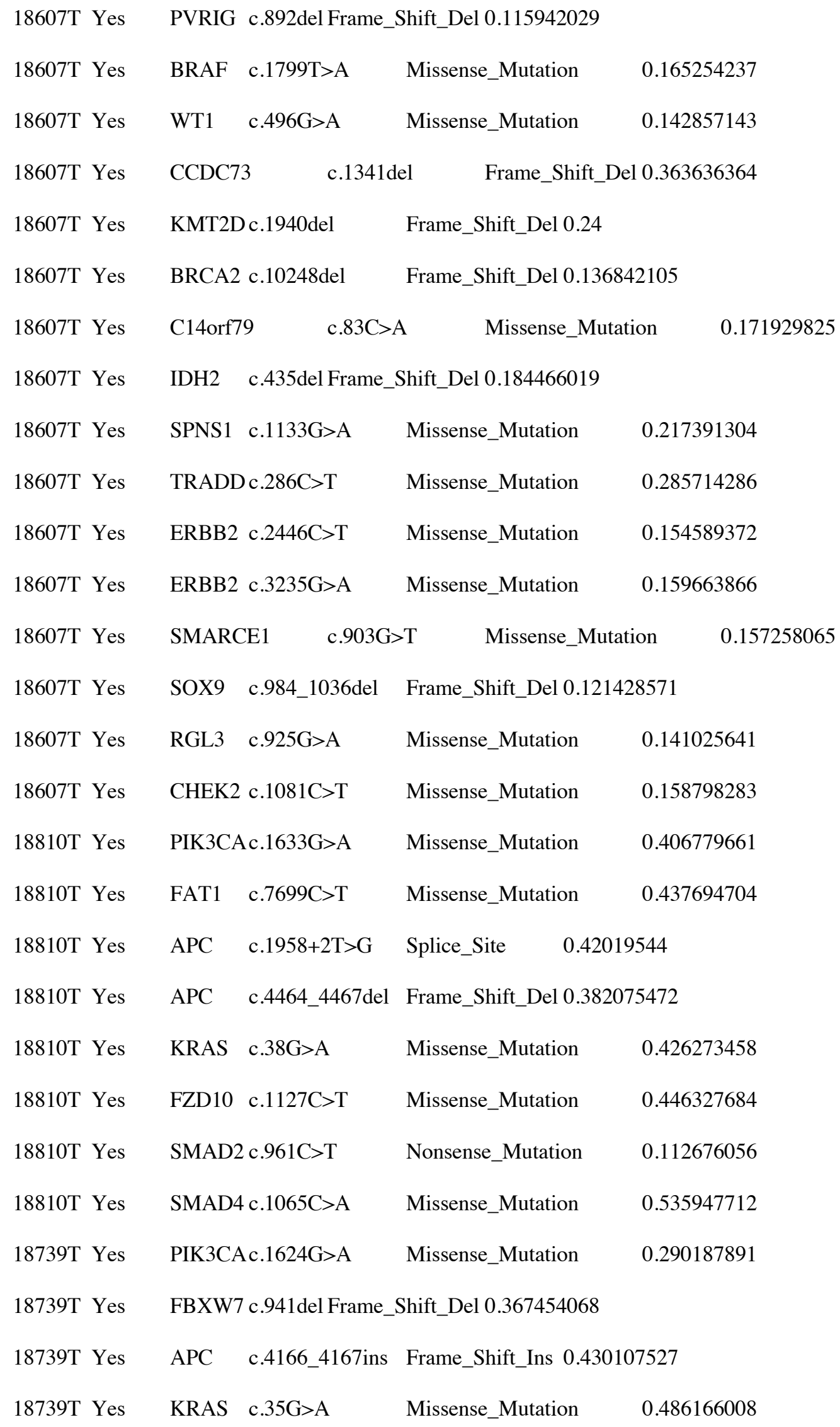




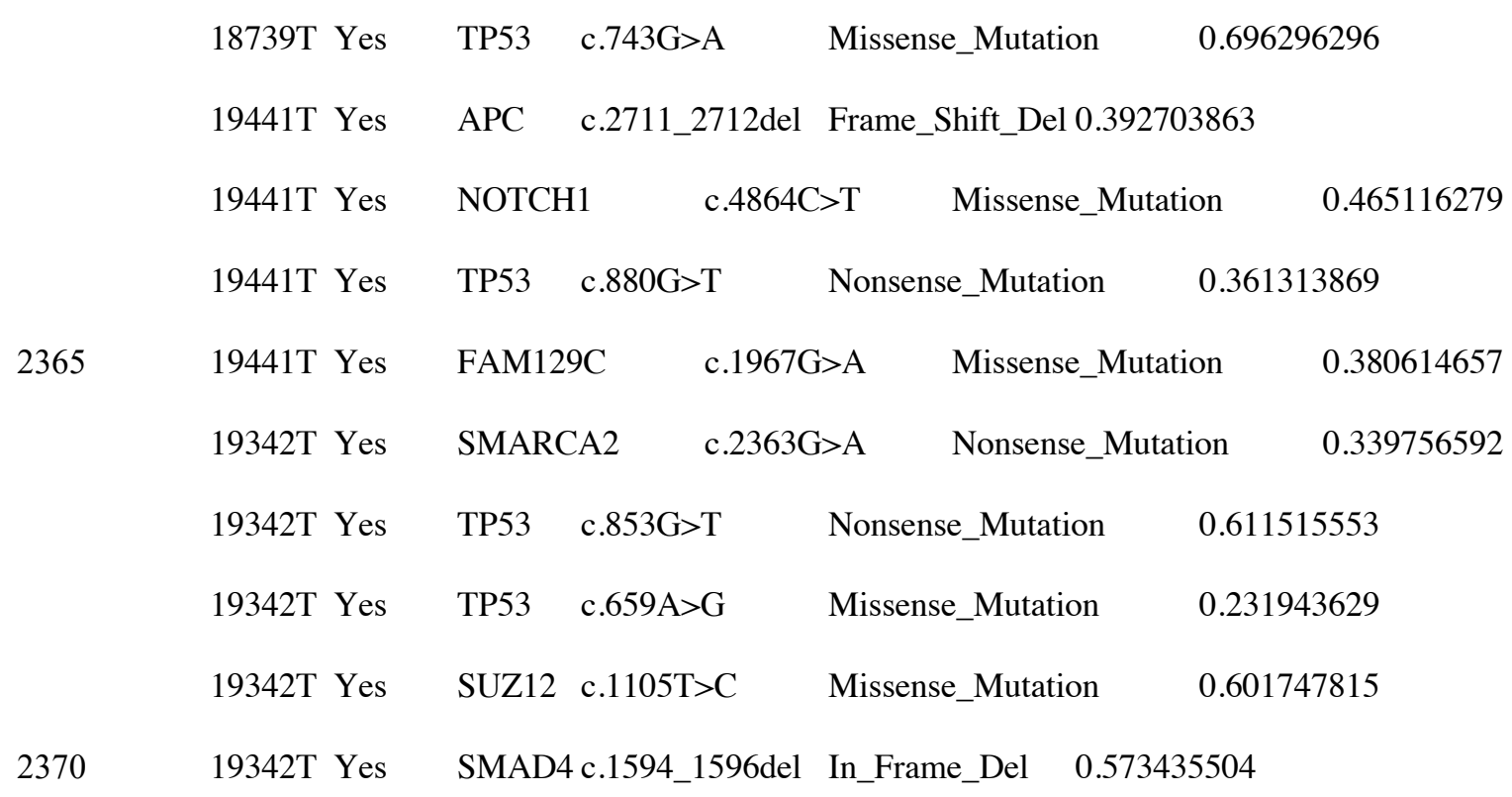




\section{Supplementary Table 6: Juxtaposition of primary CRC cases with patient demographics and PDZK1IP1 SE status.}

$\begin{array}{llll}\text { Samples Has PDZK1IP1 super-enhancer? Sex Age Colon Anatomy } \\ \text { 18481T Yes } & \text { no data } & \\ \text { 17753T Yes } & \text { Male } & 63 & \text { Sigmoid colon and rectum } \\ \text { 18607T Yes } & \text { Male } & 71 & \text { Terminal ileum appendix and ascending colon } \\ \text { 18810T Yes } & \text { Male } & 67 & \text { Terminal ileum and cecum } \\ \text { 19441T Yes } & \text { Male } & 71 & \text { Descending colon } \\ \text { 19282T No } & \text { Female } & 82 & \text { Terminal ileum and ascending colon } \\ \text { 19106T Yes } & \text { Male } & 74 & \text { Sigmoid colon and rectum } \\ \text { 19342T Yes } & \text { Male } & 53 & \text { Transverse colon } \\ \text { 18739T Yes } & \text { Male } & 63 & \text { Sigmoid colon } \\ \text { 18946T No } & \text { Male } & 83 & \text { Descending colon } \\ \text { 18081T Yes } & \text { Male } & 62 & \text { Sigmoid colon and rectum } \\ \text { 19442T Yes } & \text { Female } & 61 & \text { Terminal ileum appendix and ascending colon } \\ \text { 19395T Yes } & \text { Male } & 61 & \text { Terminal ileum, cecum, appendix, and ascending colon } \\ \text { 17627T Yes } & \text { Male } & 64 & \text { Sigmoid colon } \\ \text { 17787T No } & \text { Male } & 67 & \text { Descending and sigmoid colon }\end{array}$




\title{
Supplementary Table 7: Juxtaposition of primary CRC cases with pathological features and PDZK1IP1 SE status.
}

\author{
Samples Has PDZK1IP1 super-enhancer? Tumor Staging Primary Tumor Description
}

18481T Yes No data

17753T Yes pT4aN2a Invasive, moderately differentiated adenocarcinoma with mucinous

features. The tumor invades through the wall to the serosal surface

with acute inflammatory reaction. Lymphovascular and perineural

invasion identified. Extramural large vessel invasion identified.

18607T Yes pT3N1a Invasive poorly differentiated adenocarcinoma with medullary

feature. Invades into subserosal soft tissue. Perineural invasion

also present. Extensive lymphatic invasion seen. IHC shows

$2425 \quad$ MLH1 and PMS2 loss, possible MSI.

18810T Yes pT1N0 Invasive moderately differentiated adenocarcinoma. The tumor

invades the submucosa. Foci suspicious for lymphovascular

invasion are identified. Perineural invasion is not identified.

19441T Yes pT4aN0 Invasive moderately differentiated adenocarcinoma extending

$2430 \quad$ through the serosal surface. Perineural and lymphovascular space

invasion are presnet. Peritumoral abscess with foreign body giant

cell reaction. Large extramural vein invasion.

19282T No no data Poorly differentiated adenocarcinoma. No adenomatous

component is found to confirm primary colonic origin. The

tumor is almost entirely intralymphatic and there is focal

intramural venous invasion. The tumor is CDX2 negative which

is uncommon for primary CRC but not exlcusionary. Additional

immunostains are negative for primary breast, GYN, or pulmonary

origin.

2440 19106T Yes pT3N1a Invasive moderately differentiated adenocarcinoma with invasion to the pericolorectal adipose tissue. Lymphovascular and neural 
invasions present.

19342T Yes pT2N0 Moderately differentiated mucinous adenocarcinoma with invasion into the muscularis propria. India ink tattoo noted.

18739T Yes pT4aN0 Moderately differentiated adenocarcinoma with transmural invasion to the visceral peritoneum. Focal high-grade tumor budding and extramural large vein invasion are identified. 18946T No pT4N0 Invasive, moderately differentiated adenocarcinoma extending to the serosal surface. Submucosal ink tattoo. Lymphovascular or perineural space invasion is not identified. Exuberant fibrohistiocytic reaction of the subserosal soft tissue.

$18081 T$ Yes pT3N0 Invasive moderately differentiated adenocarcinoma. The tumor invades the mucscularis propria and into subserosal soft tissue. Tumor budding. 19442T Yes pT4aN0 Invasive moderately differentiated mucinous adenocarcinoma. Extended through the serosal surface into the visceral peritoneum with associated fibroinflammatory response. Lymphovascular or perineural space invasion is not identified. No evidence of large extramural vein invasion. 19395T Yes Moderately differentiated mucinous adenocarcinoma. The tumor invades through muscularis propria into pericolic fat. Vascular invasion is not identified. Perineural invasion is not identified. $17627 \mathrm{~T}$ Yes no data No data 17787T No pT4bN2b Moderate to poorly differentiated carcinoma with mixed

2465 morphology. Extensive lymphovascular and perineural invasion are noted. Extramural large vessel invasion is identified.

Background colon with mildly active chronic colitics and melanosis coli. Long history with quiescent ulcerative colitis. 


\section{Supplementary Table 8: H3K27ac ChIP-seq metrics.}

17627T: 74,355 called peaks stitched to 17,726 enhancers. $17627 \mathrm{~N}: 75,466$ called peaks stitched to 21,636 enhancers. 17753T: 59,688 called peaks stitched to 13,726 enhancers. $17753 \mathrm{~N}: 175,589$ called peaks stitched to 5,392 enhancers. 17787T: 76,011 called peaks stitched to 20,341 enhancers. 17787N: 66,728 called peaks stitched to 17,567 enhancers. 18081T: 54,343 called peaks stitched to 15,075 enhancers. $18081 \mathrm{~N}: 52,082$ called peaks stitched to 14,110 enhancers. 18481T: 29,640 called peaks stitched to 7,921 enhancers. $18481 \mathrm{~N}: 75,102$ called peaks stitched to 24,268 enhancers. 18607T: 47,801 called peaks stitched to 24,704 enhancers. $18607 \mathrm{~N}: 80,274$ called peaks stitched to 19,847 enhancers. 18739T: 56,757 called peaks stitched to 15,073 enhancers. 18739N: 34,545 called peaks stitched to 5,692 enhancers. 18946T: 51,652 called peaks stitched to 19,214 enhancers. $18946 \mathrm{~N}: 27,010$ called peaks stitched to 15,655 enhancers. 18810T: 72,790 called peaks stitched to 13,804 enhancers. 18810N: 57,932 called peaks stitched to 6,217 enhancers. 19106T: 58,973 called peaks stitched to 16,857 enhancers. 19106N: 61,476 called peaks stitched to 15,331 enhancers. 19282T: 63,909 called peaks stitched to 17,020 enhancers. 19282N: 59,106 called peaks stitched to 15,434 enhancers. 19342T: 53,155 called peaks stitched to 14,616 enhancers. 19342N: 52,206 called peaks stitched to 13,616 enhancers. 19395T: 63,693 called peaks stitched to 18,157 enhancers. $19395 \mathrm{~N}: 47,387$ called peaks to 13,483 enhancers. 19441T: 70,089 called peaks stitched to 18,884 enhancers. 
19441N: 63,324 called peaks stitched to 16,074 enhancers.

19442T: 62,613 called peaks stitched to 16,760 enhancers.

$2500 \quad 19442 \mathrm{~N}$ : 77,621 called peaks stitched to 19,239 enhancers.

HT29 cells: 43,055 called peaks stitched to 10.784 enhancers.

HT29 xenograft tumor rep. 1: 47,940 called peaks stitched to 13,097 enhancers.

HT29 xenograft tumor rep. 2: 61,713 called peaks stitched to 18,869 enhancers.

HT29 xenograft tumors rep. 3: 27,347 called peaks stitched to 7,049 enhancers.

2505 HT29 TNF-alpha, IFN-gamma, and IL-6 treated cells: 60,741 called peaks stitched to 15,139 enhancers. 